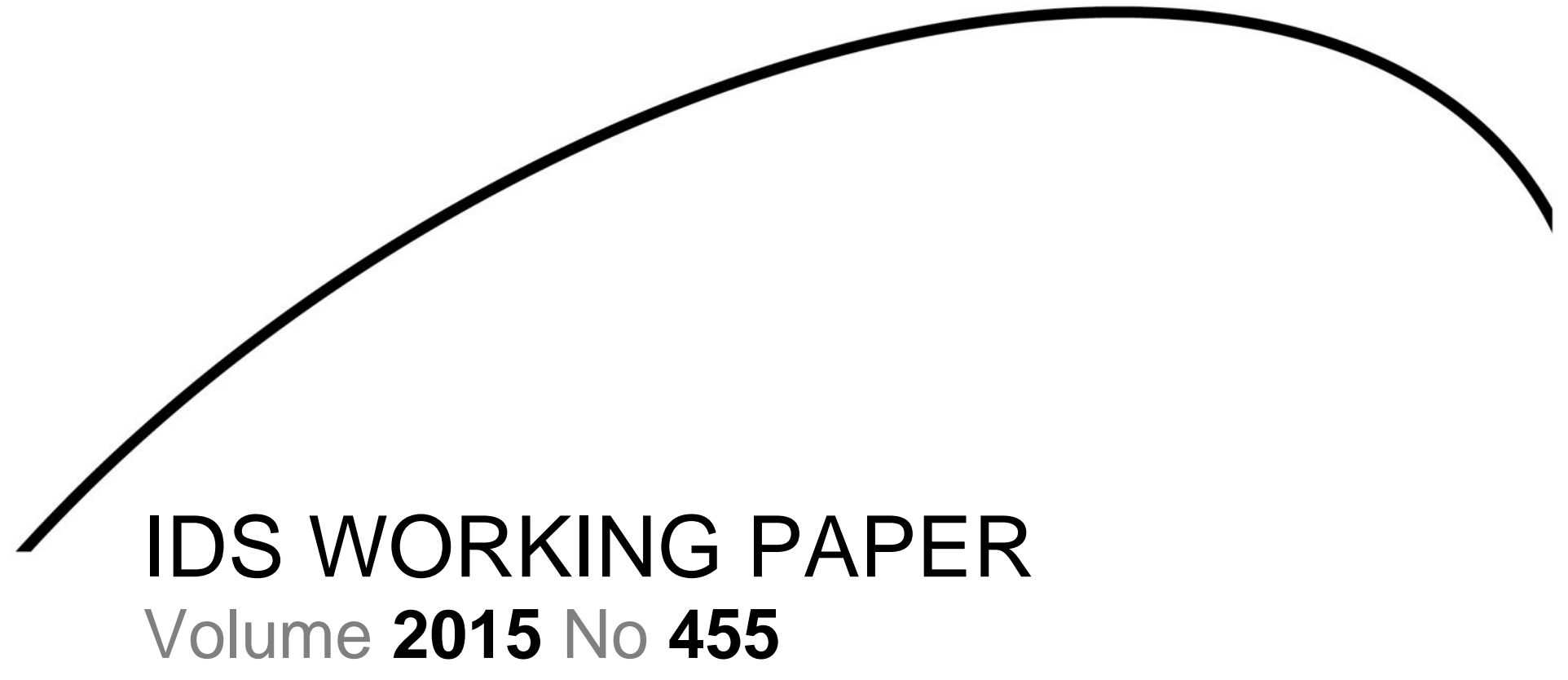

\title{
Green Growth Diagnostics for Africa: Literature Review and Scoping Study
}

Ana Pueyo, Stephen Spratt, Hubert Schmitz, Dirk Willenbockel, Chris Dent, Neal Wade and Andrew Crossland

May 2015 
Green Growth Diagnostics for Africa: Literature Review and Scoping Study

Ana Pueyo, Stephen Spratt, Hubert Schmitz, Dirk Willenbockel, Chris Dent, Neal Wade and Andrew Crossland

First published by the Institute of Development Studies in May 2015

IDS Working Paper 455

(C) Institute of Development Studies 2015

ISSN: 2040-0209 ISBN: 9781781182369

A catalogue record for this publication is available from the British Library.

All rights reserved. Reproduction, copy, transmission, or translation of any part of this publication may be made only under the following conditions:

- with the prior permission of the publisher; or

- with a licence from the Copyright Licensing Agency Ltd., 90 Tottenham Court Road, London W1P 9HE, UK,

or from another national licensing agency; or

- under the terms set out below.

This publication is copyright, but may be reproduced by any method without fee for teaching or nonprofit purposes, but not for resale. Formal permission is required for all such uses, but normally will be granted immediately. For copying in any other circumstances, or for re- use in other publications, or for translation or adaptation, prior written permission must be obtained from the publisher and a fee may be payable.

Available from:

Communications and Engagement Unit, Institute of Development Studies, Brighton BN1 9RE, UK

Tel: +44 (0) 1273915637 Fax: +44 (0) 1273621202

E-mail: bookshop@ids.ac.uk

Web: www.ids.ac.uk/publications

IDS is a charitable company limited by guarantee and registered in England (No. 877338) 


\title{
Green Growth Diagnostics for Africa: Literature Review and Scoping Study
}

\author{
Authors Ana Pueyo, Stephen Spratt, Hubert Schmitz, Dirk Willenbockel, \\ Chris Dent, Neal Wade and Andrew Crossland
}

\begin{abstract}
Summary
This paper reviews the literature for a project which seeks to develop a new Green Growth Diagnostics methodology and apply it to countries in Africa.
\end{abstract}

The original growth diagnostics methodology was developed by Haussmann, Rodrik and Velasco to identify the key constraints holding back economic growth from its full potential. Their approach was driven by the needs of policymakers facing the dilemma that most problems have multiple causes, but governments cannot tackle all of them at once, given limitations in their financial and executive capacity. This gave rise to the idea of concentrating these limited resources on the binding constraint, which would be identified going through a tool conceptualised as a decision tree. The proponents of the original growth diagnostics also realised that this binding constraint varies between countries and - we would argue - between sectors.

The central point of the original growth diagnostics method was that it offered researchers and policy makers a way of identifying priorities in analysis and policy; and finding solutions which take into account local conditions. The same rationale applies to our Green Growth Diagnostic project. We build on the original approach but adapt it in four ways: 1 . Applying it to the energy sector; 2 . Taking into account potential knock-on effects on the economy; 3 . The political economy when going from diagnostics to therapeutics; and 4 . Working out the distributional consequences. Since each step takes the project into un(der)explored territory, it is built around five research questions and corresponding methodologically distinct work packages.

Our five research questions are: 1 . What are the binding constraints for investment in economically viable renewable energy?; 2 .Which policies can more effectively target different binding constraints?; 3 . Who obstructs/drives the adoption of specific sustainable energy policies?; 4 . What would be the macroeconomic impacts of an increase in renewable energy investment/capacity, and the reforms needed to bring this increase about? and 5. Under what circumstances increased on-grid renewable energy capacity translates into increased access to and increased reliability of electricity supply in developing countries? This paper pulls together what we can learn from the international literature on these questions.

Key words: Green Growth, green growth diagnostics, renewable energy, sustainable energy, green electricity, green power, low carbon growth.

Dr Andrew Crossland gained his PhD from School of Engineering and Computing Sciences at Durham University in October 2014. His interests include social and technical modelling of off-grid energy systems. His PhD studied how energy storage should be installed in low voltage residential electricity networks to provide technical and financial benefits to distribution network operators. He remains active in the renewable sector. 
Dr Chris Dent is Senior Lecturer in Energy Systems Modelling at Durham University. He holds an MA in Mathematics from Cambridge, PhD in Physics from Loughborough and MSc in Operational Research from Edinburgh. His research interests range broadly across energy systems analysis, including system planning, economics, renewables integration and reliability assessment. In addition to Green Growth Diagnostics for Africa, current projects include consultancy for the GB Electricity Capacity Assessment Project (particularly wind's contribution), uncertainty analysis linking rigorously complex energy systems models to real systems, and grid integration of energy storage.

Dr Ana Pueyo is a research Fellow at the Institute of Development Studies development. Her research is concerned with inclusive green growth, particularly in the promotion of investments in clean energy that maximise poverty impacts, pro-poor access to electricity, poverty impacts of minigrids in Africa, green growth diagnostics in Africa and the political economy of climate compatible development. Ana has advised policymakers in EU, UK and Spanish Governments and has also worked extensively as a consultant for the private sector, including private companies in the energy sector, sectoral associations, project developers in the low-carbon business and NGOs.

Professor Hubert Schmitz is a Professorial Fellow at the Institute of Development Studies development. An economist with 30 years of experience in research, teaching and advisory work. Adviser to bilateral and multilateral development agencies on industrial policy, cooperation of public and private sectors, and interventions for strengthening competitiveness and job creation, his areas of specialisation are sustainable industrialisation, the politics of investment and growth, and the green transformation. He has published widely in development journals and is known for succinct synthesis of policy research and has a long track record in managing international research teams and integrating competences across disciplines.

Dr Stephen Spratt is a Research Fellow at the Institute of Development Studies. Previously, he has been Head of Sustainable Markets Group at IIED, Research Director at the New Economics Foundation and Lecturer in international finance and development at the University of Reading. He has also worked in the private sector in the City of London. His research interests relate to development finance and financial sector development for sustainable and equitable development.

Dr Neal Wade is a Senior Research Associate at the School of Electrical and Electronic Engineering, Newcastle University. He is project lead and researcher on projects in the electricity distribution and off-grid power sectors. These projects are investigating innovative methods to integrate generation and demand technologies as a way to address the need to cost efficiently decarbonise the power sector. Computer simulation, laboratory investigation and demonstration projects are used together to produce the new knowledge that delivers this need. He has previously worked in numerous university research and teaching roles and has experience working in the electronics industry.

Dr Dirk Willenbockel is a research fellow at the Institute of Development Studies. He is an economist with experience in the areas of trade policy and regional economic integration, climate change impact and adaptation analysis, economics of low-carbon growth, global and regional food system scenario analysis, and fiscal policy analysis. He has particular technical expertise in the design and application of computable general equilibrium models for forward-looking development policy analysis. 


\section{Contents}

Summary $\quad 3$

Contents 4

Introduction and objectives $\quad 8$

1 What is green and inclusive growth? 9

1.1 Unpacking the concept of inclusive green growth 9

1.2 Inclusive green electricity 12

2 Target power generation technologies $\quad 13$

2.1 Green power generation technologies 13

2.2 Economic and financial viability of green power generation technologies 14

2.3 Review of cost estimates of renewable electricity technologies 16

3 Constraints to investment in renewable energy generation 24

3.1 Constraints to renewable energy investments worldwide 24

3.1.1 Economic and financial constraints 24

3.1.2 Regulatory and political constraints $\quad 26$

$\begin{array}{ll}\text { 3.1.3 Technical constraints } & 27\end{array}$

3.1.4 Behavioural constraints 28

3.2 Constraints on renewable energy investment in developing countries 28

3.2.1 Economic and financial constraints in developing countries 28

3.2.2 Regulatory and political constraints in developing countries $\quad 30$

3.2.3 Technical constraints in developing countries 32

3.3 Ranking of constraints 33

4 Policies to address constraints $\quad \mathbf{3 4}$

4.1 Policies to address economic and financial constraints 36

4.2 Policies to address regulatory and political constraints 42

4.3 Policies to address technical (and capacity) and project-specific constraints 43

4.4 The policy mix 44

5 Who drives/obstructs the adoption of sustainable energy policies?

5.1 Lessons from the international literature 46

5.1.1Categorising actors $\quad 46$

$\begin{array}{ll}\text { 5.1.2 Alliance of actors } & 47\end{array}$

5.1.3 Business as Policy Actors $\quad 49$

5.2 Insights from literature on South Africa 50

5.3 Next steps 51

6 What are the macroeconomic impacts of an increase in renewable energy investment/capacity, and the reforms needed to bring this increase about? 52

6.1 Energy in Standard Top-Down CGE Models 54

6.2 Empirical Estimates of Energy Substitution Elasticities 56

6.3 Hybrid Top-Down Bottom-Up CGE Models 56

6.4 CGE-Based low-carbon transition scenario studies for developing countries 57

6.4.1 Policies to support the transition to a low carbon growth path 57

6.4.2 Economy-wide impacts $\quad 57$

6.4.3 Distributional impacts $\quad 58$

6.5 Studies for Sub-Saharan Africa 59 
7 Under what circumstances does increased on-grid renewable energy capacity translate into increased access and reliability of electricity supply? $\quad 60$

7.1 Power system reliability analysis 60

7.2 Previous research and consultancy work developing metrics of improved access as a result of improved renewable generation capacity

7.3 General characteristics of Sub-Saharan African power systems 62

7.4 Information required for power systems reliability assessment 63

8 Conclusions 65

9 Appendix- Barriers to increased investment in renewable energies and related $\begin{array}{ll}\text { policies } & 67\end{array}$

$\begin{array}{ll}\text { References } & 69\end{array}$

Tables

Table 1.1 China-UK-Africa Trade RA work 11

$\begin{array}{lll}\text { Table 3.1 Technical risks associated with different forms of energy generation } & 27\end{array}$

Table 5.1 Who drives renewable energy policy? 46

Table 7.1 Comparison of the UK, Kenyan and Ghanaian power systems, 20136 62

Table 7.2 Data requirements for power systems analysis 64

\section{Figures}

Figure 2.1 Levelized cost of electricity for commercially available RE technologies at 3, 7 and 10 per cent discount rates (UScents $2005 / \mathrm{kWh}$ ) 19

Figure 2.2 Typical LCOE cost ranges for renewable power generation technologies by region, 2012 (USD/kWh) 20

Figure 2.3 Global levelised cost of energy in Q2 2013 (USD/MWh) 22

Figure 3.1 Comparison of developed and developing country energy project costs 29

Figure 3.2 Quantification of the impact of barriers and associated risks on increased financing costs for onshore wind energy in Kenya 33

Figure 4.1 Public instrument selection for large scale renewable energy 44

Figure 6.1 Typical Nesting Structure of KLEM Production Functions 54 


\section{Acknowledgements}

The authors wish to thank Andrew Barnett for his thorough review and insightful comments to previous versions of the report and Prosper Amuquandoh for advice on the Ghanaian system. The Green Growth Diagnostics for Africa project is supported financially by the Engineering and Physical Sciences Research Council (EPSRC), Department for International Development (DfID) and Department of Energy and Climate Change (DECC).

\section{Acronyms}

BNEF
CAPEX
CCGT
CCS
CDM
CHP
CGE
DBCCAs
EIB
EPSRC
ERR
ESMAP
ETS
FiT
FRR
GGDA
GHG
IEA
IFC
IPCC
IRENA
KPLC
LCOE
MIGA
NERC
NGCC
O\&M
PPA
UNDP
UNFCCC
WACC
WEC

Bloomberg New Energy Finance

Capital expenditure

Combined Cycle Gas Turbines

Carbon Capture and Storage

Clean Development Mechanism

Combined Heat and Power

Computable General Equilibrium

Deutsche Bank Climate Change Advisors

European Investment Bank

Engineering and Physical Sciences Research Council

Economic-rate-of-return

Energy Sector Management Assistance Programme

European Trading System

Feed in Tariff

Financial rate of return

Green Growth Diagnostics for Africa

Greenhouse Gas

International Energy Agency

International Finance Corporation

Intergovernmental Panel on Climate Change

International Renewable Energy Agency

Kenya Power and Lighting Company

Levelised cost of energy

Multilateral Investment Guarantee Agency

North American Electric Reliability Corporation

Natural Gas Combined Cycle

Operating and maintenance

Power Purchase Agreements

United Nations Development Programme

United Nations Framework Convention on Climate Change

Weighted average cost of capital

World Energy Council 


\section{Introduction and objectives}

This literature review represents the first stage of the EPSRC-funded research project 'Green Growth Diagnostics for Africa' (GGDA). The project seeks to unravel what is holding back investment in promising renewable energy technologies through the development of a methodology to identify the 'binding constraint' to this investment. The methodology will be piloted in two countries - Kenya and Ghana - and refined in the light of the results. Subsequently, we hope it will be applied more broadly in Africa and beyond. The research will address five questions:

1. What are the binding constraints to investment in economically and financially viable renewable energy that would promote inclusive green growth?

2. Which policies could most effectively remove these constraints?

3. Who obstructs/drives the adoption of these policies?'

4. What would be the macroeconomic impacts of an increase in renewable energy investment/capacity, and the implementation of reforms needed to achieve this?

5. Under what circumstances does increased on-grid renewable energy capacity translate into increased access to and increased reliability of electricity supply in developing countries?

This report summarises the existing general literature on these questions. Country studies will apply the same questions to Kenya and Ghana. This is important. As we shall see, many of the answers are context specific. For example, whether or not a potential technology is 'economically viable' depends on factors such as resource abundance, existing infrastructure and financing costs. These vary significantly across regions and countries, and even within the same country.

As well as reviewing the various literatures, this report defines the following key concepts: 'inclusive green growth'; 'economic viability' and 'financial viability'. These definitions provide the basis for selecting electricity generation technologies. As described in the first research question, we are interested in understanding why technologies which have these three characteristics - and would therefore be considered broadly desirable - are not deployed at scale. Given the central role accorded to these concepts, considerable attention is paid to defining them precisely.

The review thus begins by discussing and defining inclusive green growth. We then define what is meant by green renewable energy technologies that are economically and financially viable. This definition provides the background for the review of cost estimates for different technologies, as well as the methodologies used to produce these estimates. The third and fourth chapters review the literature on constraints to investment in renewable energies and policies to address these respectively. Chapter 5 considers what we know about the political economy of sustainable energy, while Chapter 6 examines how Computable General Equilibrium (CGE) models have been used in this area. The final review chapter looks at the engineering literature on the links between increased supply, reliability and equitable access to electricity. We conclude by identifying the gaps in the current literature and showing how our approach will address these. 


\section{What is green and inclusive growth?}

In 2012, the World Bank defined 'inclusive green growth', as:

...growth that is efficient in its use of natural resources, clean in that it minimises pollution and environmental impacts, and resilient in that it accounts for natural hazards and the role of environmental management and natural capital in preventing physical disasters. And this growth needs to be inclusive.

(Fay 2012)

More expansive definitions of the 'inclusive' aspects of growth than this have also been given. For example, the United Nations Development Programme (2011) defines inclusive green growth as that which:

...embraces social, economic and environmental pillars and is promoted based on principles of inclusiveness, equity, particularly gender equity and women's empowerment, and sustainability. It supports the alleviation of poverty through green job creation, sustainable energy for all, low-carbon technologies; and promotion of sustainable urban living. It recognizes the importance of and interplay between natural capital and social capital, equally important assets that must be managed and invested in.

(United Nations Development Programme 2011)

While the Bank accepts that 'green growth' will not automatically be 'inclusive', the United Nations Development Programme (UNDP) argues for a more proactive approach to ensure that it is: redistributive measures, active policies of green job creation and the targeting of sectors where growth would disproportionately benefit the poor are all proposed. 'Inclusive green growth' can thus be understood in a variety of ways. In the first part of this chapter, the term is unpacked and defined. Having established a conceptual foundation, the second part of the chapter applies this to the issue of access to electricity.

\subsection{Unpacking the concept of inclusive green growth}

The term 'inclusive green growth' is a recent hybrid, combining the concept of 'inclusive growth' with that of 'green growth'. Before examining the hybrid form, therefore, we consider the components from which it is constructed.

'Inclusive growth' can be defined in different ways, reflecting disagreements over the related concept, 'pro-poor' growth. In its 'weak' form, growth is 'pro-poor' when it results in absolute increases in the income of the poor. For the 'strong' form, pro-poor growth requires the relative incomes of the poor to rise, so that growth also reduces inequality.

For the World Bank, inclusive growth means equality of opportunity with respect to: 'access to markets, resources and unbiased regulatory environment for businesses and individuals' (Ianchovichina and Lundstrom 2009). The authors are explicit that their 'definition is in line with the absolute definition of pro-poor growth, but not the relative definition' (ibid.). As described in Klasen (2010), others take a different view. Rauniyar and Kanbur (2010), for example, define inclusive growth as 'growth with declining inequality'.

Ali and Son (2007) define inclusive growth as 'pro-poor improvements in social opportunities.' This definition has two distinctive features: it moves the focus from income 
to the non-income aspects of welfare; and, as with the World Bank's definition, the emphasis is on equality of opportunity rather than equality of outcome.

Two dimensions of difference in definitions of inclusive growth can thus be identified. First, inclusive growth may refer to process (i.e. citizens participate in the policy process). Or it may refer to outcome (i.e. how the benefits of growth are distributed across groups in the population, how much additional electricity supply is actually consumed by different groups, or the levels of education achieved by different income groups). Second, growth may be either 'weakly' or 'strongly' inclusive. Growth would be considered weakly inclusive if the poor - or other disadvantaged groups - are able to participate in, or benefit from, it to some degree. To be strongly inclusive, however, these groups would have to participate more, or receive more of the benefits of growth, or of the additional supply of electricity, than did wealthier groups.

The concept of 'green growth' is also contested. Some view the term as an oxymoron, believing that economic growth is incompatible with sustainability, regardless of its colour (Jackson 2011). Others take the polar opposite view, arguing that 'green 'growth' is the only sort of growth that is possible over the longer term (Stern 2006).

These disagreements largely result from different views on what environmental sustainability means, particularly the extent to which 'natural capital' is substitutable for 'man-made capital'. Those arguing from a 'weak sustainability' position are more likely to think such substitution is possible than would those taking a 'strong sustainability' position. ${ }^{1}$ The implications for growth are significant. Growth involves the consumption of natural resources. From a weak sustainability perspective, this is fine as long as the natural capital used in the growth process is replaced with other forms of (man-made) capital. The total stock of capital would therefore remain unchanged. From a strong sustainability perspective, this is less straightforward. If it is not possible to replace natural capital with other forms (e.g. man-made capital), then natural capital used in the growth process is lost permanently, and the total stock of capital is reduced. If maintaining the total stock of capital is an objective, therefore, growth is a problem and 'green growth' a contradiction in terms.

In practice these distinctions are more blurred: there is a spectrum of opinion rather than a binary dichotomy. Everyone accept that some forms of natural capital are substitutable while others are not. Much of the debate thus centres around which forms of natural capital are most important, and whether these are substitutable or not. For example, (Gray 1990) identifies four forms of capital: Critical (e.g. stable climate, rainforests, oceans, water supply); non-renewable/non-substitutable (e.g. oil and mineral products); non-renewable/substitutable (e.g. energy usage); and, renewable (e.g. timber, fisheries). Using this categorisation, Neumayer (2003) argues that non-substitutability of capital is not always the main issue. Fossil fuels are not substitutable, for example, but this does not mean they should be preserved forever. What is important is energy transformation from one form to another, and this can be done using renewables. The problem of exploiting fossil-fuels therefore is the impact this has on climate change, not that they cannot be replaced, which is a different issue. ${ }^{2}$ For Neumayer, what matters is that

\footnotetext{
${ }^{1}$ For an excellent review of the concepts of weak and strong sustainability see Neumayer, E. (2003). Weak versus strong sustainability: exploring the limits of two opposing paradigms, Edward Elgar Publishing.

${ }^{2}$ The economics - and intergenerational ethics - of exploiting non-renewable natural resources turn on the use to which the resultant revenues are put. Specifically, the issue is whether revenues are invested such that the total stock of capital in the economy - i.e. that which is bequeathed to future generations - is increased. For the classical paper see: Hartwick (1977) For a more recent treatment, see: Collier (2010).
} 
'critical capital' is preserved, as this is both essential for human civilisation and cannot be replaced.

While most agree that there are certain forms of critical capital that should be preserved (or planetary boundaries respected (Rockström, Steffen et al. 2009), there are major differences on how much critical capital should be preserved, or where planetary boundaries lie. The 'weak' versus 'strong' sustainability debate can be seen through this lens. Another point of contention is the extent to which growth can be 'dematerialised' or decoupled from resource use (Jackson 2011). Does more growth inevitably lead to more resource use or is it possible to grow while using fewer resources? From a climate change perspective, does rising GDP always increase carbon emissions or is it possible to grow while emissions fall to sustainable levels? On both questions, those in the weak sustainability camp tend to take a more optimistic view, while their strong sustainability counterparts are more pessimistic, often invoking the 'precautionary principle' (Foster, Vecchia and Repacholi 2000).

For both the 'inclusive' and 'green' components of 'inclusive green growth', we therefore have a range of opinions, from weak to strong forms. This is illustrated with the four quadrants in Table 1.1.

\section{Table 1.1 Dimensions of inclusive green growth}

\begin{tabular}{|c|c|c|c|}
\hline & \multicolumn{2}{|c|}{ Inclusiveness } \\
\hline & & Weak & Strong \\
\hline \multirow{2}{*}{ 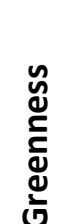 } & Weak & 1 & 2 \\
\hline & Strong & 3 & 4 \\
\hline
\end{tabular}

Quadrant 1 describes those arguments that see any form of growth that benefits the poor as 'inclusive', while also taking a relatively optimistic view on the substitutability of natural capital. The World Bank would broadly fit into this camp - when the staff at the Bank mention 'inclusive green growth', therefore, this is what they mean (lanchovichina and Lundstrom 2009; Fay 2012).

Quadrant 3 combines a lack of focus on inclusiveness, with a much stronger concern for preserving natural capital. Those that argue for the intrinsic worth of the natural environment and against an anthropocentric view that privileges human interests over those of other forms of life might be found here. Both the feasibility and desirability of 'green growth' would tend to be questioned here. Quadrant 4 shares this scepticism about the possibility of 'dematerialising' growth, but combines this with a 'strongly inclusive' approach to poverty and inequality. As growth is seen as incompatible with environmental sustainability, those who take this perspective argue for a more equitable distribution of (finite) resources, and also often stress the potential positive well-being effects of a reduced focus on economic growth. Tim Jackson's book 'Prosperity without Growth' (2009) is perhaps the best-known exposition of this perspective.

Quadrant 2 is where many of those working in the international development community would be found. A strong emphasis on poverty and inequality is the traditional focus of this community. This has been combined in recent decades, however, with an increasing 
emphasis on environmental sustainability, which has more commonly been of 'weak' than 'strong' form. An anthropocentric view is usually taken, with the 'value' of the environment being its use-value to human beings rather than anything intrinsic.

In relation to our research into green growth diagnostics, we would align ourselves with this perspective. There are two aspects to this. First, there is the question of how pro-poor (or inclusive) the growth effects of increasing the supply of renewable energy will be; second, is the question of how pro-poor (or inclusive) the access to increased energy supply will be. In both cases, we take a broadly 'strong' inclusive approach, though we are largely concerned with the latter. Specifically we are interested in identifying and removing barriers to renewable technologies where access by the poor is at least as great as that for other groups.

\subsection{Inclusive green electricity}

Electricity generation, transmission, distribution and use are key elements of inclusive green growth. Lack of infrastructure is a major constraint to economic growth in most African countries and lack of access to reliable electricity is in particular rated by most African enterprises as one of their most important constraints to growth (Goedhuys and Sleuwaegen 2010).

Inclusiveness cannot be presumed. If renewable energy sources are more costly than fossil fuel alternatives, for example, they may require scarce public finance to be diverted from other development priorities or adversely affect final consumers if tariffs go up as a result. Set against this, many developing countries currently provide fossil fuel subsidies that do not particularly benefit the poor (World Bank 2012). It is important to take full account of the different economic and financial costs and benefits associated with renewable technologies, particularly as these are allocated between groups in society. The process we will use to select technologies to examine is designed to address this.

The final impact on the poor of increased investment in renewable electricity capacity depends on a number of factors (Pueyo; Gonzalez; Dent and DeMartino 2013). First, increased capacity should increase access, as new people obtain connections and more electricity consumption is possible for those already connected. While this is relatively straightforward in off-grid systems, it is more complex for on-grid systems where the source of electricity is not known. The additional consumption enabled by new capacity depends on a number of technical factors such as: the type of low carbon generation (e.g. intermittent vs. dispatchable); the location of the plant in relation to demand; the layout, capacity and reliability of the network; the distribution of demand at different times; the availability of renewable resources at different times; and changes in the number of consumers, including illegal connections which are common in developing countries. The distributional impact of increased renewable energy capacity can be assessed by quantifying who is able to consume clean energy from on-grid projects through power system reliability evaluations. Second, poor populations need to be explicitly targeted in grid extension or intensification and off-grid access programmes. Without a requirement to reach poor populations, more densely populated and wealthier communities located closer to the grid tend to be prioritised for financial /economic reasons.

Once grid or off-grid electricity reaches a community, households and businesses are given the opportunity to connect (at a price). Despite this, connection rates and use may remain low because of low incomes relative to high upfront costs of electricity and related appliances. The cost, availability, performance and who chooses the end-use conversion technology are essential, as it is this technology that determines the nature and scale of 
impact of electricity use. Bad quality of service may also lead to low electricity use, and this is often related to the financial difficulties of electricity suppliers. To ensure that the poor can benefit, therefore, a balance needs to be struck between affordability and the financial sustainability of the provider. This may require subsidies, either for connection or for use tariffs. The evidence suggests that the former may be more important for the poor.

To ensure that investment in renewable energy capacity benefits the poor at least as much as other groups - i.e. that it is inclusive - it is crucial that these issues are fully considered.

\section{Target power generation technologies}

Having established what we mean by inclusive green growth and electricity, the next step is to identify a target group of green energy technologies that could contribute to these goals, while also having the potential to compete with fossil fuel alternatives.

\subsection{Green power generation technologies}

What qualifies as 'green energy'? Three potential categories can be identified: (i) a switch to less polluting forms of fossil fuel generation (e.g. coal to gas); (ii) efficiency measures to reduce energy use per unit of output; and (iii) new renewable energy production (Intergovernmental Panel on Climate Change 2014).

The main alternatives in the first category include:

- Switching from coal-fired power plants to modern natural gas preferably in combined cycle power plants (NGCC)

- Combined Heat and Power (CHP) Plants

- $\mathrm{CO}_{2}$ capture and storage

- Capture and use of fugitive gas emissions (including flaring)

Energy efficiency measures entail both improvements in the transmission and distribution systems which increase the amount of power generated that reaches the final consumer and the mechanisms by which the power is converted into energy services. Transmission and distribution losses as a percentage of output (including technical and non-technical losses) vary considerably between countries, with some developing countries having losses of over 20 per cent. Sub-Saharan Africa (developing only) had average transmission and distribution losses of 10 per cent in 2011. Kenya and Ghana experienced 17 per cent and 18 per cent of losses in the same year (World Bank Data 2014).

The third potential form of 'green power' is new renewable energy capacity, including bioenergy, solar energy, geothermal, hydropower, ocean and wind energy. Among renewable energy generation we can also distinguish between large scale centralised and smaller scale distributed options. We define small scale distributed generation as that independently operated, located near their customers and selling to retail customers on a mini-grid, to the national utility on the main grid or both (Tenenbaum, Greacen, Siyambalapitiya and Knuckles 2014). The differentiation between small and large scale is important because the size of the plant can have a significant impact on the cost per kW. There is not an absolute consensus on the size that qualifies as 'small', but regulations in several African and Asian countries point at $10 \mathrm{MW}$ as the capacity threshold. 
Some renewable generation technologies have achieved a level of technical and economic maturity that enables deployment at a significant scale. This is the case of hydropower, many bio-energy and geothermal technologies. Onshore wind technologies are also mature, offshore wind less so, though the gap is narrowing. Solar energy includes a wide range of maturities from R\&D stage to technically mature. Most ocean energy technologies remain at the demonstration stage.

While substantial reductions in emissions can - and should - be achieved with the first of these two categories, this will not be sufficient. The global goal to stabilise temperatures below $2^{\circ} \mathrm{C}$ requires emissions intensities to be approaching zero in the second half of the $21^{\text {st }}$ century, making even the most efficient fossil-fuel unviable. While Carbon Capture and Storage (CCS) could potentially be effective, the largest mitigation potential lies in renewable (and nuclear) energy generation.

The role of developing countries to achieve stabilisation is unquestionable. The developing country origin share in cumulated GHG emissions (including those from agriculture and land use change) since 1850, which determine current atmospheric GHG concentration levels and hence climate change, is already roughly equal to the developed country share, and has been estimated by den Elzen, Olivier, Höhne and JanssensMaenhout (2013) to reach 56 percent by 2020. Even though this has been mostly driven by upper middle income countries (mainly China), lower income countries are expected to significantly rise their share of global emissions, mainly as a result of population growth and increasing levels of welfare. An early adoption of low-carbon paths in low income countries with an underdeveloped generation infrastructure will avoid a high carbon technology lock-in right from the start, reducing the economic burden of GHG mitigation in the future (Willenbockel 2014). If this low carbon generation infrastructure is also lower cost and can potentially compete with fossil fuel alternatives, alone or with external funding, the goal of poverty reduction would not be compromised.

On the basis of its compatibility with the global goal to stabilise temperatures below $2^{\circ} \mathrm{C}$, its contribution to energy security, and to the avoidance of carbon lock-in for African countries that still have an underdeveloped generation infrastructure, we will focus our analysis of green growth mainly on renewable energy generation.

\subsection{Economic and financial viability of green power generation technologies}

We seek to target renewable energy technologies that are economically and financially viable. Economic viability takes into account costs and benefits for society, whereas financial viability looks at the actual private costs to firms or individuals. Externalities emerge when there are differences between private and social costs. They can be positive or negative. In the case of electricity generation, local pollution or global climate change are well known external costs of fossil fuel based plants. Intermittent renewable generation technologies can also present negative externalities if, for example, they impose balancing costs for the electricity system which are not covered by the generator. On the other hand, increasing the share of renewable energy in generation portfolios can act as a hedge against the volatility of fossil fuel prices and the potential increase in the carbon price (Awerbuch and Spencer 2007).

Increasing modern energy services supply in a country where demand outstrips supply is very likely to be economically viable, measured in terms of the economic-rate-of-return (ERR), as economic benefits to society outweigh costs. However, this positive economic 
return can be achieved using different technologies. By this definition, the lower the cost of energy supply, the higher the economic returns to society. Accordingly, energy planning in developing countries, as in developed ones, has been traditionally focused on finding the 'least-cost' generating alternative.

Financial viability is a related, but distinct concept. Financially viable investments yield a risk-adjusted financial rate of return (FRR) that is competitive with other investment options and sufficient to attract private investment. 'Risk-adjusted' is an important aspect of this definition. Private investors demand very different levels of return for ostensibly similar projects, depending on the risk - real or perceived - associated with the project. The returns required for a renewable energy project in sub-Saharan Africa, for example, will be higher than the same project in the UK. Similarly, within the same country, perceptions of risk can vary significantly between technologies, with those considered well-proven requiring lower return expectations. For internationally and sectorially mobile investors, therefore, the opportunity cost of a given investment is not necessarily the same investment in another country, but an investment that would yield the same riskadjusted return, which is unlikely to be the same thing.

The core difference between ERR and FRR is that the latter only captures the private returns to the investor, on the basis of their actual expenses and revenues, while the ERR also captures the broader economic costs and benefits to society (hence including externalities). While investments with an ERR that meets society's test discount rate ${ }^{3}$ would be considered viable, this is not the case for financial returns. Here an investment must have a risk adjusted FRR that is as high as potential alternatives.

In many cases, the private costs of renewables could already be competitive with fossil fuels if we considered a uniform cost of finance. However, the cost of finance may be higher in renewable energy investments due to perceptions of risk, rendering them commercially inviable. This is particularly problematic in developing countries, where risks may already be thought high. Addressing these issues of real and perceived risk such that underlying competitiveness can translate into commercial competiveness (i.e. financial viability) is thus very important. When the cost of finance cannot be reduced to an appropriate level for otherwise competitive investments, an alternative solution is boosting the revenues accruing to renewables (through price premiums delivered via feed-in-tariffs, for example), or by subsidising costs (e.g. fixed capital investment costs). Here the questions are how large this subsidy needs to be, and whether the source of funds is external to the country or not. Where the subsidy is small and likely to diminish further over time, the benefits of renewable energy may justify this. Where the cost is large, however, it may be unreasonable to expect the government of a developing country to bear this cost, which amounts to a drag on its development prospects more generally when looked at from an economy-wide perspective, very high costs could even undermine the economic viability of the investment in question. If additional financial costs are met externally, perhaps through donor support, this constraint no longer applies.

To summarise, we are interested in why certain renewable energy technologies are not deployed or are not deployed at scale in developing countries. We are not interested in just any technologies, however, but in those that meet the following criteria:

\footnotetext{
${ }^{3}$ Generic single discount factor be used by government departments to appraise policies, programmes and projects and that is intended to value the social time preference
} 
i. That they are the lowest economic cost renewable technologies in the country concerned

ii. That they bring positive externalities and minimise negative ones

iii. That they have the potential to be financially competitive with fossil fuel alternatives (excluding taxes and subsidies).

iv. That this financial competitiveness is not achieved at an unacceptable cost to government (i.e. that financial viability is not achieved at an excessive expense for economic viability).

\subsection{Review of cost estimates of renewable electricity technologies}

A useful tool to identify least cost renewable options and compare their competitiveness with fossil fuel based alternatives is the 'levelised cost of energy' (LCOE). LCOE measures the total cost of producing electricity over the lifetime of an electricity generation project, and is comprised of capital investment, operating and maintenance (O\&M), and financing costs. These costs are discounted from a shared reference date.

The selected discount rate has a considerable influence on the calculated LCOE. Different types of technologies and in different locations have a different risk profile and hence assume different interest rates. Renewable energy technologies are more sensitive to high discount rates because they have relatively high capital costs per unit of output and relatively low recurrent costs, while non-renewable options have relatively low capital costs and higher recurrent costs. This feature often limits the use of renewable energy by poor countries, because the opportunity cost of capital increases with lower incomes and so the present is valued more highly than the future. Similarly, where generating utilities have very severe limits on capital expenditures, their opportunity cost of capital at the margin rises to very high levels. They will then commonly opt for technologies with a lower initial capital cost, such as diesel generators, over an apparently preferable renewable option, such as microhydro (Barnett, Lucas and Standing 2002). Using identical discount rates for all technologies and locations, as many studies do, is bound to result in deviations from the actual LCOE. More accurate estimates can be obtained by using discount rates that represent the usual capital costs in the market for the respective investment, and that take into account the usual share and interest rates of debt and equity, calculated as the weighted average cost of capital (WACC).

The cash values of expenditures over the project lifecycle discounted at an appropriate rate are divided by the amount of electricity generated over the same period to give an average cost per kWh, usually in US\$ cents. The annual amount of electricity generation in $\mathrm{kWh}$ is also discounted to account for the fact that the farther electricity generation is in the future, the lower its cash value today (Kost, Mayer, Thomsen, Hartmann, Senkpiel, Philips, Nold, Lude, Saad and Schlegl 2013).

LCOE are usually estimated taking into account only the private cost for the investor, including taxes and subsidies in costs, excluding externalities and using financial discount rates. They are therefore useful to evaluate the financial viability of the project. However, LCOE could also include the cost to society (for example, by adding the cost of GHG emissions using a particular carbon price or the costs of disposing of by-products, whether or not the utility pays for these) hence reflecting economic viability. In an economic analysis the costs are before taxes and subsidies, the discount rate is be the country's social discount rate and the asset lives are the time period over which the asset 
continues to give service (Chubu Electric Power Company \& Economic Consulting Associates Ltd. 2012).

One important shortcoming of the LCOE is that it does not represent the cost of individual projects for the electricity system as a whole, which would need to consider grid connection, costs of integrating intermittent sources or the requirement of back-up capacity based on conventional thermal plants (World Energy Council 2013).

The following formula applies for calculating the LCOE for new plants:

$$
L C O E=\frac{I_{0}+\sum_{t=1}^{n} \frac{A_{t}}{(1+i)^{t}}}{\sum_{t=1}^{n} \frac{M_{t, e l}}{(1+i)^{t}}}
$$

Where:

- 10 : Investment expenditures in common currency

- At : Annual total costs in year $t$ in common currency (private or social)

- Mt,el : Produced quantity of electricity in the respective year in $\mathrm{kWh}$

- $\quad \mathrm{i}$ :Real interest rate in \%. The share of external financing and equity financing can be included in the analysis explicitly through the weighted average cost of capital (WACC).

- $\mathrm{n}$ : Operational lifetime in years

- $\quad t$ : Year of lifetime $(1,2, \ldots n)$

The apparent simplicity of the formula hides the multiple assumptions that need to be made when providing LCOE, which are the reason for the differences in values provided from different sources. These include the following (mainly based in the META model by Chubu Electric Power company and Economic Consulting Associates 2012):

- Capacity factor for the estimation of the quantity of electricity produced. It is defined as the actual output compared to the maximum possible output at which the plant can operate. The higher the capacity factor, the lower the LCOE will be. However, some plants are specifically chosen for peaking duty and have deliberate low capacity factors. For this reason, the LCOE of peak power plants are not directly comparable with those of base load plants.

- Effect of unit sizes. Different plant sizes lead to different costs as a result of economies of scale.

- Debt to equity ratios and the cost of finance. They are often assumed to be uniform, but in fact vary enormously per type of technology, location and size.

- Capital costs. They can vary a lot per location and include or not different elements, such as batteries or environmental control technologies.

- Fuel characteristics, including heating value, sulphur, carbon and ash content. For example, the quality of coal supplied to a plant influences the capital and 
operating costs of coal thermal plants, as well as the emission values used if externalities are included in the costs.

- Fuel prices. Fossil fuel prices are highly volatile. Predicted values are based on a number of assumptions and likely to differ between sources.

- Operation and maintenance costs. They are influenced by local technology maturity, economies of scale and wages.

- Transmission and distribution costs. They are highly project specific, dependent on the distance between the energy resource and demand and the availability of existing transmission lines. Even though these could significantly increase project costs, particularly in developing countries, they are not considered by most sources.

- Transmission and distribution losses. Accurate estimates of the cost of electricity should take into account the cost of losses along a transmission and distribution network.

- Externalities. Measurements of externalities are controversial, as they involve putting money values on environmental burdens and damages to people, primarily health and reduced life expectancy (Markandya 2012). Those estimates that include them may only take into account climate change by using carbon prices, or go further to also include the cost of local pollution on health, building materials, crops and biodiversity (ibid).

We consider four sources for the purposes of this review of LCOE: the Intergovernmental Panel on Climate Change (2012); IRENA (2013), the World Energy Council (2013) and International Energy Agency (IEA 2010).

The Intergovernmental Panel on Climate Change (IPCC) (2012: 846-7) concludes that 'a comparison of LCOE of RE technologies with those of other technologies (nuclear, gas and coal power plants) shows that- as long as externalities are not taken into account $\mathrm{RE}$ sources are often not yet competitive with other sources, especially if they both feed into the electricity grid'. However, 'given suitable conditions, the lower end of the LCOE ranges indicate that some $\mathrm{RE}$ technologies already can compete with traditional forms at current energy market prices in many regions of the world'.

The LCOE value ranges calculated by the IPCC are shown in Figure 2.1. The IPCC calculations use three different discount rates $-3,7$ and 10 per cent - and do not include the cost of transmission and distribution. Data are from 2008 and 2009, and exclude outliers. The range is often huge, at many hundreds of percentage difference between the lowest cost and the highest cost even on the same technology.

Figure 2.1 does not include the range of LCOE for non-renewable sources, but it is shown somewhere else in the IPCC report as between 0-10 UScents ${ }_{2005} / \mathrm{kWh}$, with aggregated technology subcategories and discount rates. As we can see, under particular circumstances some forms of renewable energy can be competitive with fossil fuel alternatives. This include bioenergy (co-firing, small scale CHP, Steam turbine,

\footnotetext{
${ }^{4}$ We could not access the raw data of all these sources and hence are unable to analyse the differences in the parameters listed above and their influence in the final values of LCOE estimated.
} 
gasification ICE), geothermal, hydropower and onshore wind. Competiveness is easier at lower discount rates, the effects of which are more pronounced in some cases than others. Solar PV can only compete with fossil fuel alternatives with a low discount rate, for example, and in regions of high solar irradiation (this is the lower bound of the cost range). With low discount rates and high capacity factors, offshore wind technology could also compete with fossil fuel alternatives. Ocean energy is still far from being competitive at the present time.

\section{Figure 2.1 Levelized cost of electricity for commercially available RE technologies at 3,7 and 10 per cent discount rates (UScents $\mathbf{S}_{2005} / \mathbf{k W h}$ )}

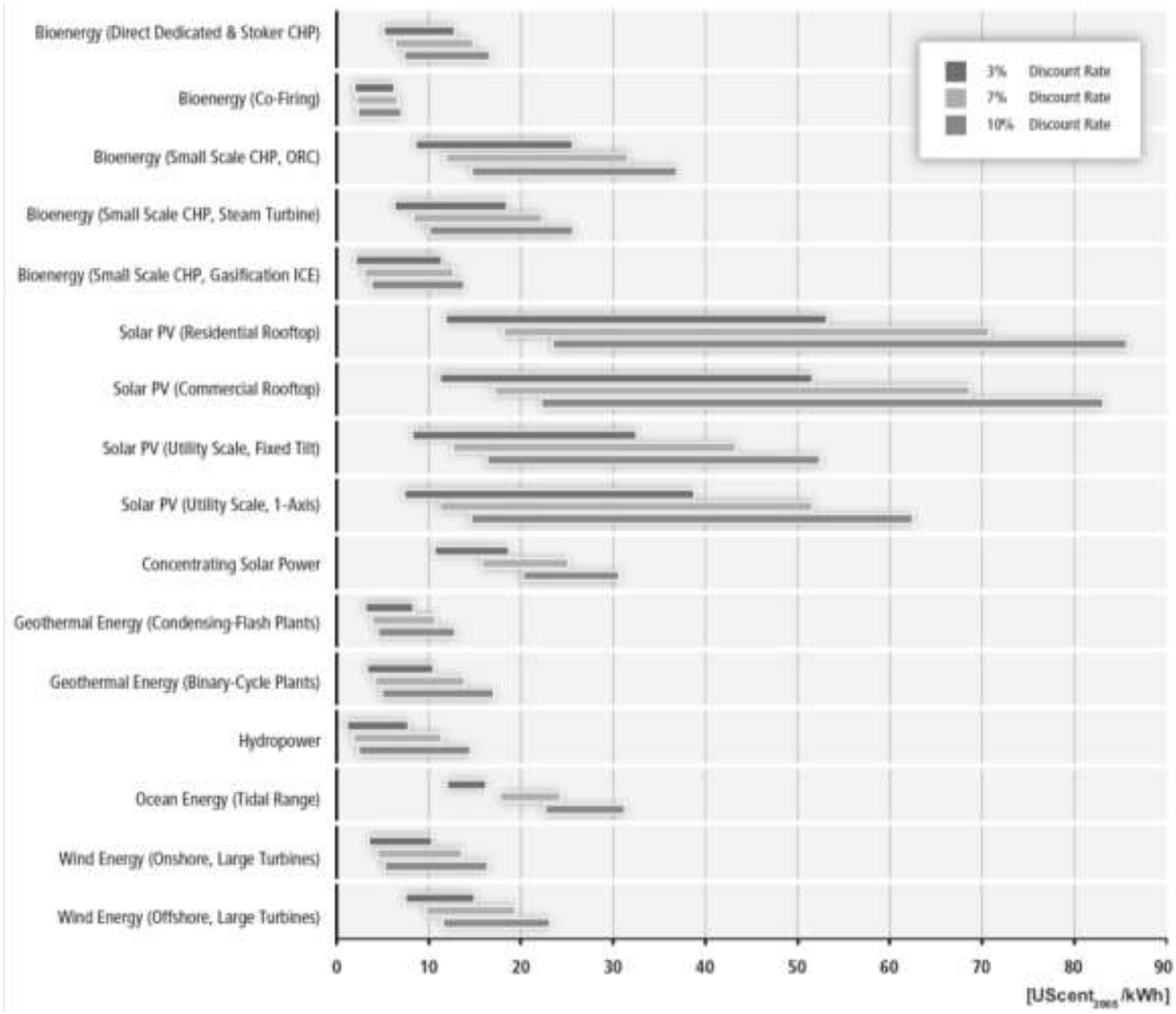

Source: Reproduced with Permission of Intergovernmental Panel on Climate Change (2012) ${ }^{5}$

There are thought to be significant opportunities to decrease the LCOE of renewable energy through learning processes, upsizing of technologies and economies of scale (and increasing load factors). While we have strong evidence of learning rates for onshore wind, solar PV and biomass technologies, using historic experience to extrapolate future

\footnotetext{
5 IPCC 2012: IPCC Special Report on Renewable Energy Sources and Climate Change Mitigation. Prepared by Working Group III of the Intergovernmental Panel on Climate Change, Figures... Cambridge University Press
} 
learning effects is very uncertain. Important technological advances and cost reductions are also expected in advanced PV and CSP technologies, enhanced geothermal systems, ocean energy and offshore wind. However technical changes in battery technology appears stubbornly difficult and costs remain relatively high.

Even though the aggregate LCOE ranges presented by IRENA (2013) do not differ highly from those in the IPCC report, IRENA shows a more optimistic view, in contrast with the more moderate views of the IPCC, concluding that

renewable technologies are now the most economic solution for new capacity in an increasing number of countries and regions. Where oil-fired generation is the predominant power generation source (e.g. on islands, off-grid and in some countries) a lower-cost renewable solution almost always exists today.

Renewables are also the most economic solution for new grid-connected capacity where good resources are available.

(IRENA 2013)

The analysis is based on around 8,000 projects around the world, with data collected from a variety of sources such as business journals, industry associations, consultancies, governments, auctions and tenders. Data is for 2011 and 2012, and although their database has project information on the debt/equity ratio and cost of finance from these two sources, all LCOE calculations assume a 10 per cent cost of capital to allow for direct comparisons. Transmission and distribution costs are excluded, although the report acknowledges that T\&D costs of 5 to 15 USD cents/kWh would need to be added to the total costs of utility-scale solutions. The range of fossil fuel LCOE used for comparison is 6-12 USDc $\mathrm{U}_{2012} / \mathrm{kWh}$, based in OECD values. However, this range does not take into account the very low cost of fossil fuel based generation in developing countries such as China or South Africa with abundant coal reserves and very low installed costs.

Like the IPCC, IRENA's analysis stresses the context specificity of costs, which depend on local resource availability and cost structures. Mature technologies such as biomass, geothermal and hydropower are able to produce electricity at competitive costs with fossil fuel based technologies when excellent local resources are available, although in limited quantities. The next most economic technology is onshore wind, followed by solar PV and CSP.

Figure 2.2 shows LCOE cost ranges per technology and region, with the horizontal bar representing the weighted average LCOE. The figure shows significant differences by region, with China and India having some of the most competitive renewable costs for hydro, biomass and onshore wind. These countries, also have some of the cheapest fossil fuel based plants, which makes it hard for renewables to be competitive without policy support. Biomass and hydro are also cheap options, and geothermal particularly so, in the rest of Asia. Latin America is most competitive in bioenergy and hydro resources, with very good wind resources in many locations, which compensates for higher installed costs for wind. Additionally, excellent solar resources in Peru and Chile, and economies of scale for large PV projects can provide competitive solar PV power plants in this region. Data for African projects are thin, but suggest competitive wind, biomass, hydro and geothermal resources. IRENA forecasts significant equipment cost reductions expected by 2020 , particularly for CSP, solar PV and wind. 
Figure 2.2 Typical LCOE cost ranges for renewable power generation technologies by region, 2012 (USD/kWh)

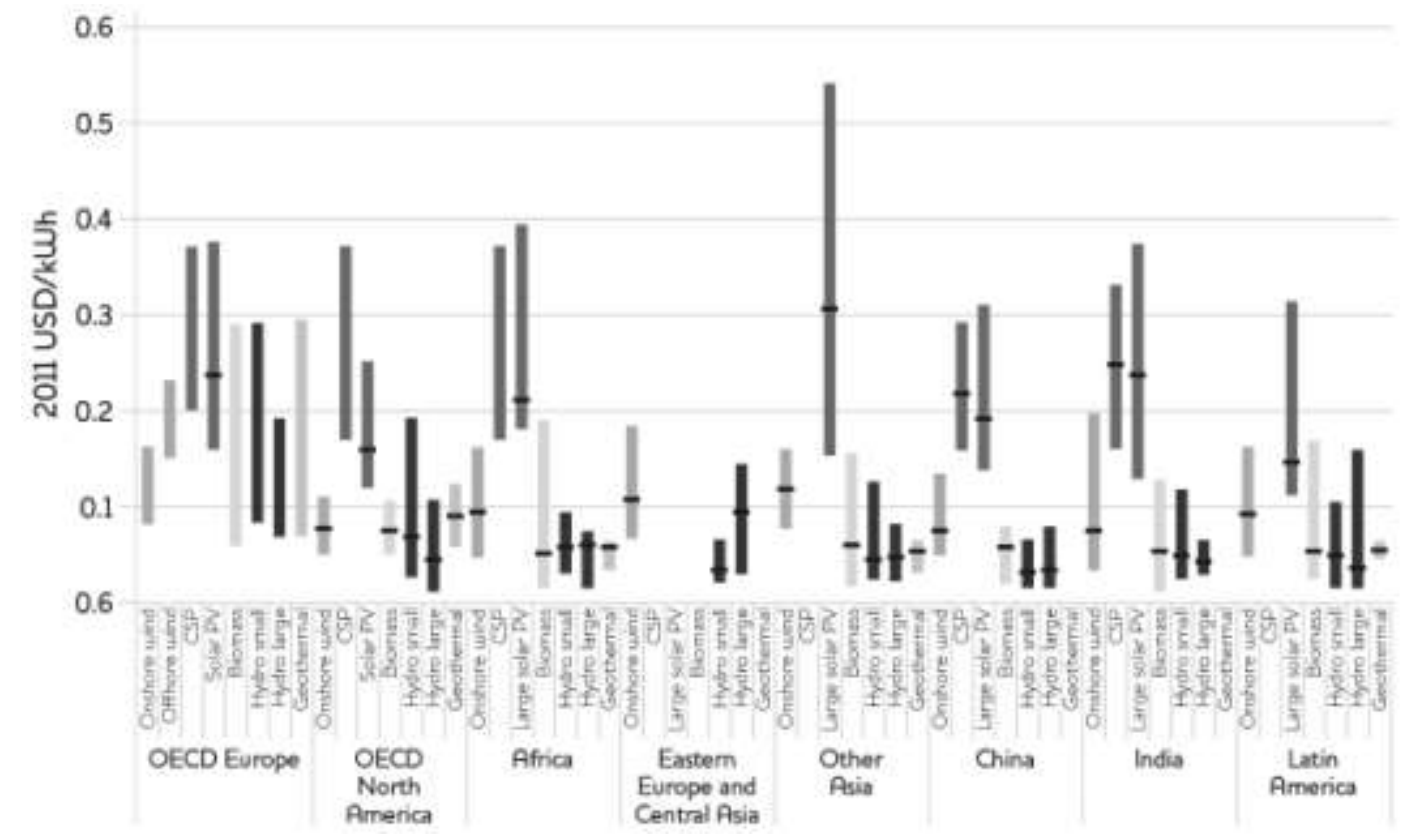

Source: Adapted from IRENA (2013)

The World Energy Council (WEC 2013) uses actual project data from Bloomberg New Energy Finance (BNEF), proprietary data on renewables and conventional generation technologies to calculate LCOEs. A 'sophisticated discounted cash flow model' allows them 'to capture the cost impact of the timing of cash flows, development and construction costs, multiple stages of financing and interest and tax implications of longterm debt instruments and depreciation, among other factors' (World Energy Council 2013: 6). Details of the model are not provided. Depreciation is not included in the cash flow stream of most other models, as cash flow is generally understood to only represent actual cash revenues and expenses, which means their costs could be higher than those provided by other sources. The cost of debt applied is not disclosed but the report explains that it uses 'appropriate debt/equity ratios, spreads and tenors for the operational term loans and where applicable construction and development loans' for technologies that are bankable. The study assumes that all equity investors require a 10 per cent return in constant prices. Capital costs exclude transmission and distribution costs, even though they recognise that for certain technologies such as offshore wind, they can represent a large share of total costs. Taxes are included, with tax rates sourced from the corporate income tax surveys of KPMG and Deloitte. Externalities are not included.

Figure shows the most recent WEC estimates for the US and Canada, Western Europe, China, India and Japan. These indicate a wide cost spectrum across the renewable energy technologies, considerably wider than that for conventional power generation. In these estimates mature technologies, such as hydro, geothermal, onshore wind or landfill gas when in good locations, can easily compete with conventional sources.

The WEC estimates of the LCOE of conventional power generation sources show a wide range for coal, with Chinese coal as low as 3.5-3.9 USD cents/kWh and as high as 12-17 USD cents/kWh for a comparable new build plant in the United Kingdom. Combined Cycle Gas Turbines (CCGT) are cleaner, cheaper and easier to build than coal plants but face 
higher costs of fuel. The estimated global LCOE of new CCGT plants is 6.9 USD cents/kWh, but costs are highly variable regionally, depending on local gas resources. New plants are particularly attractive in the US, for example, where natural gas prices have fallen due to shale gas extraction.

A comparison of WEC estimates with those of the IPCC and IRENA points at significantly lower costs for solar PV, a wider range for LCOE, with much higher bound values for some renewables, as they don't seem to have eliminated outliers, and a higher cost of fossil fuel based generation. Some of the reasons behind these differences could be: that they use more recent data which takes into account the decline in solar PV technology costs over the past few years; and that they primarily take into account projects from developed countries, where the cost of finance is lower and hence renewables can be more competitive.

\section{Figure 2.3 Global levelised cost of energy in Q2 2013 (USD/MWh)}

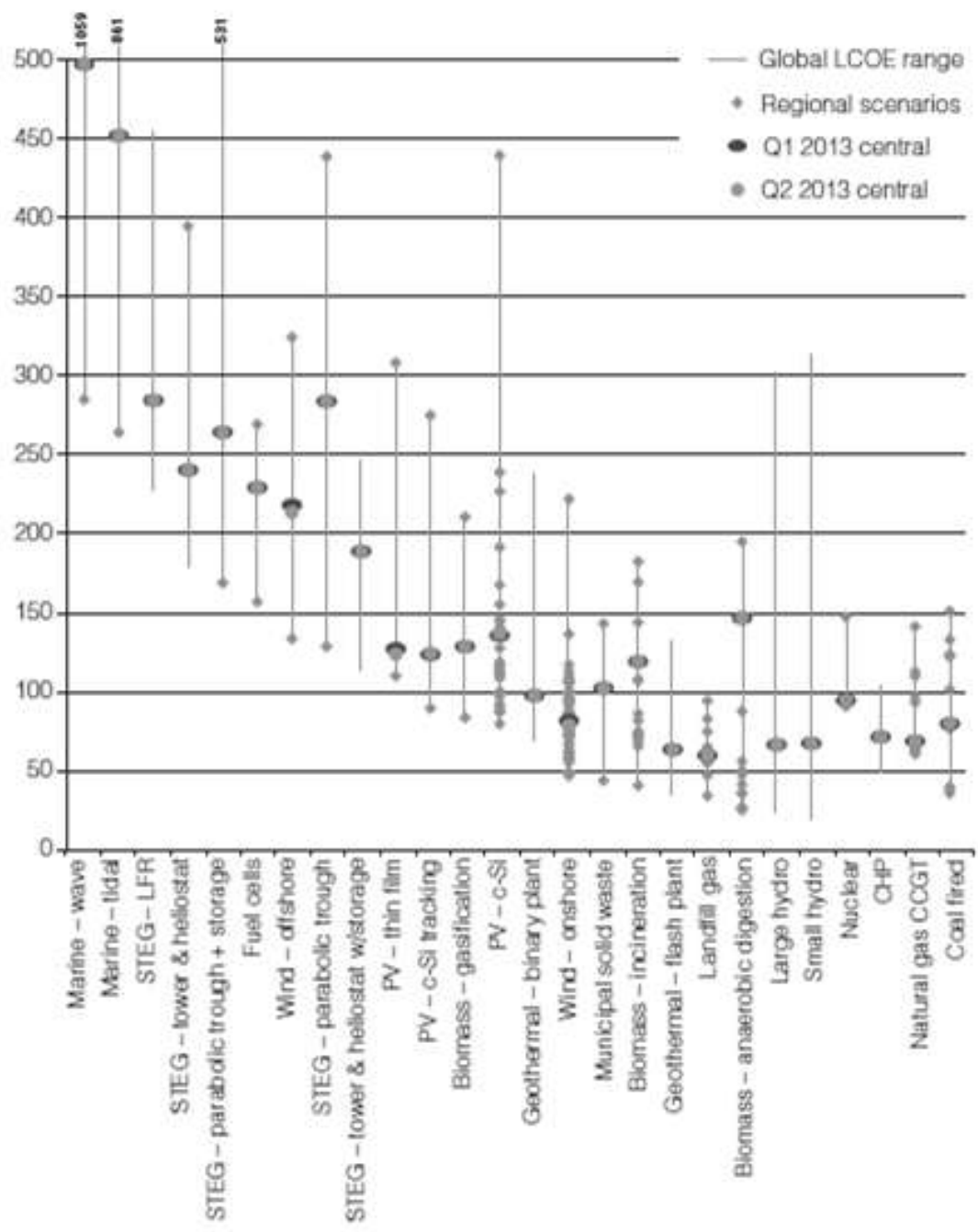

Source: Reproduced with Permission of the World Energy Council (2013) ${ }^{6}$

\footnotetext{
${ }^{6}$ World Energy Council (2013), London, www.worldenergy.org
} 
Further estimates of LCOE for conventional generation and renewables are provided by the International Energy Agency (2010). Using 2009 data of projects to be commissioned by 2015 , costs are provided for nuclear and fossil fuel thermal power stations as well as electricity from renewable sources. The study considers 21 countries, including nonOECD members Brazil, Russia, South Africa and China. Estimations are based on real data from 190 power plants. Two real discount rates were used: 5 per cent and 10 per cent, as well as a social carbon price of USD 30 per tonne of $\mathrm{CO}_{2}$. As with the previous sources, transmission and distribution and other systemic costs, such as the costs of back-up for intermittent sources, are not included. The study agrees with the findings of the previous literature reviewed: 'there is no technology that has a clear overall advantage globally or even regionally'. Nuclear, coal, gas, hydro and wind are considered as fairly competitive technologies for baseload power generation, but their costs are highly context specific.

Using the 10 per cent discount rate and OECD countries data, the LCOE of coal-fired power plants ranges between 0.067 USD cents/kWh in Australia and 14.2 USD cents/kWh in the Slovak Republic. For gas-fired plants they range between 7.6 USD cents/kWh in Australia and 12 USD cents/kWh in Italy. The LCOE of fossil fuel based plants would be reduced considerably if carbon prices were not taken into account, as many other LCOE estimates do. Onshore wind generation shows costs between 7 USD cents/kWh in the US and 23.4 USD cents/kWh in Switzerland. The LCOE of solar PV reaches 33.3 USD cents/kWh for high load factors and 60 USD cents/kWh for low load factors, with CSP reaching 24.3 USD cents/kWh.

The International Energy Agency (2010) study includes extensive sensitivity analyses for key cost parameters which demonstrate that the relative competitiveness of different power generation technologies is highly sensitive to the discount rate applied and to projected prices for $\mathrm{CO}_{2}$, natural gas and coal.

As regards the economics of on-grid versus off-grid electricity supply, the cost of each option depends on the size and distribution of energy resources and populations, the per capita electricity consumption, the local cost of infrastructure and the characteristics of the terrain (Parshall, Pillai, Mohan, Sanoh and Modi 2009; Deichmann, Meisner, Murray and Wheeler 2011; Levin and Thomas 2012). Studies modelling the least cost mix of centralised and decentralised electricity show that for the majority of the world's population and area, centralised power supply is the most cost effective approach. Decentralised options are the least-cost option of a significant minority of population, particularly in rural and remote parts of Africa. An analysis of 150 countries shows that for 11 countries, all of them African except for Afghanistan, decentralised generation would be the least cost alternative for more than 50 per cent of the population (Levin and Thomas 2012), which does not mean that the electricity provided would be affordable. Calculations for Ethiopia, Kenya and Ghana show that the largest percentage of the population can be cost-effectively served with centralised options. However, in remote locations with very good hydro, wind or solar resources, minigrid systems are lower cost than grid connected options. Provision of off-grid energy for health centres, schools or administrative centres is part of Government policy or recognised by Governments as a viable solution in a number of countries such as in Rwanda ${ }^{7}$ and Kenya ${ }^{8}$. On a smaller scale, Kenya has a large market for small PV systems (12-50Wp) for off-grid power. These are expected to have an install rate of 10 MW by 2020 .

\footnotetext{
${ }^{7}$ Republic of Rwanda Ministry of Finance and Economic Planning. (n.d.).

${ }^{8}$ Republic of Kenya Ministry of Energy and Petroleum. (2013).
} 
Decentralised options may still be preferred even if they are not the most cost-effective option, for example when grid supply is unreliable or when central utilities are slow and ineffective to expand grid connections (Deichmann et al. 2011; Levin and Thomas 2012).

To summarise, estimating renewable energy costs is complex, highly dependent on local conditions, the many assumptions that have to be made, what is included and not (i.e. transmission costs) and on financing costs. These factors play a large part in determining whether particular technologies are competitive with fossil-fuel alternatives in any given location, as does the cost and availability of fossil-fuel generation. Generally more mature technologies will be more competitive, but this may be more than offset by local factors. Besides, global LCOE estimates that assume a maximum 10 per cent cost of finance need to be looked at with caution in Africa, where a reasonable weighted average cost of capital is 15-20 per cent except where strong guarantees are in place (IRENA, 2013). Considering the actual cost of finance in Africa would damage the competitiveness of renewables in LCOE estimations as compared to fossil fuels. Approaching this question on a location-specific way is therefore essential.

\section{Constraints to investment in renewable energy generation}

A number of reviews of constraints to renewable energy investment have been undertaken over the past 10 years. As well as academic, policy and industry expertise, these often draw upon interviews with investors of various kinds.

Constraints are usually organised into one of three categories: financial and economic; regulatory and political; and technical. Some recent research also points at the role of perceptions and preconceptions in investment decisions in the renewable energy sector. In this section, we first review each category of constraints with respect to renewable energy investments in a general sense. The extent to which constraints in developing countries differ is then explored.

\subsection{Constraints to renewable energy investments worldwide}

\subsubsection{Economic and financial constraints}

In most studies, economic and financial factors are the most important constraints on private sector investment.

The economics of low carbon projects are often less attractive than those of their high carbon alternatives. One major reason is that the carbon externality is not yet adequately priced in many geographies, and there continue to be significant fossil fuel subsidies.

(WWF 2011)

As this quote suggests, the financial costs of renewables tend to be higher than fossil fuel alternatives. However, as the previous review of cost estimates suggests, renewable energy technologies can be the most economical solution for electricity generation in many cases when the right conditions are in place. Besides, the cost of renewable 
technologies (i.e. the capital investment component) has fallen dramatically over the past few decades. The price of solar PV modules, for example, has fallen by more than 95 per cent since 1979 (IRENA 2012), but cell costs are minor elements in overall solar PV system costs. Wind turbines have seen cost reductions of similar magnitude. On the other side, the rapid fall in the cost of imported diesel engines from China has also had a disruptive effect in Africa. All in all, renewable energy remains a more expensive option than fossil fuel alternatives in many cases, although these differentials vary significantly as we have seen.

Many studies see this cost differential as artificial, pointing out that the pollution costs of fossil fuels are not included in their price or 'internalised' (Stadelmann, Castro and Michaelowa 2011; IRENA 2012; Nelson and Pierpont 2013; Spratt, Griffith-Jones and Ocampo 2013; OECD 2014). Many also highlight the fact that this is exacerbated by the large subsidies provided to fossil fuels in many countries. Globally, these have been estimated at US $\$ 522$ billion in 2012 ( International Energy Agency 2013), double the entire renewable energy investments in the world in that year.

Cost differentials are also driven by the high initial investment costs of renewables compared with fossil fuels. Capital investment comprises 80 per cent of the technology component of the LCOE for wind power projects, but only 15 per cent for gas (Nelson and Pierpont 2013). As a result, renewable energy investments require much larger up-front investment than is the case with fossil-fuel projects, which can act as a further constraint to investment by increasing the amount of finance that needs to be raised.

Different classes of investor cite different constraints. For institutional investors (equity), the primary issue is that returns available from renewable energy investments are often not large enough relative to risk and relative to other places they can put their money:

...financiers are concerned that insufficient returns will be generated given the risks involved in a project. This illustrates a key point that it's not sufficient to create a return for investors; the return must be attractive relative to all other investment opportunities. Therefore, to stimulate institutional investors' involvement in climate change finance, the returns expected on climate investments must be commensurate with perceived levels of risk and also competitive with the returns on normal business investments.

(Parhelion 2010)

Other institutional investors cite location specific constraints. Tax incentives are commonly used in the US to boost the returns available from renewable energy investments. US pension funds are tax-exempt, however, removing the benefits of such mechanisms (Nelson and Pierpont 2013).

Bankers also cite the insufficiency of returns with respect to risk, suggesting that the revenue streams from renewable energy projects can be unpredictable (WWF 2011). With the debt financing provided by banks, this represents a significant investment risk. Conceptualising investment constraints as four different forms of risk, Spratt et al. (2013) also suggest that 'economic risks', where returns are too low relative to the perceived risk, is the principle barrier to renewable energy investment. This constraint is particularly acute when the aim is to provide energy services to poor people because effective demand (need backed by ability to pay) is too low and too widely spread geographically.

From an economics and finance perspective, therefore, the primary constraints are: a) low returns relative to perceived risk; b) low returns relative to alternatives (due to cost 
differentials, un-priced externalities, and fossil-fuel subsidies); and c) the relatively high fixed investment costs of renewable energy projects.

\subsubsection{Regulatory and political constraints}

For investors, many of the risks associated with renewable energy projects are regulatory or political in nature. While all infrastructure projects carry risks of this kind, these are particularly important with renewable energy. In order to attract investment, governments generally intervene to address problems with the underlying economics of many projects. In such circumstances, the economic viability of the project becomes dependent on the maintenance of government support. The high fixed investment costs of renewables amplifies these risks, as the bulk of the investment is made at the beginning of the project, with returns accumulating over the projects' lifetime. The long-term nature of renewable energy projects make this problem worse still:

...investors are most concerned with the apparent mismatch between the longterm nature of capital commitments inherent in climate change financing and the relatively short time frame of climate change regulations. Investment horizons and/or capital commitment periods can range from 20 years for a reasonably sized renewable energy project to 50 years or more for a climate change adaptationrelated investment. Compare this with the duration of regulations that promote climate change investments.

(Parhelion 2010)

These concerns clearly have some foundation. Since the global financial crisis, and the pressure of government finances that resulted, many countries have reduced their subsidies for renewable energy projects. Given these policy-related risks, investors tend to demand higher returns for renewable energy projects, exacerbating the economic problems described above (Sullivan 2011).

While this is the most important form of regulatory risk, there are other constraints to investment in this area. Rather than the removal or modification of policy, these relate to the presence of unhelpful regulations or policies.

Other regulatory constraints specific to the energy sector include uncertainty regarding governmental renewable energy strategy and targets, limitations related to energy market liberalisation; uncertainties related to priority dispatch competitive landscape and price outlook; lack of well-designed regulations, processes and standard contracts (e.g. Power Purchase Agreements, PPAs) (Glemarec, Rickerson and Waissbein 2012). Institutional constraints occur when there is a lack of clear functional responsibility of different authorities for renewable energy project approvals or no clear recourse mechanisms (ibid).

Some of these problems - such as those described in the World Bank's 'Doing Business' indicators are not specific to renewable energy investment, but are general constraints on private investment. Examples would be the administrative burden of establishing a business, contract enforcement or tax policy (World Bank 2011a). More generally, The OECD stresses the need for consistency across different areas of policy:

Governments need to stand back and look across the entire range of signals they are sending to consumers, to producers and investors, to avoid incoherent and inconsistent policies, eliminate mixed messages when it comes to supporting renewable energy, and price carbon in a cost-effective way. In addition, neglecting 
the consequences, sometimes unintended, of domestic energy policies in such areas as water, agriculture and food can undermine their effectiveness.

(OECD 2014)

To summarise, regulatory or political risks can constrain renewable energy investment in three ways. First, as project viability is often dependent upon government financing, investors face the risk that this support will not be maintained. Second, negotiating the existing regulatory and policy landscape can impose significant costs on investors. Third, contradictory or inconsistent policies in other areas can create unintended consequences. Each of these risks are likely to exacerbate the economic problems detailed above, making renewable energy projects less attractive to private investors.

\subsubsection{Technical constraints}

To a greater or lesser extent, renewable energy technologies, except hydro, remain relatively new. This directly affects the risks investors attach to different projects:

The maturity or deployment of a given technology appears to be the dominant intrinsic factor that defines the overall risk perception for that technology. For example, there are significant uncertainties around the technical viability and performance of certain low-carbon electric generation technologies. Ultimately, these questions can...only be addressed through the relatively wide deployment of the technology, enabling its operation to be tested under a range of operating conditions and in a range of operating environments, thereby providing robust information on issues such as reliability (and maintenance costs), availability and equipment lifetimes.

(Sullivan 2011)

Table 3.1 groups technologies according to levels of technical risk. Some, such as onshore wind and solar PV are relatively mature, while others such as floating wave power remain quite new.

Table 3.1 Technical risks associated with different forms of energy generation

\begin{tabular}{|l|l|l|}
\hline Low & Medium & High \\
\hline Hydro & Biomass & Tidal stream \\
Solar PV & New build nuclear & Tidal barrage \\
Biogas & Offshore wind & Carbon capture and storage (CCS) \\
Onshore wind & Wave (fixed) & coal \\
& & CcS gas \\
& & Wave (floating) \\
\hline
\end{tabular}

Source: Sullivan (2011)

Technologies that have not been deployed at scale, in a range of different environments, and over a protracted period of time are thus unproven. From an investment perspective, this creates uncertainty. Performance, in terms of the energy generation may be worse than anticipated. Resolving unanticipated technical problems generates additional costs, even if these are only 'teething problems'.

The lack of accurate resource assessments for all renewable sources and uncertainties about future supply (for bioenergy) are another important technical barrier (Glemarec et al. 2012). There are also technical constraints related to the integration of variable renewable energy resources in electrical power systems. Power generation technologies 
can be classified in terms of whether they are variable, predictable/uncertain or controllable/uncontrollable. For instance conventional sources such as gas would be classed as non-variable, predictable and controllable given mechanical availability and fuel supply. Wind and solar PV however, would be classed as variable, uncertain and uncontrollable as their available output depends on the weather. Tidal stream generation is variable, predictable (it can be forecast many years ahead) and uncontrollable, whereas tidal barrages and some concentrated solar power plants are variable, predictable and semi-controllable due to intrinsic heat or water storage. The integration of large shares of time variable renewable energy resources is expected to result in higher systembalancing costs. Intermittent renewable energy sources contribute less to capacity adequacy (capacity that can meet peak residual demand ${ }^{9}$ ) than flexible sources, many of which are fossil fuel based. Intermittent renewable energy sources may also require additional investments in transmission infrastructure if resources are remote from demand centres (Intergovernmental Panel on Climate Change 2014). However, IRENA (2013) argues that integration costs can be significantly reduced through proper system design and increased system flexibility, where additional storage is only needed when intermittent renewables reach 20-50 per cent of total system capacity. An extensive summary of technical constraints related to the integration of intermittent sources may be found in studies such as North American Electric Reliability Corporation (2010).

From an investment perspective, the more untested the technology in question, the higher the technical risks and larger the impact on required returns.

\subsubsection{Behavioural constraints}

A new stream of literature builds upon behavioural finance and institutional theory to conclude that renewable technologies still suffer from biased perceptions and preconceptions that favour status quo over innovative alternatives. An analysis of the investment decisions of a large sample of European investors, for example, shows that priori beliefs about the technical adequacy of technologies and about the effectiveness of policy measures have a positive influence on investors' willingness to back renewable energy projects and to diversify their portfolios (Masini and Menichetti 2013). However, confidence in technical adequacy has a much stronger impact than confidence in policy effectiveness, which the authors interpret as an indication that the proven reliability of a technology is a precondition for investing. Importantly, however, the study also shows that technological views are influenced more by a priori belief than by factual information.

\subsection{Constraints on renewable energy investment in developing countries}

In most instances, constraints on renewable energy investment in developing countries are the same as those described in the previous section, only more acute. There are also a small number of constraints that are particular to developing countries.

\subsubsection{Economic and financial constraints in developing countries}

The rapid decline in technology costs that we have seen in recent decades has led some to suggest that grid parity is achievable (Lilliestam, Battaglini et al. 2012). While a case can be made to support this for some technologies in some resource-rich locations in developed countries, this is not often the case for most renewable energy technologies in

\footnotetext{
${ }^{9}$ Defined as total demand minus generation from renewables.
} 
developing countries. The reason is that hardware is only one component of total costs, as illustrated in Figure 3.1.

\section{Figure 3.1 Comparison of developed and developing country energy project}

\section{costs}

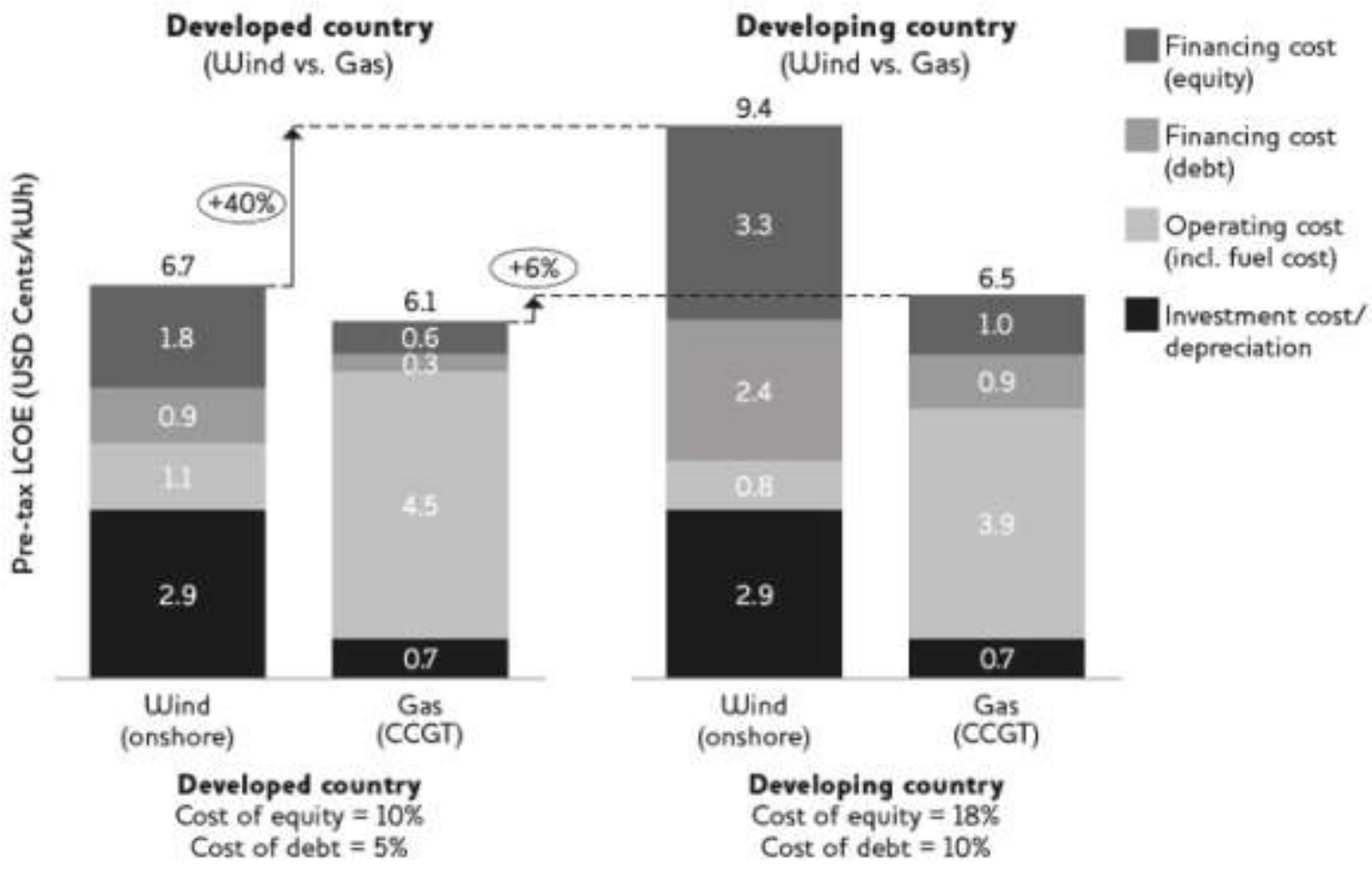

Source: Adapted from Waissbein, Glemarec, Bayraktar and Schmidt (2013)

Figure 3.1 compares the pre-tax LCOE for a generic onshore wind energy plant and a generic CCGT plant in a developed country and the same plants in a developing country. Looking at the developed country situation on the left-hand side of the figure, we can see that onshore wind energy costs $6.7 \mathrm{UScents} / \mathrm{kWh}$, while gas is only slightly cheaper $6.1 \mathrm{UScents} / \mathrm{kWh}$. The developing country picture is very different. Despite the fact that operating costs are somewhat less, wind costs are 40 per cent higher, while gas is only 6 per cent more expensive to generate.

These effects are driven by the higher cost of finance in developing countries and the capital-intensive nature of renewable energy investments. In the example above, the cost of developed country debt is assumed to be 5 per cent, compared with 10 per cent in developing countries. The figures for equity are 10 per cent and 18 per cent respectively. The reason why the cost differential in wind is so much greater than for gas is because of the capital intensive nature of the investment: most of the financing for wind has to be raised at the outset, so the fact that it is much more expensive in developing countries has a disproportionate impact on overall energy costs (Waissbein et al. 2013).

It is certainly the case that finance is much more expensive in developing than developed countries. Indeed, in many low-income countries, the cost differential may be even greater than is assumed here, with equity investors seeking returns of 25 per cent or more (Spratt et al. 2013). 
The cost of finance is a function of risk and return. As reflected in different sovereign credit ratings, the perception is that developing countries are riskier places to invest than developed countries. Generally speaking, the lower the income-level of a country, the riskier it is perceived to be, so that - as with individuals - the poorest pay the most for finance. In addition to being more expensive, there is less long-term finance in most developing countries. Wind projects in developed countries can now obtain loans of up to 18 years maturity, which is close to a projects' lifetime (Tan 2012). In developing countries, the typical loan maturity is less than half of this (Waissbein et al. 2013).

As a result of the higher perceived risks, debt investors in developing countries demand a larger share of equity than is the norm, with debt equity ratios of 60/40 being common, compared to the normal 70/30 in developed countries (IRENA 2012). As equity is more expensive than debt, this serves to further inflate funding costs, and the scarcity of equity finance in most developing countries acts as a further constraint. ${ }^{10}$ Finally, revenues may also be depressed, as many countries keep the cost of power artificially low for developmental reasons (United Nations Environment Programme 2012). Many developing countries show a history of manipulation of electricity prices for political reasons, typically aimed at keeping prices artificially low hence damaging the financial sustainability of the sector (ibid). Additionally, many countries spend large amounts in fossil fuel subsidies which damage the competitiveness of renewable energy alternatives.

Apart from this, limitations in utility's credit quality and payment track record raise nonpayment risks. For example, in Kenya:

investors view KPLC's ${ }^{11}$ credit profile, and the overall risk of non-payment by the utility, as a serious impediment to arranging financing. Investors have been seeking to obtain, with varying success, government guarantees, support letters and derisking instruments such as MIGA political risk insurance to mitigate this risk.

(Waissbein et al. 2013)

To summarise, while the economics of renewable energy projects in developing countries are often challenging, the situation is worse in developing countries, and particularly acute in low-income environments. This is caused by: a) the capital intensive nature of renewable energy projects, which amplifies funding cost differentials; $b$ ) the higher level of perceived risk, which raises costs through the higher cost of finance and the larger share of equity in project's finance structure; c) the lack of domestic debt-finance of suitable maturity and scarcity of equity finance, particularly private equity; d) low prices of electricity that prevent cost-recovery.

\subsubsection{Regulatory and political constraints in developing countries}

As measured by the World Bank's 'Doing Business' surveys, the time and resource costs associated with regulation are often higher in developing than developed countries (World Bank 2011). The intricacies of negotiating access to domestic grids may also be more difficult, with incumbent energy producers attempting to protect their market positions (United Nations Environment Programme 2012). This is a particular feature of African power markets with uncertain allocation of responsibilities for power planning, ensuring

\footnotetext{
${ }^{10}$ Debt is cheaper than equity as, in the event of insolvency, debt investors are paid before equity investors. Also, in many cases, income from debt-interest is tax deductible, while equity dividends are not.

${ }^{11}$ KPLC (Kenya Power and Lighting Company) owns and operates most of the electricity transmission and distribution system in the Kenya.
} 
adequate and reliable supply and organising procurement processes across public institutions and with the private sector. Hybrid power markets, where the state-owned utility occupies a dominant market position and private sector participation compensates for the lack of public investment were the result of the ineffective power sector reform prescriptions in Sub-Saharan Africa in the 1990s (Eberhard, Rosnes, Shkaratan and Vennemo 2011). Reform involving utility unbundling and privatisation followed by wholesale and retail competition was impractical for the region, as most power systems were too small to support meaningful competition. In the resulting hybrid model monopolistic and vertically integrated power utilities have no incentives or flexibility to provide easy access to third parties (United Nations Environment Programme 2012). This model poses multiple policy, regulation, planning and procurement challenges.

While such issues will increase costs and potentially constrain private investment, another significant risk is that government support will not be maintained, undermining the economic viability of projects. As described above, the economics of renewable energy investment make financial support essential. Given that these economics can be considerably worse in developing countries due to high financing costs, this support is even more needed.

Credibility is key. It is simple for a government to announce a FIT [feed-in-tariff] at a suitable rate for a long time period. The question is whether this commitment will be met, especially in difficult times. Investors may take confidence from the presence of long-term renewable energy targets, but this also depends on the credibility of this commitment.

(Spratt et al. 2013)

While many developed country governments have reneged on commitments, investors generally assign more risk to governments from developing countries where sudden policy changes - not least in the energy sector - have not been uncommon:

In South Africa, for example, investors began preparations for preliminary investments after a feed-in tariff was announced by the government, which was subsequently cancelled and replaced by an auction scheme.

(IRENA 2012)

In this example, the FiT was scrapped before the project began. A greater fear than policy inconsistency for investors is that that this will happen at a later stage, after the (very large) initial capital investment has been made. At the most extreme, investors may fear the expropriation of assets. As with the previous material considered, such risks tend to loom larger in lower-income countries, particularly those with a history of political instability.

It is these concerns which largely explain the higher cost of finance in developing countries, where investors demand higher returns to compensate them for higher risks. The fact that renewable energy projects are dependent on government support makes them much higher risk than other investments in the same country, amplifying the cost differential with other forms of energy. This can make it difficult for governments to justify continued support for renewables, particularly as:

“...many developing country populations lack an affordable and consistent basic energy supply, which can complicate the ability of the national government to justify a focus on renewable energy.

(IRENA 2012) 
This is particularly the case in Africa, where electrification is a much higher political priority than renewable energy or cogeneration (Tenenbaum 2014).

\subsubsection{Technical constraints in developing countries}

Developing countries face the same technical constraints described above with newer, untested technologies carrying more risks than more established forms of energy generation. Other technical constraints are particular to lower-income countries, however. From a connectivity perspective, technical constraints include: lack of standards for the integration of intermittent, de-centralised renewable energy sources into the grid; limited experience of the utility or grid operator with intermittent sources which prevents an appropriate system design enabling minimisation of system balancing costs; lack of readily available transmission lines from the renewable energy source to load centers; and delays in timely completion of these (Glemarec et al. 2012). For example, in the case of Mongolia:

With coal dominating the country's energy mix, investors comment on the transmission company's clear lack of experience with wind energy. Investors also raise additional concerns regarding overall grid stability due to the Mongolian grid's antiquated, Soviet-era technology. Another barrier is the lack of a public grid code for wind, without which manufacturers have been prevented from tailoring turbines.

(Waissbein et al. 2013)

As well as constraints caused by problems with physical infrastructure (i.e. lack of roads or transmission lines), many developing countries suffer from local knowledge and experience gaps with respect to project design, construction, operation and maintenance and financial structuring, particularly for immature sectors such as renewables. Investors may find that there aren't any local firms that can offer construction and maintenance services or any local staff that can operate the plants. The lack of local manufacture of hardware would require that all parts are imported, which would add to the time and cost of repairs:

There is less experience with project finance structures, limited equipment operations and maintenance expertise, and a greater need for technology transfer support. Bankers often do not understand renewable energy technologies and are unwilling to approve financing due to an inability to assess the risk of the project. (IRENA 2012)

To summarise, renewable energy investments face three types of constraint: economic/financial; regulatory/political; and technical. In each case, these constraints are more severe in developing countries, which also face technical constraints that do not arise in developed country contexts.

As well as being harder to deliver logistically, renewable energy projects in developing countries are perceived to be riskier. Consequently, investors demand very high returns to compensate for these risks, making it much harder for projects to be economically viable. To offset this, tariffs need be set very high, and/or government support needs to be proportionally larger than is the case in developed countries (Spratt et al. 2013). Given poverty levels in many developing countries and the limited ability of governments to maintain financial support at the levels required, it may be difficult to justify renewable 
energy projects in the absence of mechanisms to address these constraints and alter these dynamics.

\subsection{Ranking of constraints}

Two of the studies that have been reviewed attempt to rank investment constraints according to their importance for investors.

The UNDP's de-risking framework, for example, starts by identifying barriers and associated risks and then quantifies the impact of different risks categories on financing costs for a specific country (Waissbein et al. 2013). This is done by comparing the financing cost of a best-class investment environment (for example wind energy in Germany) with that of a developing country, with the additional cost being the element requiring 'derisking'. Each barrier's contribution to this additional cost is based on the probability of the barrier occurring and financial impact if it occurs. Estimates on these parameters are derived from interviews with equity and debt investors.

The framework is applied to four case studies involving onshore wind energy in Kenya, Mongolia, Panama and South Africa. Figure 3.2 presents the results of this exercise for Kenya. 'Power market risk' - resulting from a lack of coordination between Governmental bodies with responsibility over the power market and deficiencies and uncertainties in the PPA with the Kenyan utility - has the highest estimated impact on financing costs. Grid integration risk is also significant due to weaknesses in grid management and a lack of skills in the local utility. Potential for non-payment by the Kenyan utility creates high counterparty risk.

\section{Figure 3.2 Quantification of the impact of barriers and associated risks on increased financing costs for onshore wind energy in Kenya}

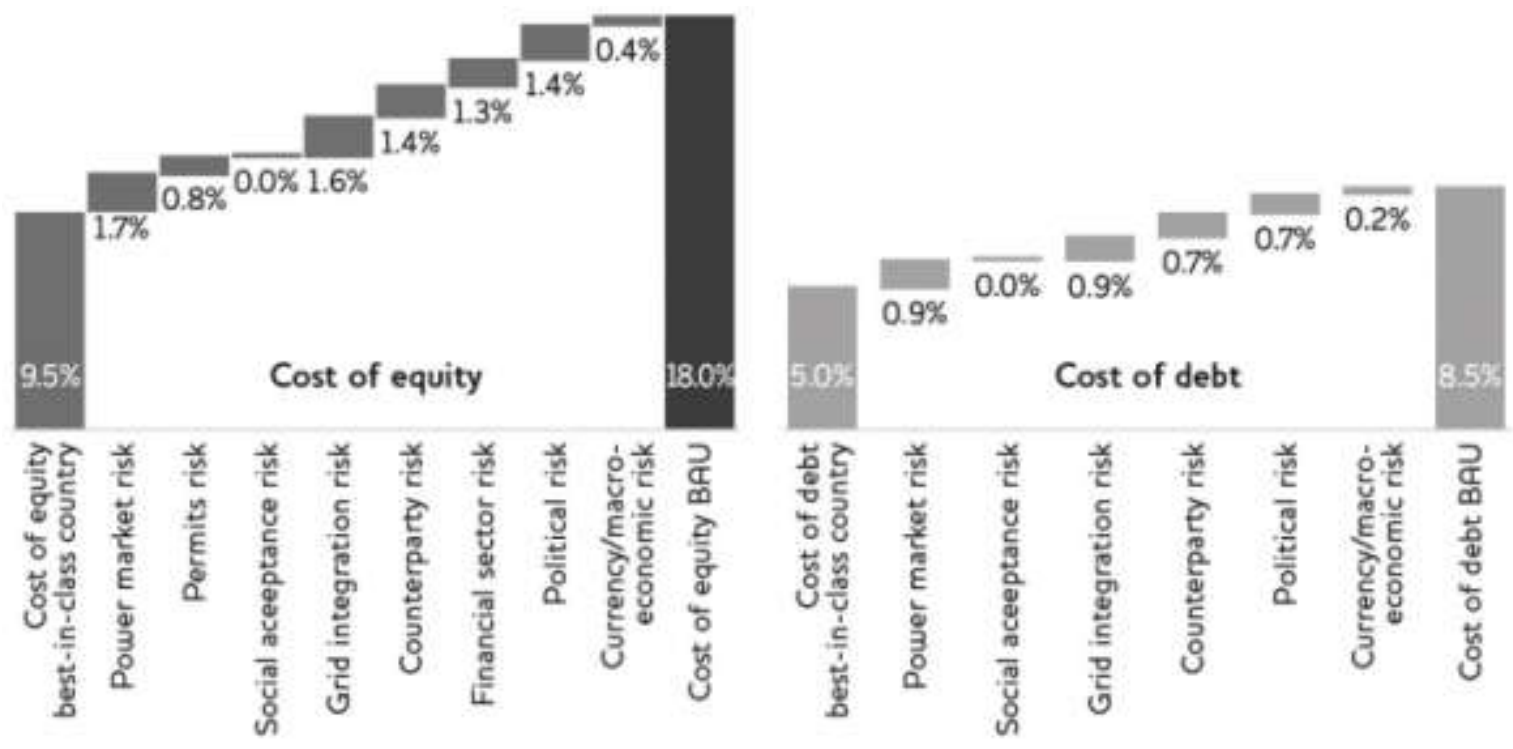

Source: Adapted from Waissbein et al. (2012)

In Mongolia, the lack of long-term targets for wind create uncertainty for investors, while regulations are flawed due to lack of experience of the Government and utility in wind energy. The process to obtain a PPA is also lengthy and non-transparent. For other risks, the transmission company lacks experience in the integration of intermittent sources and there are concerns over grid stability due to obsolete technologies. As in Kenya, concerns over the utility's ability to pay power generators are also a factor. 
Panama presents a different picture, with counterparty, political and currency risks considered low. Lack of knowledge of wind energy by government actors, the novelty of grid management for wind and lack of coordination between government bodies during permitting processes are seen as the major sources of risk.

Finally, in South Africa currency/macro-economic risk and power market risk are the largest contributors to an increased cost of finance. Investors show concerns about the difficulty of access to the market for IPPs, as well as a tendering process that experiences significant delays and encourages aggressive bidding and unsustainable low prices. With PPAs denominated in local currency, the historical volatility of the Rand is also an issue.

Another source on the relative importance of different barriers comes from Standard\& Poor's Ratings Services and Parhelion Underwriting Ltd, a UK-based specialist insurer, in 2010. Participants in a roundtable discussion from multilateral agencies, development banks, investment banks, the insurance industry, policy think tanks, and institutional investors were asked to identify, and score for probability and severity, the barriers that prevent investment by institutional investors in climate change finance.

Risks with the highest probability and severity were: longevity, risk/reward imbalance, transaction cost risk, human and operational risk, economic risk, and commodity price volatility. Longevity risk relates to the mismatch between long-term capital commitments and short term climate change regulations. The risk/reward imbalance is insufficient returns compared with other investment opportunities, for a given level of risk.

While the most severe risks were unexpected policy changes, institutional and property rights, and enforcement risks, the roundtable did not perceive these as highly probable, as the event did not focus in developing countries. Given that the probability of these events occurring would be considered much higher in a low income context, we can reasonably increase their weighing for the purposes of this research. This is fundamental, as it is not simply a matter of investors adjusting returns expectations to price in additional risks. Rather, there is a tendency to avoid altogether countries with a history of these risks, as shown by Africa's struggle to attract interest in Clean Development Mechanism (CDM) projects. The need for stable and predictable policy regimes for renewable energy investment, which are credibly protected from political interference, would seem an essential precondition for large-scale private investment.

\section{Policies to address constraints}

In the previous chapter the main constraints to increasing investment in renewable energy were organised into three categories: economic and financial; regulatory and political; and technical/project-specific. In this part of the review, we examine policies and tools that have been used, or proposed, to address these constraints.

Broadly, we have organised constraints and policies according to the nature of the risk that investors face, following the same categorisation as in the chapter on constraints: economic, regulatory or technical. Before examining interventions under these categories, it should be noted that other formulations are possible. One would be to organise according to types of investor or asset class. Deutsche Bank Climate Change Advisors (DBCCAs), for example, explore how to improve the risk and return characteristics of renewable energy investment in the following categories: private equity/venture capital; 
infrastructure (project finance); public equity; fixed income; carbon overlay; and quantitative risk and return (Deutsche-Bank 2011).

The rationale for such a categorisation is that different types of investors have different approaches to risk and return, which partly reflect the fact that they enter and exit the project life-cycle at different stages. As a result, interventions to adjust risk and return issues need to be targeted carefully:

...the return investors look for partly reflects the nature of the asset classes and are commensurate with the risks inherent in each asset class. Despite recent volatility, the return potential for public equities can be significant and since the end of 2006, clean-tech equities have outperformed the MSCI World, where investors are looking for secular movements in a variety of industries across the climate change universe. The Private Equity and Venture Capital asset class also continues to show opportunity for capital deployment and exit opportunities to strategic buyers and into the IPO market. More measured returns, yet with lower risk, will come from infrastructure markets, where returns are in the low single digits, but have a more secure yield embedded into the return. Investors can seek out strong risk-adjusted returns from the climate change tilted fixed income asset class, which can act as a hedge against further development expansion of carbon markets. And finally, investors can deploy a carbon overlay strategy using carbon offset credits to hedge their carbon price risk at a portfolio level.

Deutsche-Bank (2011: 7)

In the quote above, DBCCAs, describe these considerations as they appeared in 2011. As well as giving a flavour of market sentiment, the quote highlights some interesting distinctions between developed and developing countries. While infrastructure investments (e.g. renewable energy facilities) may be considered low-risk/low-return investments in development markets, this is unlikely to be the case in most developing countries. As we saw in the previous chapter, higher return expectations in developing countries create a severe constraint on leveraging investment.

As well as the way that different investors view risk and return, another consideration is the type of financing used. The UNDP highlight three important distinctions in this regard:

Corporate finance vs. project structures. If a corporate finance structure is taken, a bank will typically lend on the strength of the business' balance sheet, and the cost of debt is less likely to price in the specific risks faced by the renewable energy investment. If a project finance structure is taken, the only collateral a bank can have recourse to is the underlying assets of the investment. In this case, a bank is likely to perform detailed due diligence on the investment itself, and in turn will price in the various risks faced by the investment. Core vs. non-core investments. If the investment is a non-core activity, the risks associated with the investment are less likely to affect financing costs. A common example of non-core activities in this context are energy efficient investments. As an illustration, an upgrade of an inefficient industrial boiler in a textile factory may simply use a cost of financing associated with the factory's core activity (textile manufacturing). Unsophisticated vs. sophisticated investors. Generally, the more experienced and sophisticated the investor, the more capable the investor is of pricing in the particular risks. So, for example, an inexperienced IPP investing its own equity may underestimate the uncertainty associated with certain risks, resulting in a low cost of equity and overly aggressive bidding in a PPA-based bidding process...commercial banks in an immature domestic financial sector may 
not be fully comfortable with investments related to renewable energy technologies, resulting in a conservatively priced high cost of debt.

(Waissbein et al. 2013)

When exploring how to remove the barriers to different types of investment it is clearly sensible to take account of the type of investor that is required, and the nature of the appropriate financing mix. While the following analysis looks at constraints in terms of risks that face all investors, it is important to bear in mind that these risks do not affect all investors equally, and also do not apply equally in different forms of finance, asset classes, or investment mixes. With these caveats in mind, we first consider policies to address economic and financial constraints to investment. A summary table of policy instruments is provided as an appendix to this report.

\subsection{Policies to address economic and financial constraints}

Often the most challenging barriers to increasing private investment in renewable energy production are economic and/or financial: economic, in that the economic cost of renewables (e.g. the LCOE) is often not competitive with fossil fuels; financial, in that even when this is not the case, the nature of renewable energy financing, combined with the high returns expectations of investors with respect to developing countries, may undermine the economic viability of projects.

These seem to be rather crude generalisations: why do people invest in coal; what has happened to investment in large hydro (the state did this when its test discount rate was less than 5 per cent, but the private sector is not interested when the project lifetime is so long - this 'failure of capital markets' to invest in infrastructure was the reason Keynes gave for the creation of the World Bank.

Historically, the recommended solution to the economic constraint to renewables has been to increase the price of fossil fuel energy, so as to better reflect the costs of carbon emissions. In many developing countries, this requires phasing out fossil fuel subsidies. There are also two main options to increase the relative price of fossil fuels: price-based (i.e. carbon taxes) and quantity-based (i.e. 'cap and trade'). In the former, the price is known but the impact on carbon emissions uncertain. That is, a carbon tax may be designed to achieve a particular reduction in emissions, but the actual emission reduction will be somewhat uncertain. Conversely, under a quantity-based system such as 'cap and trade', the quantity of emissions reductions is fixed, but the price at which these trade i.e. the market price of carbon - is uncertain. From an economics perspective, the two approaches are equivalent: the level of carbon tax to achieve a given level of emissions reduction, should be the same as the price of carbon that would result in a carbon market where the same emissions reduction was imposed with a cap (Spratt 2009).

It is beyond the scope of this review to consider the relative merits of carbon taxes versus 'cap \& trade,', but this debate remains largely academic anyway. Although examples of carbon markets exist - most notably the European Trading System (ETS) - these remain the exception. The workings of the ETS have been much criticised, with carbon price levels far below those needed to incentivise a shift from fossil fuels. ${ }^{13}$ The global carbon market remains a dream, which even its most ardent admirers have stopped promoting.

\footnotetext{
${ }^{12}$ For a discussion of the economics, see Goulder, L. H. and A. Schein (2013). For an argument in favour of carbon taxes that takes account of political and practical considerations, see Hansen, J. E. (2009).

${ }^{13}$ For a discussion of price drivers in the ETS, and an agent-based simulation of reform proposals, see Richstein, Chappin and de Vries (2014).
} 
Most countries have taxes on high carbon emitting activities such as fuel use, but vanishingly few tax carbon directly. Interestingly the UK was the first country to introduce a 'floor' to carbon prices 2013, which is levied on large energy producers, and is effectively a tax on carbon. The rationale was that the 'floor' would rise progressively, performing the same function as a well-functioning carbon market. Starting at $£ 16$ per ton, the original framework saw carbon prices rise annually to reach $£ 30$ per ton by 2020 . Faced with opposition to rising energy prices, however, the UK Chancellor announced in the 2014 Budget that the price would be fixed at the 2015 level (i.e. £18) until 2020.

This highlights the difficulties in implementing carbon taxes that work - i.e. provide a sufficient disincentive to fossil fuel energy use. Public opinion is likely to object to the rising energy prices that result, as are energy intensive producers. This is particularly the case where the tax is implemented differently between countries. Given their economic equivalence, cap \& trade systems face the same issues: low carbon prices in the ETS partly result from the oversupply of credits following lobbying from European industry.

For the foreseeable future, therefore, we look set to remain in a second-best world where carbon prices are not widespread and other measures are put in place to increase the return or lower the risk of renewable energy as compared to fossil fuel alternatives.

\section{(i) Policies to boost returns}

The most commonly used - and proposed - policy to boost returns is a feed-in-tariff (FiT) at a premium rate for a guaranteed length of time (Bloomberg New Energy Finance2010; World Bank 2011b; International Finance Corporation 2013; Waissbein et al. 2013). There are several definitions of FiT but here will follow the same definition as Waissbein et al. (2013) as 'mechanisms that provide renewable energy generators with a power purchase agreement (PPA) ensuring a fixed long-term price for power and guaranteed access to the electricity grid'. An above-market price premium is not an essential characteristic of $\mathrm{FiT}$, but it is often the case when there is a need to increase the return on investment to ensure financial viability of renewable energies.

FiTs with an above market price premium have three distinct advantages. First, they reduce market access risk by ensuring access and incorporating must-take requirements. Second, they remove uncertainty over future price movements by a guaranteed price over periods of 15-25 years with built in automatic inflation adjustments. Third, they address cost differentials between renewables and fossil fuels by paying renewable providers a premium rate. They can also remove currency risk if they are set in foreign currency, usually USD. These advantages can generate dynamic growth in installed renewable capacity, particularly where access to the FiT is quite widely available. Here the growth in renewable distributed capacity in European countries may offer interesting lessons for developing countries. ${ }^{14}$

It is important to get the design of FiTs right, as once the share of renewable energy generation becomes significant FiT can become unsustainable for national budgets. The use of FiTs may not be appropriate in countries with very low electricity access rates, where underinvestment affects electricity generation and transmission as a whole. Indeed, using limited national resources to provide a price premium for renewables or

\footnotetext{
${ }^{14}$ For a review of different approaches to regulating distributed energy in Europe see Ropenus and Skytte (2005); Future Power Systems, 2005 International Conference on, IEEE.For the specific case of Germany's promotion of wind and solar PV see Luetkenhorst and Pegels (2014).
} 
transferring the extra costs to the final consumer, instead of supporting least-cost capacity could undermine efforts to reduce energy poverty. In countries where renewable energy technologies are more competitive with conventional energy, the introduction of relatively low FiT could stabilise or even reduce prices, by reducing the risk of the energy portfolio as a whole and providing higher certainty to investors (Haselip 2011).

Numerous studies have explored the economics of this for developed countries, proposing frameworks to create 'optimal' FiTs with respect to desired levels of capacity expansion, efficiency improvements, innovation and other policy objectives (Klein, Held, Ragwitz, Resch and Faber 2007; Lesser and Su 2008; Couture and Gagnon 2010). Politics also matter, however. FiTs need to adjust over time to changing costs -i.e. as the costs of renewable energy generation fall, price premiums need to fall accordingly. If this is not built into the framework, public opinion may turn against FiTs, undermining their political sustainability (Deutsche-Bank 2011).

PPA-based auctions or tendering processes are an alternative mechanism to ensure grid access and a guaranteed long-term electricity price. The main difference is that FiT prices are administratively determined, whereas in competitive tenders developers bid for the right to sell electricity at a particular price. Broadly, FiTs tend to be more favourable for project developers, whereas competitive tenders carry more advantages for the administration as they drive down the price premium required. However, pressure on prices can result in unrealistically low bids that do not result in projects being developed. In this case, they can make it difficult for a country to reach its renewable energy capacity targets. ${ }^{15}$ FiTs are relatively simple for project developers, whereas auctions usually carry higher transaction costs and result in clusters of big developers (Whittaker 2012).

As well as increasing revenues, the other way of boosting returns is to lower costs. This can take a number of forms. First, the cost of upfront fixed capital expenditure (CAPEX) can be subsidised. As we have seen, this represents a disproportionately large proportion of total renewable energy project costs, so that targeted subsidies at this point in the project life-cycle could also have a disproportionate impact on financial viability. Deutsche Bank describe the impact this had on the viability of wind energy in the US:

One of the most successful outcomes of the American Recovery and Reinvestment Act was the Section 1603 Treasury Cash Grant program, where project developers were provided with cash grants of $30 \%$ of project costs to help pay the high upfront capital cost of renewable energy projects, making some 'marginal' projects economical. Importantly, the program also filled the market void left from the reduction in tax equity capacity due to the 2008 financial crisis. As of February 2011 , some $83 \%$ of all section 1603 grants were directed to wind projects.

(Deutsche Bank 2011: 29)

Another way of reducing costs and boosting returns is via project finance. Most directly, loans can be provided on concessional terms directly from institutions such as national or multilateral development banks (WorldBank 2011b; International Finance Corporation 2013). Less directly, development finance institutions can supply credit lines to commercial banks on favourable terms to fund renewable energy projects ( Agence Française de Développement 2010 ).

\footnotetext{
${ }^{15}$ See Spratt (2014) for an examination of this issue in the evolution of wind and solar energy in China and India.
} 
More generally, development finance institutions may channel funds to project developers on the terms which they borrow. As these institutions are generally backed by sovereigns - either individually in the case of national institutions, or collectively for multilateral institutions - they have high credit ratings, and are able to borrow more cheaply than private financial institutions. ${ }^{16}$

An example is the 'Climate Awareness Bonds' issued by the European Investment Bank (EIB), with the money ring-fenced for renewable energy and energy efficiency projects, in the EU and developing countries. The EIB is thus able to provide finance for projects on better terms than private developers, or developing country sovereigns, could have obtained.

A more direct example is the IFC's 'B loan' structure, where the IFC effectively borrows money on behalf of a syndicate of banks. The advantages of the structure are described as follows:
When an IFC loan includes financing from the market through the $B$ Loan structure, IFC retains a portion of the loan for its own account (the "A Loan"), and sells participations in the remaining portion to participants (the "B Loan"). The borrower signs a single Loan Agreement with IFC, and IFC signs a Participation Agreement with the participants. IFC is the sole contractual lender for the borrower...The A/B Loan structure allows participants to fully benefit from IFC's status as a multilateral development institution. All payments including principal, interest, and fees gain the advantages of IFC's Preferred Creditor Status...As a result, IFC cannot be paid in full until all participants are paid in full. Similarly, a default to a participant would be a default to IFC.
(International Finance Corporation n.d.)

As well as obtaining finance on better terms, the B loan structure protects banks in the syndicate from the risk of default. Given that no borrower has ever defaulted on a loan to the IFC, this is a very valuable benefit (Spratt and Collins 2012). While not strictly 'concessional', therefore, these types of structure directly lower the cost of financing, and so boost project returns.

\section{(ii) Policies to reduce risk}

In this section we are concerned with policies that address financial risks - regulatory or political risk are covered in the next section. In practice, of course, the distinction is less clear: political and regulatory risk do affect the financing costs and return expectations of projects. What we are concerned with in this section, however, are policies that are designed to directly mitigate the financial and economic risks of projects.

One way of looking at this is by financing type. Project financing for renewable energy is a mix of debt and equity, and risk mitigation mechanisms apply differently to each. For debt, the principle risk mitigation tool is to guarantee some proportion of the loan in the event of default. Guarantees are extensively used by bilateral multilateral agencies in practice (Agence Française de Développement 2010 ; WorldBank 2011b; International Finance Corporation 2013), and supported by many commentators in the literature (Caperton 2010; Brown 2011; Griffith-Jones, Ocampo and Spratt 2012).

\footnotetext{
${ }^{16}$ For a discussion of this with respect to infrastructure finance in developing countries, see Spratt and Collins (2012).
} 
The cost of capital in many developing countries is higher because of the perception of higher political or economic risk. Some investors may not be prepared to accept these risks at all and others may demand higher returns for doing so. But with underwriting from developed countries, more investors may be attracted to clean energy in developing countries and the costs of borrowing may be lowered.

Caperton (2010: 3 ) describes the rationale. The same author suggests that the use of guarantees has a high 'leverage ratio' of $6-10$, implying that the use of public financing is able to leverage between 6 and 10 times its level of private finance. As well as attracting private finance through underwriting risk, the impact of guarantees is multiplied as, unlike with the direct provision of loans, they are only used in the event of default. Where no such problems arise, the public funds are retained and can be recycled as another guarantee. For this reason, well targeted and calibrated guarantees can be preferable to 'one-off' mechanisms in terms of maximising long-term impact.

In cases where a high level of risk prevents access to private funding, a guarantee can be more useful than a grant or subsidy. If the (perceived) risk turns out to be real, the guarantee turns into a subsidy; if the risk does not occur during implementation, the money will not be spent.

(United Nations Framework Convention on Climate Change 2006)

Debt providers also face foreign exchange risk when debt is provided in non-domestic currency, as is generally the case for developing countries. The problem is that project revenues are denominated in domestic currency, so a potential currency mismatch is created. If the debt is provided in US dollars, for example, and the domestic currency falls in value relative to the dollar, real debt repayment costs rise proportionally. This is a perennial issue in developing countries, where large currency devaluations are far from uncommon: from 3 July 2013 to 3 July 2014, for example, the Ghanaian Cedi lost 32 per cent of its value against the US dollar. The debt service costs - as well as the principle of dollar-denominated debt in Ghana has therefore risen by a third in one year.

Cost movements on this scale can undermine the financial viability of even the most robust project. Given the high CAPEX costs of renewable energy, this is a particularly important issue. An important policy solution has been the use of foreign exchange liquidity facilities. Brown describes the approach as follows:

"A foreign exchange liquidity facility can help reduce the risks associated with borrowing money in a different currency by creating a line of credit that can be drawn on when the project needs money and repaid when the project has a financial surplus. If a local currency is devalued and the project developer cannot afford the debt repayments, the developer can draw down funds in the liquidity facility and repay either when the exchange rate improves or the project can increase revenues. The cost of such a foreign exchange liquidity facility is expected to be cheaper than either a loan guarantee or policy insurance. (Brown 2011: 3)

As with guarantees, the mechanism is only triggered under certain conditions. Unlike guarantees, however, there is also the possibility of 'upside', where an appreciation of the currency would see inflows to the liquidity facility. This explains why it would be more cost effective over time, assuming that currency movements are not all in the same direction. As well as renewable energy projects, therefore, such mechanisms are thus widely promoted for infrastructure investments generally in developing countries (World Bank 
2011b; Griffith-Jones et al. 2012; International Finance Corporation 2013; Waissbein et al. 2013).

An obvious solution to this problem is to obtain debt in domestic currency. For most developing countries - particularly smaller, lower-income countries - this has often not been a viable option, as domestic creditors are generally unable or unwilling to provide finance on the scale required, and external lenders unwilling to take on the currency risk. For larger, emerging economies with growing domestic bond markets and increasingly large banks, this is becoming an increasingly feasible and desirable financing mode, however, and some donor initiatives have explicitly been designed to address this in lowincome countries. ${ }^{17}$

While (non-domestic) equity investors also face currency risks - though to a lesser extent - their other risks are different. The issue is not risk of default, but of a significant reduction in project profitability, or in the extreme insolvency and the loss of the invested capital. While this risk cannot be eliminated it can be mitigated. Subordinated equity funds, for example, create different classes of equity. Bodies like development finance institutions buy the subordinated tranche of equity, so that in the event of insolvency, the private equity investors are paid first (Brown 2011; World Bank 2011b). Caperton (2010) estimates that the leverage ratio of subordinated equity funds is 2 , such that a tranche of subordinated equity is able to leverage twice as much commercial equity.

Another option to attract equity investors is the 'pledge fund':

Some projects are too small for equity investors to consider, or simply cannot access sufficient equity, despite having a strong internal rate of return (IRR). If provision of equity is the primary limiting factor, an equity capital 'pledge' fund may be appropriate. In this model, public finance sponsors (which could be developed country governments or international financial institutions) provide a small amount of equity to anchor and encourage much larger pledges from private investors, such as sovereign wealth funds, large private equity firms and pension funds.

(Brown 2011: 3)

As described in the quote above, the use of public 'seed' equity capital can act as the founding 'anchor' for such funds. There are a number of important potential benefits of this mechanism. First, it sends a signal to private investors that particular forms of investment are potentially viable. Second, public investors may undertake project due diligence, which both reduces risk for private investors - by weeding out overly risky projects - but also saves them the significant costs associated with this process. More generally, the difficulty, and expense, of project preparation is well understood by development agencies, ${ }^{18}$ though many would argue that insufficient resources are devoted to addressing this issue (Bhattacharya, Romani and Stern 2012).

As well as financial risks, 'anchor' investors also play an important role in mitigating regulatory and political risk, which is the subject of the next section.

\footnotetext{
${ }^{17}$ The Private Infrastructure Development Group (PIDG) has a facility dedicated to supporting the development of domestic currency debt markets in low-income countries. GuarantCo provides guarantees to lenders to support local currency lending for infrastructure, which both prevents currency risk and also promotes the development of domestic financial sectors: www.pidg.org/what-we-do/companies/guarantco

${ }^{18}$ The PIDG, for example, also has a Technical Assistance Facility (TAF) that assists with project development.
} 


\subsection{Policies to address regulatory and political constraints}

As described above, feed-in-tariffs and competitive tenders can address constraints related to market access and price uncertainty by guaranteeing access to the grid and a long-term price for renewable energy generation. Most renewable energy projects also require these cornerstone instruments for financial viability. However, it is one thing for a country to announce a FiT and another for investors to believe this will be honoured for its formal duration. This can be a major issue for investors in developing countries, particularly those with a history of regulatory policy change.

As with financial risk, different mechanisms have been developed for debt and equity investors. For the former, the equivalent of a loan guarantee is policy insurance: 'Low carbon policy risk cover', for example, could be offered as insurance against the prospects of developing country governments discontinuing support policies such as FITs (VividEconomics 2009). There are a number of ways this could be implemented. The first is through a standard insurance policy:

As most projects depend on one or more specific policies to be profitable, public finance can be used to insure investors against the risk of policy uncertainty. This can be done through conventional insurance bought by the public finance institution to cover the risk of policy change. For example, if the policy is a feed-in tariff to support renewable electricity projects, the public finance institution could buy an insurance policy against the feed-in tariff being abandoned or reduced...This type of tool is most likely to succeed in countries with strong regulatory systems and institutions, and where certain policies are already in place or under development.

(Brown 2011: 5)

A minimum level of institutional quality would be required for this be feasible. An alternative would be for official agencies to purchase a 'put option' from the energy producer, whereby they would guarantee to buy the energy generated at a specified, minimum price, if the FiT were revoked or substantially reduced (Caperton 2010).

Political risk is akin to regulatory risk, only more extreme. Here the risks are of an expropriation of assets, or of the social and political situation becoming so unstable that it is impossible for the project to function. Once again, insurance is the primary tool. This may be provided by public agencies, such as the Multilateral Investment Guarantee Agency (MIGA) ${ }^{19}$, which is an arm of the World Bank, or from private political risk providers such as Lloyds of London. ${ }^{20}$

The primary means of mitigating regulatory and political risk for equity investors is through co-investment. As described above, no borrower has defaulted on a loan from the IFC, presumably as this would jeopardise their wider relationship with the World Bank Group. Co-investing with a multilateral or bilateral agency from an important donor will also make it less likely that regulations will be radically changed, or more extreme political risks come to fruition (Spratt and Collins 2012). This insurance, or 'political umbrella' is a key reason why the 'anchor funds' described above are so important. Recent examples are the IFC's Catalyst Fund, the UK Department for International Development's CP3 Fund,

\footnotetext{
${ }^{19}$ www.miga.org/

$20 \frac{\text { www.lloyds.com/redirect-pages/risk locator/political risks insurance }}{}$
} 
both of which aim to leverage commercial private equity into renewable energy in developing countries by co-investing.

A related form of risk relates to the way policy is formulated and implemented in the first place, not the risk that it will be changed or revoked. Waissbein et al. describe this in the context of policy 'derisking':

Policy derisking instruments seek to remove the underlying barriers that are the root causes of risks. These instruments include, for example, support for renewable energy policy design, institutional capacity building, resource assessments, grid connection and management, and skills development for local operations and maintenance (O\&M).

(Waissbein et al. 2013: 12)

Other commentators also stress the importance of providing significant support for renewable energy policy design (Bloomberg New Energy Finance 2011; International Finance Corporation 2013).

\subsection{Policies to address technical (and capacity) and project-specific constraints}

Investors' perceptions of risk are higher with less mature technologies, and/or where these technologies are deployed in new settings. The development of local technology standards can reduce uncertainty about the quality of equipment. Besides, co-investing may help to mitigate this by protecting investors from some of the technical risks from new technologies. In this case, the appropriate mechanism would be to create a fund with public and private funds to invest in promising new technologies:

One possibility is to allow private investors to buy out the government share of the fund at a nominal return on capital once the technological risks of the overall portfolio have been reduced with time, experience and financial progress (Bloomberg New Energy Finance 2010)

While such a mechanism might work well in a developed country, it is unlikely that investors would be prepared to invest in untried technologies in developing countries. The model could be adapted, however, and made more applicable to the specific technical risks in developing countries.

Technical constraints arising from the integration renewable generators into a power system can be addressed through a number of methods, mechanisms and policies: ${ }^{21}$

- Design renewable generators to be more grid friendly through offering voltage support, reactive power regulation, fault ride through, active power control, frequency regulation, inertial response and limiting fault currents.

- Additional flexible generation and storage to maintain the instantaneous balance of supply and demand and additional frequency/voltage regulation and support.

\footnotetext{
${ }^{21}$ See International Energy Corporation (2012)
} 
- Additional network upgrades to connect remote wind and solar generation to load centres. This can be achieved with new lines, FACTS and raising the voltage level.

- Improved modelling of generation and weather forecasting to mitigate the unpredictability of the power output from wind and solar.

- Coordination of the control of clustered renewable generators.

- Policies to strengthen the transmission company's operational performance and grid management, so that it can cope with the new, flexible generation.

- Formulation of a grid code for new renewable energy technologies.

Technical constraints arising from uncertainty about the size and cost of the renewable energy resource can be addressed through capacity building and public funding for the preparation of renewable energy resources assessments and pre-feasibility studies (Waissbein et al. 2013).

The lack of a skilled local workforce may require a general improvement of the education system, but specific renewable energy skills can be reinforced through training and apprenticeship programmes and the support to specialist programmes at local universities.

Project and operational risk is distinct from technical risk, but may be a significant factor in some developing countries. There are two main options to address this issue. First, as with regulation, insurance can be supplied to cover for operational risk. Given their longstanding experience with this form of insurance, some have suggested that private insurers may be able to offer this at lower cost than the public sector (Bloomberg New Energy Finance 2011). The second option is to mitigate project risk directly. Some development finance institutions - such as Norfund, for example - work directly with Norwegian construction and maintenance firms, which have particular experience in delivering hydropower projects (Griffith-Jones et al. 2012).

\subsection{The policy mix}

The previous sub-sections have considered policy interventions to address risk in isolation. In practice, however, barriers to investment are likely to be multiple, and policies to address these will thus also be multiple. Waissbein et al. (op cit) illustrate how a mix of public policies can be built upon a 'cornerstone instrument' such as a FiT. 
Figure 4.1 Public instrument selection for large scale renewable energy

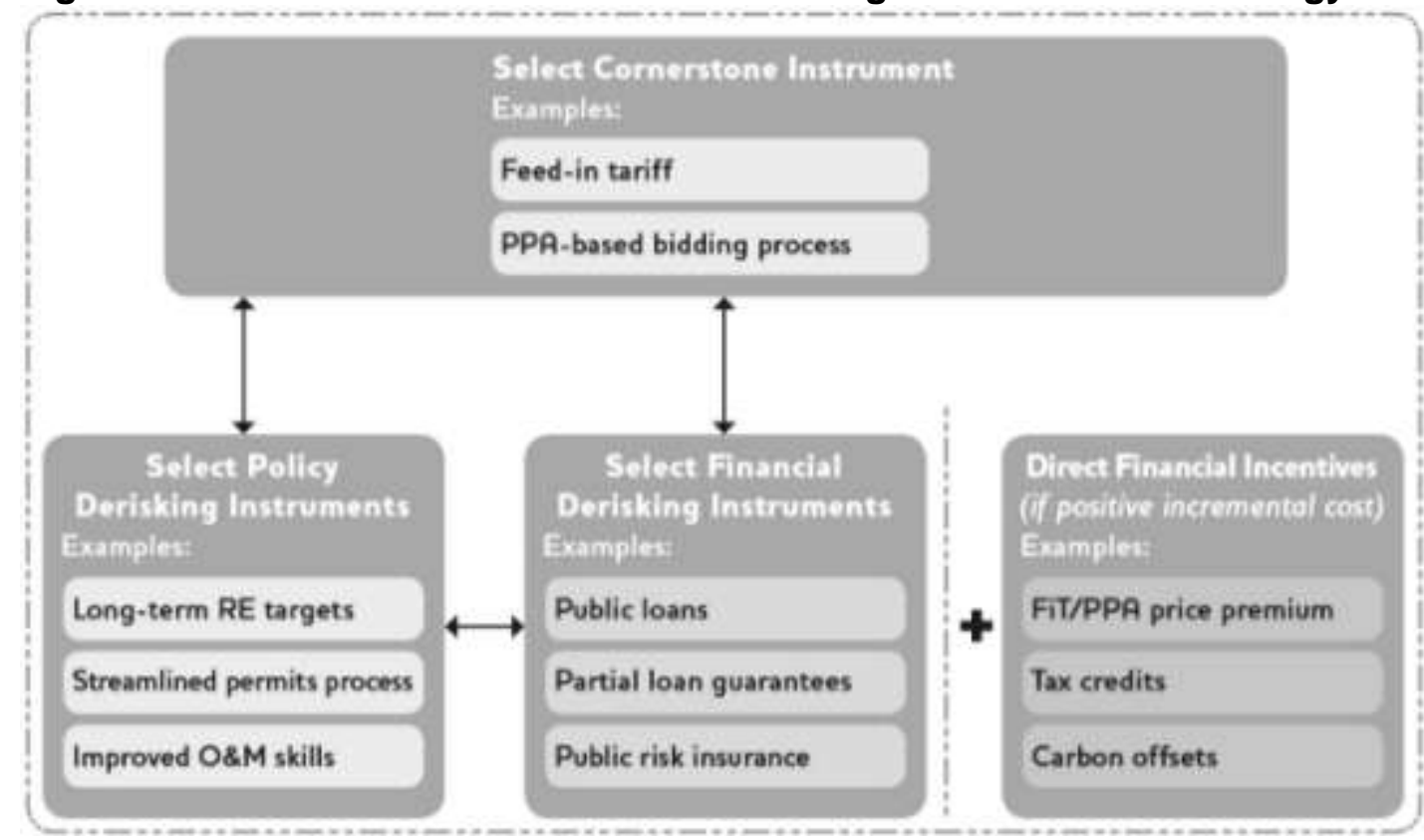

Source: Adapted from Waissbein et al. (2013)

The same authors also describe the complexities involved in finding the right policy mix:

Decision-makers...have to identify the different stakeholders associated with each investment barrier, and closely understand the varying interests that have resulted in the barrier coming about. The appropriateness of different public measures to address these barriers needs to be assessed: some public instruments may be less effective and require a longer amount of time to take effect in some countries than others. For example, institutional strengthening within ministries may be an important precursor to a well-designed FiT regime. While a public instrument may be effective, the public expenditures required to achieve this might be disproportionate and therefore politically unbearable. Determining the ex-ante cost of public instruments involves multiple, complex assumptions. Direct financial incentives for renewable energy are becoming particularly controversial in industrial countries and are likely to prove even more problematic in developing countries.

(Waissbein et al. 2013)

The ultimate aim of this research is to develop a robust methodology to enable policymakers to chart a path through this complex labyrinth. Identifying the best policies and policy mix is only the first part of the process, however. To have the predicted effect these policies need to be implemented, and this is a not a technical question, but a matter of political economy. Accordingly, the next chapter explores the literature in this vital area.

\section{Who drives/obstructs the adoption of sustainable energy policies?}

The transition from fossil fuel to sustainable energy and selection of the low carbon technology tends to be a highly politicised process. Identifying those actors in 
government, business or civil society that obstruct or drive the policy process is an essential part of our approach. The purpose of this chapter is to draw together the key insight from the recent political economy literature.

There is now a substantial literature on why political economy analysis is needed and what adopting a political economy means in particular policy field. Amongst the most useful contributions are Department for International Development (2009), Williams, Duncan, Landell-Mills, and Unsworth (2008), Unsworth and Williams (2011) and Fritz, Kaiser and Levy (2009):

An annotated bibliography of these and many other papers is available from the Policy Practice Library. ${ }^{22}$

The question driving our political economy analysis is: Who obstructs/drives the adoption of specific sustainable energy policies in Kenya and Ghana? The energy sector in these countries is politically and institutionally complex, as is evident from the difficult history of power sector reform. Identifying the binding constraint and the most promising policy is essential but not sufficient for testing the practical relevance of our approach. Identifying the actors who (seek to) block or adopt the most suitable policy is equally important. This is what our political economy analysis is about. Pulling together what the literature tells us on this question is the purpose of this chapter. We will do this in two stages: first, distil the international literature and then concentrate on Africa.

\subsection{Lessons from the international literature}

Who drives renewable energy policies and who holds them back? There are many actors to be considered. Grouping them is essential to make sense of the literature. Table 5.1 seeks to do this. It distinguishes between top down and bottom up approaches and between actors of different types, operating at different levels and in different locations.

\subsubsection{Categorising actors}

Over the last decade, the policy debate has given most attention to the left side of the table. The ambition was to bring economic development within planetary boundaries by pursuing an approach which was top down, had global scale, was (supposed to be) led by the North, and driven forward by public actors that recognised the need to mitigate climate change. This global governance approach has failed as shown by successive climate conferences (COPs) and the sustainability conferences in Rio de Janeiro (Latin 2012). In the meantime however, progress was made on the right side of the table: using bottom up approaches and relying on local initiatives in which civic actors play a major role (Leach and Scoones 2015). Local government has also played an important role - as shown by case material from both West and East (OECD 2010; Harrison and Kostka 2012).

\section{Table 5.1 Who drives renewable energy policy?}

\begin{tabular}{|c|c|c|c|c|}
\hline Approach & Top Down & & & Bottom Up \\
\hline Level & Global & National & & Local \\
\hline Location & North & Rising Powers & & South \\
\hline Actor & Public & Private & & Civic \\
\hline Motive & Climate Change & Energy Security & $\begin{array}{l}\text { New Industrial } \\
\text { Sectors }\end{array}$ & Green Jobs \\
\hline
\end{tabular}

Source: Authors' own

\footnotetext{
${ }^{22}$ See www.thepolicypracticelibrary.com
} 
Similarly, at the national level, substantial progress was made in some countries, with governments implementing green industrial/energy policies and the private sector making big investments in renewable energy and other low carbon technologies. Such progress made at the national level risks however running out of steam in the countries expected to lead the green transformation: most of Western Europe and North America is politically paralysed and financially constrained. The rising powers (China, India and Brazil) have become the default movers and shakers in the green transformation - in both the negative and positive sense. While responsible for the continuing growth of carbon emissions they are also the biggest investors in mitigation. Seen globally, China is number one investor in renewable energy and India has recorded high recent growth rates in 2011 (Bloomberg New Energy Finance 2013).

Table 5.1 helps to categorise existing approaches and actors. On their own none of them will achieve the green transformation. Most observers would agree that the bottom up and top down approaches need to be combined and that multi-level governance is needed (Bulkeley and Newell 2010:3). But which forces can bring this about?

Who can drive the required policies forward? Recent literature suggests that actors who believe in green causes cannot bring about the required advances on their own (Newell and Paterson 2011). Those with motives other than climate change need to be brought into the picture. Their main motives are included in the last line of Table 5.1. Schmitz (2015a) suggests that the analysis of actors and motives then needs to take four critical steps: first, recognise that no single actor has the resources to bring about the green transformation; second, recognise that within government, civil society and business there are actors seeking to block or slow down the green transformation. Third, attention needs to focus on supportive alliances across these categories. Fourth, including actors with different motives helps to understand and accelerate the green transformation. The transformative alliance becomes the central concept. Let us elaborate.

\subsubsection{Alliance of actors}

Bringing about green transformations requires resources of different types: expertise, money, organisational capacity, legitimacy and leadership. These resources tend to be distributed over a range of public, private and civic actors. It is therefore useful to concentrate on alliances between actors in government and business and civil society.

Who then can be considered a member of such an alliance? Is the deciding criterion motivation or action? While it is tempting to let motivation count and opt for an alliance of the like-minded, this is a limiting step to take. There is a range of actors that can support the green transformation through their action (such as investing, providing expertise, lobbying) but their motive need not be to mitigate climate change; the main motive might be to secure energy, to build competitive green industries, or to foster green jobs - with climate change mitigation at best a 'co-benefit'. In other words, there is a potential for alliances that include actors whose priority is not environmental sustainability. This can be a 'game changer' in the policy process. It is supported by historical research which shows actor groups with differing intentions advancing the change in a specific direction (WBGU 2011:85).

Such alliances seem to have been important in both China and Europe. In Denmark, for example, the experimentation with wind energy received substantial support from politicians and business leaders concerned with energy security - in the wake of various oil crises. Actors with environmental motivations played a role at the start and increased 
in importance over time but they were never sufficient. Actors motivated by the chance to build a globally competitive hub (for providing wind energy solutions and creating highly paid jobs) have played a big role. In China, such alliances were equally if not more relevant. China's massive investment in renewable energy was not driven primarily by concerns with global climate change but by concerns to secure energy and ambitions to build new competitive sectors. These were major concerns in both Chinese government and industry (Schmitz 2015b). Add to this the more recent concern in urban society to reduce pollution - now openly acknowledged in the Chinese media.

Recent research in China (Dai 2014) shows that such alignments of interest matter in both policy formulation and implementation. In China, policy formulation tends to take place at central level and implementation at local level. Dai (2014) stresses that the local take up of centrally designed policies varies enormously within China. 'Dynamic' localities which implement central policies for solar and wind energy are led by local government and often supported by business. These government and business actors have ambitions which are rarely about mitigating climate change; they are more concerned with promoting local economic development, creating jobs, increasing tax revenue (local government) and generating profit (business).

The relevance of alliances is confirmed by the research of Harrison and Kostka (2012) on the local politics of climate change in China and India.

In both countries the ability to build and sustain coalitions is central to the effectiveness and sustainability of climate change policy. For various reasons, state strategies in China and India have focused on the need to bring different parties with otherwise divergent interests on board to build a coalition in favour of climate mitigation measures.

(Harrison and Kostka 2012: 5)

Recent research in India (Chaudhary, Narain, Krishnan and Sagar 2014) shows that such coalitions have played a critical role also at the national level but that the combinations of interests varied between sectors. The solar industry was supported for the purpose of both securing energy and building competitive low carbon industries. The 'National Solar Mission' is the most visible symbol of an industrial policy for this sector. The most vigorous implementation of this policy occurred in the state of Gujarat where Chief Minister Narendra Modi (now Prime Minister of India) spearheaded an alliance of government and business interests determined to accelerate economic development. There is no equivalent 'national wind mission' in India indicating that concerns with building a competitive wind turbine industry played less of a role in policies supporting this sector (Chaudhary et al. 2014). Energy security was the main driver - on the part of government. Climate change mitigation was only a 'co-benefit' (Dubash, Raghunandan, Sant and Sreenivas 2013).

To summarise, the composition of transformational alliances varies, depending on the specific policy or project or sector in question. Actors in these alliances might see climate change mitigation as a co-benefit but tend to have other priorities such as securing energy, building new competitive industries, creating new jobs in their region, raising public revenue or generating private profit.

This is not to suggest that there are only winners. Some stand to lose, and in the early stages the losers might even outnumber the winners. Whatever the numbers, they are agents of resistance and they need to be analysed in the same way as the agents of change. The opponents also seek alliances. The opposing forces are not necessarily 
against de-carbonisation as such but they are fighting for their jobs and/or protecting their assets which are tied to fossil fuel and related sectors. Geels (2014) provides a detailed political economy analysis of the UK electricity system and policy debate, unravelling the forces which block or resist the changes to renewable energy.

To return to our overall argument, focusing on alliances is essential for understanding advances and setbacks in renewable energy policy formulation and implementation. Such alliances are best seen as vehicles for bundling diverse interests for a particular purpose, such as influencing legislation, policies, or projects. In order to be effective, analytical and political work needs to deal with both agents of change (prospective winners) and agents of resistance (prospective losers).

Putting such alliances centre stage is a critical step for addressing our central question, but it is not sufficient. Two further steps are needed: first, we need to be able to distinguish between alliances of different types. At one end there is the strategic alliance based on joint action. At the other end there is the mere alignment of interest without coordination between the parties. Both can be transitional (short term) or enduring (long term). All types can be instrumental in bringing about collective action or blocking it.

Second, we need to ask where these alliances come from. They are not given but are in themselves a product of history. Lockwood (2014) shows that the policies adopted in one stage have knock-on effects for subsequent stages and influence the momentum of the policy debate. Depending on how these policies are designed and implemented they give rise to new stakeholders, for example business and workers who invested their money or careers in the deployment of green technologies. But these policies can also create a backlash from those who pay for the subsidised investments through increases taxes or energy bills.

\subsubsection{Business as Policy Actors}

The need to consider the full range of societal actors has been increasingly acknowledged in the European renewable energy policy debate. A clear example is the German Council for Global Change which stresses that the transition from fossil fuel to renewable energy is above all a political task. Central to this political task - according to the Council - is the forging of 'A Social Contract for Sustainability' (title of WBGU 2011), a contract between the state and the citizens. 'The contract has to bring two important new protagonists into the equation: the self-organised civil society and the community of scientific experts' (WBGU 2011: 8). Others put more explicit emphasis on including business actors in the policy process. Since this is central for our project, it deserves further elaboration.

The focus on alliances and inclusion of business in such alliances finds strong support in the literature. Recent political science analysis shows that alliances (or coalitions) can be effective in overcoming complex collective action problems (Leftwich 2009; Peiffer 2012). Including business in the analysis and formation of alliances makes a significant difference. Maxfield (1991: 421) stressed long ago the critical role of policy coalitions which cut across state and society and include business. More recently, Abdel-Latif and Schmitz (2010) have shown why and how state-business alliances matter for overcoming bottlenecks in economic development. When it comes to green transformations, the inclusion of business seems particularly important. As stressed by Newell and Paterson (2011) 'many capitalists and state elites, for a range of different reasons, now have a political and financial stake in the project of decarbonisation' (p.41) ... 'short or medium term transitions to a low carbon economy will have to be supported (financially and 
politically) by powerful fractions of capital with a stake in the success of such a project.' (p.23).

This is a key point. There are parts of the business community which are keen to support green policies but are in fact driven by ambitions in other fields, notably securing energy or building a competitive new industry. Understanding the political dynamics needs to include also those interests which are not green in themselves but support the green cause. Effective cooperation between public and private actors does not require that the players support renewables for the same reasons. On the contrary, the chance of cooperation achieving results increases dramatically if players with different motivations are brought into the picture.

\subsection{Insights from literature on South Africa}

There is a substantial literature on the political economy of energy policy in Africa. It covers 'green' issues (the push for renewable energy), 'red' issues (provision of energy for the poor) and 'brown' issues (expanding energy production (whatever the source), expanding the grid, and the pricing of energy). The latter has attracted most attention because the shortage of energy has been a major bottleneck to economic development. In this project, and hence this literature review, we are however more concerned with where the energy comes from, in particular the policies that aim to increase the share of renewables in the energy mix. Who drives or obstructs such policies? The country for which this question has received the most insightful attention is South Africa which is therefore the focus of this section.

The South African case is most interesting because it provides insights on both the forces that hold back the transition to renewable energy and on the forces that (seek to) move it forward. The forces against emerge clearly from a number of sources, including Eberhard (2007), Baker (2012), Baker et al.(2014), Pegels (2014) and Morris and Martin (2014). For a long time South Africa has relied mainly on abundant coal reserves to produce electricity. Cheap and plentiful coal-generated energy was essential for its 'minerals and energy complex'. Actors from business, government and trade unions had an interest in the competitiveness of this complex. They used their engagement in the policy making process to keep energy prices low and minimise the cost of supporting renewable energy. A key actor in this alliance was the energy supplier Eskom, a vertically integrated stateowned monopoly, well connected to key government departments and energy-intensive companies. In the words of Baker et al. (2014):

Given the strength of the incumbent regime in the form of the MEC (minerals and energy complex) that is so tied to and reliant upon the production of cheap fossil fuels and their distribution through a grid controlled by a virtually monopoly actor, opportunities for large-scale and widespread transitions (to renewables) are hard to discern.

(Baker et al. 2014: 23)

But 'moments of crisis create opportunities for change' (Baker et al. 2014: 23) and such a change towards renewables has emerged. Understanding why is critical.

There are strong environmental reasons for raising the share of renewables in the energymix of South Africa: its carbon emissions per capita are twice the global average. The 
opportunities for bringing these down are very favourable as far as nature is concerned; the country has one of the world's best solar resource areas (Pegels 2014). ${ }^{23}$

However, the driving force pushing South Africa into renewable energy policies did not result from a commitment to reduce high carbon emissions and mitigate climate change. It was rather prompted by a crisis in the supply of electricity.

The importance of achieving energy security was brutally put on the political agenda by an inability of Eskom to meet the new demands of a post-apartheid period of industrial growth and rapid electrification for the poorer, previously disadvantaged segments of South African society. The breakdown of Eskom's generating capacity, transmission and distribution capacity and rapidly escalating electricity prices shook business and residential householders to the core. (Morris and Martin 2014: 82)

The crisis loosened the grip of the 'minerals and energy complex' on the policy process but moves towards renewables continue to be contested. Morris and Martin (2014) unravel a struggle between two coalitions, one against and one in favour of renewables, splitting the public and the private sectors while civil society (trade unions and householder associations) remains undecided. On the government side, the coalition in favour consists of the newly created Department of Energy, the Treasury, the Department of Environmental Affairs, and parts of the Department of Trade and Industry; and private sector support comes from foreign based independent power producers and ancillary business professionals tied to their operations. This alliance is gaining influence over the policy process and creating a platform for a renewable energy path but the process has been messy. So as to cut through this complexity, Morris and Martin offer the following insights:

- Support for renewables comes from a range of actors with different motives.

- Alignments of such actors have driven the change to renewables.

- The process has not been smooth, it has had considerable ups and downs.

- The governance of the value chain of electricity generation and distribution helps to understand these ups and downs.

- Distinguishing between different phases of the transition helps to make sense of the changes.

\subsection{Next steps}

These are the main insights on the question of who drives or obstructs policies for renewables in South Africa. As mentioned, there are other good political economy analyses not discussed here but these address different issues (for an overview see Barnett 2014). Their relevance for our question is only indirect because the problem constellations and actor constellations tend to differ with the question which one seeks to answer.

\footnotetext{
${ }^{23}$ Buying hydro electricity from Mozambique or DRC are complementary options.
} 
The most prominent example of political economy analysis which is well developed but only of indirect relevance is that concerned with 'power sector reform' (Victor and Heller 2007; Dubash and Williams 2011). It is primarily concerned with how to increase the supply of energy and how to lower the unit cost. The political economy analysis then informs who promotes or blocks the required restructuring and liberalisation. It is about 'reconfiguring the distribution of power between state and private actors and the balance of power within the state' (Newell et al.2014). Understanding these power struggles provides important backdrop but does not provide the insights required for understanding the forces that promote or block the transition to renewables which is our main concern. The battle lines are different. However, the South Africa situation shows that the broader struggle over power sector reform can have indirect effects in that it opens up or closes down political spaces for accelerating the transition to renewables. As mentioned above, the unexpected shortage of energy and increase in prices undermined the legitimacy of the existing coal-based regime and provided a political opportunity for advancing the renewables agenda in South Africa. Morris and Martin (2014) give fascinating insights into how an alliance of actors was able to use this opportunity.

The task for our project is to apply our main question (who drives or holds back the transition to renewables) to the cases of Kenya and Ghana - and to discern whether and how this influenced by 'old' power sector reform. There is some very useful literature on these countries (for example, Newell et al.2014; Byrne et al.2014, Bawakyillenuo 2009, 2012), which will be considered in country studies as part of this project.

Finally, in order to make the literature review directly relevant for our project, we need to give explicit attention to the issue of energy access. There is a good deal of material on energy access - why it is important, where the technical constraints lie, what the economic constraints are, what regulatory changes are needed, what grid configurations are most effective (Tenenbaum et al.2014); but there is little on the political obstacles. The political economy of low carbon energy access is surprisingly underdeveloped. The literature contains useful observations that the agenda on low carbon energy access is donor driven and that pro-poor energy projects do not receive priority attention in government decisions (Newell et al. 2014) but we need to go to deeper than that. Why is that the advances made in supplying energy and increasing renewables do not extend to more pro-poor access? Perhaps a partial explanation can be derived from our previous sections which showed that advances that have been made were driven in particular by the energy security lobby. This is a lobby consisting of government and business actors. One would expect them to be concerned mainly with securing on-grid energy for the nation and for particular industries. Spill over in terms of access to on-grid energy for the poor can occur but is unlikely to be a central concern for the energy security lobby. Access to off-grid electricity is even less a concern for those whose priority is energy security. Who then is likely to prioritise off-grid energy in particular for those in more remote regions? The most likely candidates are donor agencies, NGOs, local government agencies and makers/installers of the equipment. Whether and how alliances between them make a difference is something that will have to be ascertained through our own primary empirical work. 


\section{What are the macroeconomic impacts of an increase in renewable energy investment/capacity, and the reforms needed to bring this increase about?}

Increased investment in renewable energy and the public policies required to achieve it may have unintended effects on the economy. We can increase our understanding of these economy-wide repercussions through the adoption of a multi-sectoral general equilibrium approach that captures the input-output linkages between the energy sector and the rest of the economy, as well as those between production activity, household income and expenditure and government policy.

Computable general equilibrium (CGE) models - aka applied general equilibrium (AGE) models - are widely used tools in energy and climate mitigation policy analysis.

Applications range from short-run impact assessments of shocks to the energy system for particular countries to global long-run energy system scenario studies with a time horizon of multiple decades. ${ }^{24}$

The main appeal of - and need for - a general equilibrium approach is that energy is an input to virtually every economic activity. Hence, changes in the energy sector 'will ripple through multiple markets, with far larger consequences than energy's small share of national income might suggest' (Sue Wing, 2009). The unique advantage of the CGE approach over partial equilibrium (PE) approaches is its ability to incorporate these 'ripple effects' in a systematic manner.

In contrast to PE approaches, CGE models consider all sectors in an economy simultaneously and take consistent account of economy-wide resource constraints, intersectoral intermediate input-output linkages and interactions between markets for goods and services on the one hand and primary factor markets including labour markets on the other. CGE models simulate the full circular flow of income in an economy from (i) income generation through productive activity, to (ii) the primary distribution of that income to workers, owners of productive capital, and recipients of the proceeds from land and other natural resource endowments, to (iii) the redistribution of that income through taxes and transfers, and to (iv) the use of that income for consumption and investment.

In line with the purposes of the present project, the following selective literature review focuses on CGE applications concerned with the evaluation of low-carbon energy transition scenarios and their economy-wide impacts. Section 7.1 reviews the standard 'top down' production function approach to the representation of energy use and power generation used in most energy-focused CGE studies. As simulation results based on this approach depend critically on a set of model parameters that govern the energy intensity of production and the substitutability among energy sources, section 7.2 reviews the existing empirical evidence on the size orders for these key parameters. This section also reflects on the proper interpretation of these empirical estimates in the presence of

\footnotetext{
${ }^{24}$ For a survey of energy-focused CGE studies up to the mid-1990s see Bhattacharyya (1996). For more recent overviews, see Sue Wing (2009) and Kemfert (2009)
} 
binding non-technical barriers to the adoption of renewable technologies. Section 7.3 looks at so-called hybrid 'top-down bottom-up' approaches to the representation of energy technologies in CGE models. These less common approaches aim to overcome the limitations of top-down models with a highly stylised specification of energy technology options through the incorporation of detailed bottom-up engineering information. Finally, section 7.4 provides a selective review of studies that explore low-carbon energy scenarios in a developing country context.

\subsection{Energy in Standard Top-Down CGE Models}

In standard multisectoral CGE models, technologies for the transformation of inputs into real outputs in a country or region are described by sectoral production functions. In energy-focused models of this type, technology specifications belonging to the generic class of KLEM (Capital (K), Labour, Energy, Materials) production functions are commonly employed to capture substitution possibilities among energy and-non-energy inputs and among different energy sources. In technical terms, the sectoral KLEM production functions typically take the form of nested multi-level functions with a (positive or zero) constant elasticity of substitution (CES) among inputs grouped together within the same nest. Figure 6.1 provides a schematic representation of the substitution hierarchy between different inputs in production in a typical top-down CGE model. ${ }^{25}$

The share parameters of the sectoral KLEM production functions are calibrated ${ }^{26}$ in line with the empirically observed sectoral input cost shares for a benchmark year, so that the model solution replicates the observed input demand patterns for that year in the absence of exogenous shocks. In contrast, the parameters governing the substitutability among inputs in response to changes in relative input prices are free parameters that are set by the modeller on the basis of secondary econometric evidence or more or less educated guesses.

\footnotetext{
${ }^{25}$ See e.g. Böhringer and Löschel (2004), Böhringer, Löschel and Rutherford (2009), Willenbockel and Hoa (2011). There are variations in the detailed specification of the KLEM nesting hierarchy across applied models in terms of complexity and the composition of the input aggregates. See van der Werf (2008) and Burniaux and Truong (2002) for a comparison of different upper-level nesting structures in models with a KLEM technology specification. For empirical tests of alternative nesting structures see section 3

${ }^{26}$ For a discussion of the general principles underlying the calibration of CGE models see Dawkins, Srinivasan and Whalley (2001).
} 


\section{Figure 6.1 Typical Nesting Structure of KLEM Production Functions}

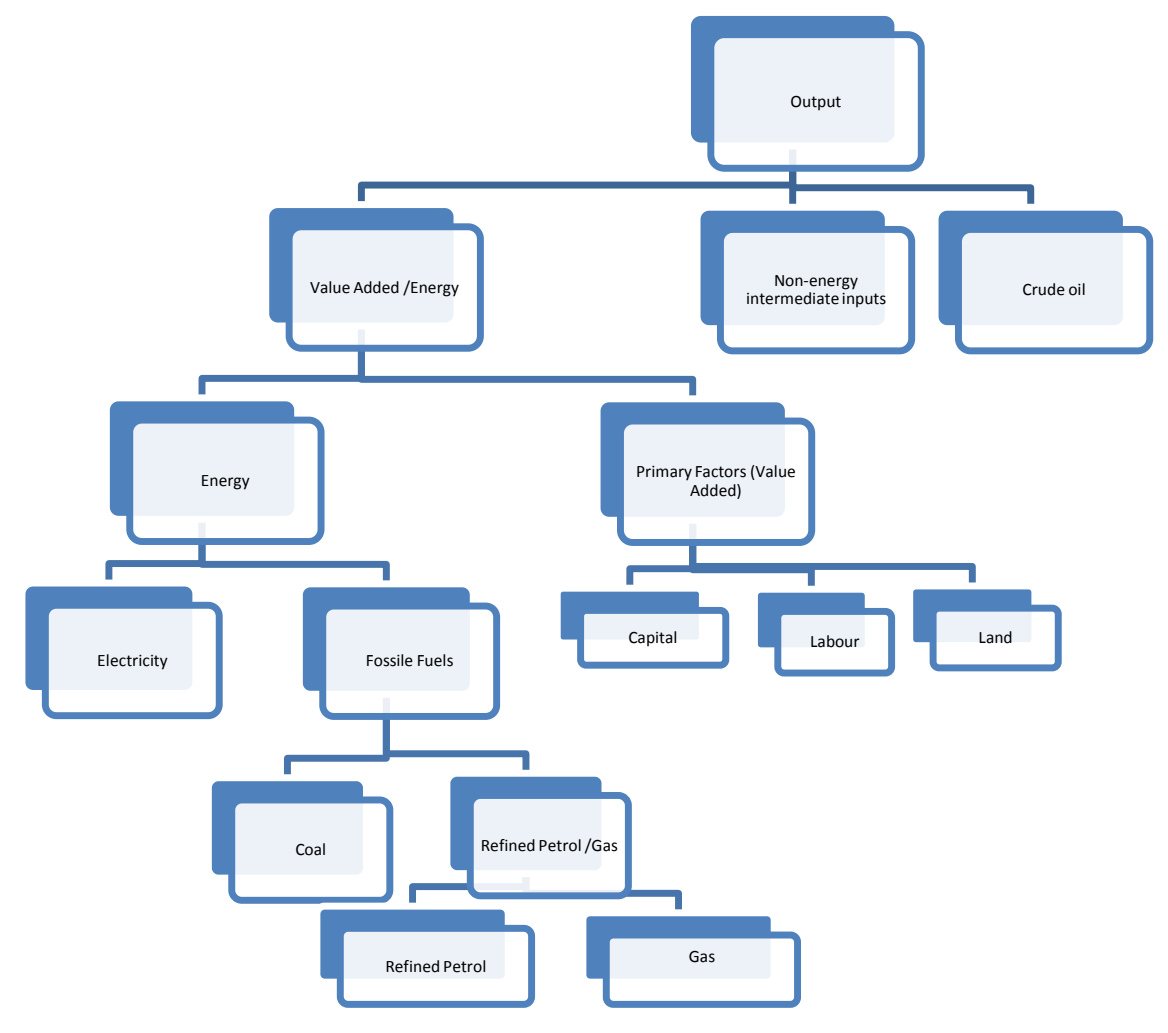

Source: Willenbockel and Hoa (2011) based on Böhringer and Löschel (2004)

In each sector, the production of a given output quantity requires non-energy inputs and a composite 'value-added/energy' composite in fixed proportions. In the case of sectors that use crude oil directly as an input (in particular the refined fuels industry and the chemical industry), crude oil inputs are also a fixed proportion of output. The value added/energy composite requires energy and primary factors in variable proportions. Required energy inputs in each sector are composed of electricity purchases from the electricity sector in the model and direct use of fossil fuels. At the bottom of the input substitution hierarchy, the sectoral production functions allow for imperfect substitutability between coal and a refined oil/gas composite, and between refined oil and natural gas.

Echoing the standard representation of the power sector in the input-output blocs of social accounting matrices (SAMs) that constitute the main empirical data source for the calibration of CGE models, electricity generation and distribution is typically treated as a single production activity in top-down models. Correspondingly, in these models a transition towards a higher share of hydro, solar or wind in the power mix is represented in a highly stylised abstract form as a substitution of fossil fuel inputs by physical capital under the assumption of a continuous space of available technologies.

The lack of explicit detail with regard to the characterisation of current and future technology options entails the danger that in the case of simulation scenarios involving large departures from the initial benchmark equilibrium may violate fundamental physical restrictions such as the conservation of matter and energy (Böhringer and Rutherford, 
2008) or exceed other technical feasibility limits (McFarland, Reilly and Herzog, 2004; Hourcade, Jaccard, Bataille and Ghersi 2006; Bibas and Mejean 2012). Moreover, the lack of technological explicitness limits the ability of top-down models to incorporate detailed information on cost differentials among alternative energy technologies from engineering cost studies and to simulate technology-specific policy measures in a fully persuasive manner (Hourcade et al. 2006).

In response to these limitations of conventional top-down CGE models, various approaches to the incorporation of detailed 'bottom up' information on energy technology options into a CGE modelling framework have emerged over the last decade. Such hybrid top-down bottom approaches are briefly reviewed in section 4 .

\subsection{Empirical Estimates of Energy Substitution Elasticities}

Simulation results based on the KLEM approach depend critically on the elasticities of substitution ${ }^{27}$ between energy and non-energy inputs and among different energy sources employed at the various levels of the nesting hierarchy in Figure 6.1.

Most econometric estimates focus on the elasticity of substitution between energy and capital. Koetse, de Groot and Florax (2008) provide a meta-analysis of pertinent empirical studies up to the mid-2000s. Van der Werf (2008) and Koesler and Schymura (2012) present more recent multi-country and multi-industry results. Stern (2009) conducts a meta-analysis of existing interfuel substitution elasticities. Van der Werf (2008) and Kemfert (1998) provide empirical tests of alternative KLEM production function nesting structures.

While many CGE studies base their selection of values for the production function elasticity parameters on the empirical evidence - see Beckman, Hertel and Tyner (2011) for a recent articulated example - a widespread practice is to set substitution elasticities for the bottom nests in Figure 6.1 to unity in the absence of conclusive empirical evidence. Dawkins, Srinivasan and Whalley (2001) have labelled this common practice 'The Idiot's Law of Elasticities'.

A key point to be borne in mind for the present study is that empirical estimates will reflect existence of binding non-technical constraints to the adoption of renewable energy technologies - and are thus not invariant to policies aimed at relaxing these constraints.

Or as Hourcade et al.(2006) put it, '(i)f the input substitution elasticities critical to technological response in TD models are estimated from historical data, there is no guarantee that the values for these parameters would remain valid in a future with ambitious policies for environmental improvement.'

\subsection{Hybrid Top-Down Bottom-Up CGE Models}

In response to the limitations of conventional top-down CGE models mentioned in section 6.1 , various approaches to the incorporation of detailed 'bottom up' information on energy technology options into a CGE modelling framework have emerged over the last decade. These efforts to develop hybrid top-down bottom-up models are still in a state of infancy and face a range of challenges related to theoretical consistency, computational

\footnotetext{
${ }^{27}$ See Blackorby and Russell (1989) and Thompson (2006) for clarifications of the relation between alternative substitution elasticity concepts in multi-input production functions.
} 
complexity and empirical validation (Hourcade et al. 2006). A major difficulty is the construction of databases which integrate macroeconomic data with engineering detail in a way that facilitates a straightforward transparent calibration of hybrid models. As Sue Wing (2008) has put it, '(t)he current state of the technical art in this regard is more a matter of judicious assumptions and careful, manual calibration than systematic, replicable procedures'. Despite further research efforts in this direction over the past few year, this assessment still applies today.

Examples for the development and application of such hybrid top-down bottom-up models include inter alia McFarland, Reilly and Herzog (2004), Laitner and Hanson (2006), Böhringer and Löschel (2006), Sue Wing (2008), Böhringer and Rutherford (2008, 2013), Sassi et al.(2010), Boeters and Koornneef (2011), Lanz and Rausch (2011), Bibas and Mejean (2012), Okagawa et al.(2012) and Fortes et al.(2013).

\subsection{CGE-Based low-carbon transition scenario studies for developing countries}

\subsubsection{Policies to support the transition to a low carbon growth path}

To achieve the transition to a low-carbon growth trajectory in market-based economies, relative prices between fossil fuels and low-carbon energy sources play a decisive role. It is critical that the fossil fuel prices faced by market participants reflect the long-run marginal social costs associated with GHG emissions in order to incentivise the required structural transformation of the energy system as well as to induce energy efficiency investments and shifts to less carbon-intense demand patterns (Willenbockel 2014).

Correspondingly, the primary focus of CGE-based low-carbon energy transformation scenario studies is on policy reforms that directly trigger changes in the relative prices of high- and low-carbon energy alternatives, namely the reform of existing fossil fuel tax/subsidy systems, the introduction of a carbon tax or the implementation of a cap-andtrade scheme.

\subsubsection{Economy-wide impacts}

Willenbockel and Hoa (2011) spell out the chains of causation through which the imposition of a carbon tax on fossil fuel use or the elimination of fossil fuel subsidies affect macro-economic outcomes. The immediate effect of such measures is a rise in the user prices for coal, refined fuels and electricity. On the production side, the price increases induce substitution effects between energy inputs and affect production costs and hence the supply prices of domestically produced commodities. On the household side these user price effects induce income and substitution effects in final consumption.

As the real purchasing power of household incomes declines due to the price increases, the pure income effect reduces demand for all consumer goods unless the carbon tax revenue is redistributed to the household sector in the form of income transfers or tax cuts, while the pure substitution effect entails a marginal shift in demand from the goods subject to a relative price increase to other goods. The changes in the commodity composition of demand are associated with corresponding shifts in the domestic sectoral structure of production. In particular, the growth of fossil-fuel extraction sectors, energyintensive sectors and sectors closely linked to these industries along the value chain slows down relative to the baseline growth path, while production in other sectors expands compared to the baseline. This climate-policy-induced structural change is associated with intersectoral factor movement and changes in relative facto prices, the 
directions of which depend primarily on factor intensity differentials between expanding and contracting sectors.

The dynamic impacts on macroeconomic performance depend essentially on the assumptions on how the additional fiscal space, arising from carbon tax revenue or from cuts in fossil fuel subsidies funds released by the cut in subsidy flows, is used. The dynamic simulation analysis by Willembockel and Hoa (2011) suggests that if the increase in government savings is effectively channeled into additional productive investment and measures to foster the accelerated adoption of energy-efficient technologies, GDP growth and hence long-run aggregate real consumption may actually rise relative to the baseline path. In contrast, if the additional fiscal space is used to compensate households for the initial real income losses due to the price increases for energy and energy-intensive goods (e.g. via income support transfers or a cut in household taxes), initial reductions in household consumption growth after the implementation of the reform are lower, but GDP growth and future consumption possibilities will also be lower than under the accelerated investment scenario.

The possibility of the emergence of a 'double dividend' in the form of additional economic growth on top of the environmental benefits associated with the transition to a less carbon-intensive growth path suggested by this analysis is also found in other pertinent CGE-based studies. For example, using a dynamic top-down CGE model for China, Chi, Guo, Zheng and Zhang (2014) consider the introduction of a carbon tax in combination with an investment-stimulating cut in enterprise income taxes and report an increase in GDP on the order of 3 per cent relative to the baseline path for a carbon tax scenario in which China's annual $\mathrm{CO}_{2}$ emissions drop by around 11 percent below baseline. ${ }^{28}$

\subsubsection{Distributional impacts}

While many CGE studies represent the household sector by single aggregate representative consumer per country, which precludes an analysis of inter-household distribution effects, a number of studies disaggregate households by income class or link the CGE model to a separate micro-simulation model to study distributional impacts. ${ }^{29}$

The ultimate distributional incidence of a carbon tax or a cut in fossil fuel subsidies depends primarily on the shares of energy and energy-intense goods in household expenditure by income group, on the aforementioned indirect factor price effects, and again - on the use of the additional fiscal space generated by these policy reforms. The study by Willenbockel and Hoa (2011) may again serve to illustrate the point: In the absence of compensatory transfer payments, the middle-income groups in both urban and rural areas suffer marginally more during the implementation phase of the policy reform than households at the bottom and at the top end of the income distribution, because the energy shares in household expenditure are highest for the middle-income groups.

Adverse impacts on poor households can be neutralised (or turned into pro-poor impacts) by using part of the government savings arising from the subsidy cut for compensating cash transfers. However, as indicated earlier, there is an intertemporal trade-off. Using the additional fiscal space instead to foster additional productive and more energy-

\footnotetext{
${ }^{28}$ Another recent carbon tax simulation study for China that considers alternative tax revenue recycling scenarios is $\mathrm{Lu}$, Tong and Liu (2010).

${ }^{2929}$ See Boccanfuso, Estache and Savard (2011) and Ellis (2010) for recent surveys.
} 
efficient investments may actually raise income and consumption for all households in the medium run.

A further general point on the distributional impact of fossil fuel subsidy cuts is worth emphasising. Such subsidies in developing countries are commonly justified as a means to make modern energy services affordable to the poor, and their removal is widely seen to hurt poor households disproportionally. Fact is, however, that fuel subsidisation is a grossly inept instrument to target the poor. Using data for a sample of 20 developing countries, Arze del Granado, Coady and Gillingham (2012) show that on average across sample countries, households in the top income quintile receive 42.8 per cent of the benefits from fuel subsidies while the bottom quintile receives only 7.2 per cent. This implies that the average burden to government budgets of transferring one dollar to the poor quintile is a mindboggling $\$ 13.89$, as nearly 93 per cent of the subsidy leak to the higher quintiles. ${ }^{30}$

Willenbockel (2015) provides a critical review of the wider literature on the potential synergies between the promotion of access to low-carbon energy technologies and propoor growth.

\subsection{Studies for Sub-Saharan Africa}

The very few existing pertinent CGE studies for Sub-Saharan Africa to date focus almost exclusively on South Africa. ${ }^{31}$ Following earlier efforts by Pauw (2007), Kearney (2008) and Devarajan, Go, Robinson and Thierfelder $(2009,2011)$ use a comparative-static topdown model to explore the impacts of various forms of carbon taxation on the South African economy. Their results suggest that a carbon tax which cuts $\mathrm{CO}_{2}$ emissions by 15 percent is associated with a moderate GDP loss on the order of 0.2 percent and an aggregate welfare loss of 0.3 percent. If the carbon tax revenue is used to finance reductions in existing tax distortions, the aggregate welfare loss drops significantly. The study also analyses the potential interaction of a carbon tax with existing labour market rigidities and concludes that 'if South Africa were able to remove some of the distortions in the labour market, the cost of carbon taxation would be negligible'.

Alton, Davies, Hartley, Makrelov, Thurlow, and Ubogu.(2012) employ a dynamic CGE model with a detailed treatment of the energy sector and an explicit incorporation of renewable energy technologies (hydro, solar, wind) to simulate the economic impacts of a carbon tax that reduces annual emissions by 40 percent towards 2030 relative to baseline emissions. Real GDP is projected to drop by 1.2 per cent below the baseline path if the carbon tax revenue is used to finance a reduction in indirect sales taxes and by 0.7 per cent if carbon tax revenue is recycled through a reduction in corporate taxes, as the former primarily stimulates consumption while the latter primarily induces additional capital accumulation.

\footnotetext{
${ }^{30}$ The average figures mask even more extreme cases of bad policy targeting (taking the pro-poor motive for such subsidies at face value) that become apparent by looking at the disaggregated results for country groups and fuel types in Arze del Granado, Coady and Gillingham (2012: Table 12). E.g. in Africa, only 2.2 per cent of gasoline subsidies reach the bottom quintile, implying a budgetary burden of over $\$ 45$ to transfer a single dollar to the poorest quintile through this instrument (Willenbockel 2014).

${ }^{31}$ An exception is a study by Nwaobi (2004) for Nigeria. A number of CGE studies for Sub-Saharan Africa (e.g. Willenbockel (2013) for Kenya and Uganda) analyse a prospective expansion of biofuels feedstock production. These studies focus on land use and food price implications and are not coverd by this review. Robinson, Willenbockel and Strzepek (2012) and World Bank (2010) analyse the impacts of climate change on hydropower generation potentials in Ethiopia and Ghana respectively within a dynamic CGE modelling framework.
} 
None of the CGE simulation studies under review consider the impacts of a removal of non-price barriers to the adoption of economically viable low-carbon technology options that are the focus of the present study.

\section{Under what circumstances does increased on-grid renewable energy capacity translate into increased access and reliability of electricity supply?}

On a simplistic level, installation of additional on-grid renewable energy capacity increases the energy available to consumers. For non-variable and deterministic generation such as geothermal, the benefits can be assessed in a similar manner to conventional power generation (coal, gas, diesel and nuclear); hydro may be assessed in a similar way, apart from the fact that it may be necessary to account for seasonal constraints on energy production arising from finite water supply.

However, assessing the benefit of variable renewables such as wind and solar in increased access to power and improved reliability is more complex, due to the dependence of available capacity on the statistics of resource availability at different sites at any point in time, as opposed to available capacity of conventional plant being primarily driven by mechanical availability. Combined with lack of cheap energy storage, this means that if there is a possibility of very low renewable resource at times of high demand the capacity contribution of wind or solar may be very limited even if its energy output over an extended period exhibits limited variability.

In a developed world context, risk based generation adequacy studies have been common practice for many years. However, limited technical data on power system performance can make running such a study challenging. Further, it is important to understand the specific metrics which will be relevant to determine the extent to which additional renewable energy will increase access and reliability. i.e. who benefits from increased access? Is reliability defined as the number of power outages per person, or is it regionalised? Is the quality of electrical power important? Should urban access be improved or rural access? What are the in-country drivers?

\subsection{Power system reliability analysis}

Power system reliability analysis generally aims to make assessments of the proportion of time for which all electrical demand cannot be supplied by the power system, or of the amount of energy which is demanded by users and not supplied. The outturn of these quantities is of course uncertain, as generation availability is uncertain ahead of time (due to random variability in generator mechanical availability and renewable resource), as are demand (which is constantly fluctuating) and availability of the network (e.g. if a power line fails). All of these uncertainties must be modelled in the language of probability and, given appropriate probabilistic representation of demand plus mechanical and resource availability, plus a system model which can work out consequences in terms of unsupplied demand of a given demand/supply scenario, it is possible to evaluate how 
likely different severities of shortfall events are. Usually results are expressed through summary statistics such as a probability-weighted average of the different possible supply shortfall outcomes, or as statements of how often events of a given severity occur in the long run.

Data required for reliability analysis include demand and variable generation profiles (usually historic time series), conventional generating unit and network availability statistics, the necessary technical specifications of all components, plus the layout of the network including where supply and demand are connected.

A good summary of basic issues and techniques may be found in Billinton and Allan's classic textbook (1996).

\subsection{Previous research and consultancy work developing metrics of improved access as a result of improved renewable generation capacity}

There has been very little work in the power system reliability community specialised to developing country issues. Such technical analysis is mostly based on the paradigm that everyone gets all the supply they want almost all the time, which holds in systems such as Great Britain and the US. Presently, it may be in African systems that demand is explicitly restricted by available supply much more frequently. Hence while much of the usual model structures may carry across to an Africa context, rather different risk index outputs may be required. These might look at how many customers can be moved to higher quality of supply or given access at all, rather than looking at how much these resources improve further the already high quality supply which everyone enjoys in (for instance) Great Britain - i.e. specification of these indices should reflect the interests of the host countries rather than assumptions based on developed country contexts. Determination and application of these will be one of the main subjects of the engineering part of the Green Growth Diagnostics for Africa project.

This limited existing literature is summarised in a previous review by one of the present authors (see Chapter 5.1 of Pueyo et al. [2013]) In international journals, the only two lines of work found were the PhD of M. Pandey (supervised by Roy Billinton at Saskatchewan in Canada) which looked at the Nepalese national system, and ongoing work at the University of Cape Town in South Africa led by Profs Trevor Gaunt and Ron Herman.

The remainder of this section summarises reports arising from work in the international development community. This contains much important material about the issues which matter in countries such as Kenya or Ghana, but does not elaborate on technical risk modelling approaches to quantifying access to supply.

The Energy Sector Management Assistance Programme at the World Bank has produced 'A New Multi-Tier Approach to Measuring Energy Access' (ESMAP 2014). The key feature of this is that it correctly recognises that energy access is not a binary parameter, i.e. it is not the case that someone either has access or they do not. The multi-tier matrix divides customers into 6 tiers (0-5) according to the following features of their supply: Capacity, Duration, Reliability, Quality, Affordability, Legality and Health \& Safety. Much 
more information on the World Bank's activities in energy access is available on ESMAPS's energy access programme website ${ }^{32}$.

The World Bank's Africa Infrastructure Country Diagnostic project (Eberhard et al. 2011) provides a comprehensive overview of issues in increasing energy access in sub-Saharan Africa. One particular perspective to note is Rosnes and Vennemo (2008) which presents results from a least cost optimisation model for supply with respect to a country's given demand. The model structure is given, and code is available online, but this does not go into detail of probabilistic assessment of supply reliability.

A US National Renewable Energy Laboratory report (Cox,Katz and Würtenberger 2014) investigates carbon abatement resulting from different technologies with Kenya as a case study. This report however concentrates on carbon emissions for a given energy supply rather than enabling access to energy.

\subsection{General characteristics of Sub-Saharan African power systems}

The African Infrastructure Country Diagnostic (2010) provides a good overview of Sub Saharan African power systems (not including South Africa):

- The entire generation capacity of Sub-Saharan Africa is less than that of Spain. Having such a low generation capacity means there is a need for additional generation if something approaching universal access to on-grid energy is to be achieved, and a small investment in renewables can make a proportionally larger contribution to the power system. However, with a small installed capacity there are likely to be fewer generation plants with which to balance intermittent generation.

- Average annual demand per capita is $124 \mathrm{kWh}$. Less than a quarter of the population has access to any electricity, and only 10 per cent of the bottom half of the income distribution have access.

- On average, power outages occur 56 days per year in manufacturing enterprises, compared to the standard planning target of an average of one day every ten years in the USA.

Table 7.1 provides a comparison between the UK, Kenyan and Ghanaian power systems. The general characteristics previously described are evident here. Both systems have significantly smaller installed capacities and demands than the UK, both in absolute terms and when the size of the grid relative to the population is considered. However, both have disproportionately large hydro generation which dominates the installed generating capacities (46.7 per cent and 52.5 per cent respectively in Kenya and Ghana), and provide the bulk of energy supply (53.3 per cent and 64.4 per cent). Losses in both systems are higher than in the UK, and further study would be interesting to understand the proportion of these which are technical (e.g. losses in transmission) or non-technical (energy used but not paid for). Both Kenya and Ghana have high electrification targets of 100 per cent of the population connected by 2030, but of interest also is the quality of service and anticipated annual demand of various parts of the population. The latter is important in technical analysis for this project.

\footnotetext{
${ }^{32} /$ www.esmap.org/Energy_Access
} 
Table 7.1 Comparison of the UK, Kenyan and Ghanaian power systems, 2013

\begin{tabular}{|l|l|r|r|r|}
\hline Parameter & Units & UK & \multicolumn{1}{l|}{ Kenana } \\
\hline Population & M & 64.1 & 45.0 & 26.5 \\
\hline Installed generating capacity & GW & 82.25 & 1.64 & 2.63 \\
\hline Electricity consumption & TWh & 317 & 6.58 & 10.6 \\
\hline & MWh/capita & 4.95 & 0.15 & 0.40 \\
\hline Electricity from fossils & \% of installed capacity & $75.1 \%$ & $43.6 \%$ & $47.4 \%$ \\
\hline & TWh generated & 229 & 2.11 & 4.64 \\
\hline Electricity from hydro & \% of installed capacity & $1.9 \%$ & $46.7 \%$ & $52.5 \%$ \\
\hline (not including pumped storage) & TWh generated & 4.70 & 4.30 & 8.23 \\
\hline Electricity from other & \% of installed capacity & $23.0 \%$ & $9.6 \%$ & $0.1 \%$ \\
\hline & TWh generated & 123 & 1.61 & 0.003 \\
\hline Imports/Exports & TWh import (+ve) / export (-ve) & 17.5 & 0.04 & -0.10 \\
\hline Losses (tech and non-tech) & \% of energy produced & $15.1 \%$ & $18.6 \%$ & $17.8 \%$ \\
\hline Load factor & \% & $44.0 \%$ & $45.8 \%$ & $45.9 \%$ \\
\hline Electrification target (2020/2030) & \% & $\mathrm{n} / \mathrm{a}$ & $65 \% / 100 \%$ & $100 \% / 100 \%$ \\
\hline
\end{tabular}

Sources:

- Statistics for Ghana taken from http://energycom.gov.gh/files/ENERGY\%20STATISTICS.pdf, valid end of December 2013. Dependable generation shown and losses are calculated as the difference between generated energy and consumed energy

- Statistics for Kenya taken from www.kplc.co.ke/content/item/40/Annual-Reports valid end of June, 2013. Effective generation capacity shown. Operation statistics included for KenGen, independent power producers and emergency power producers but not for off-grid energy sources. Kenya's population is sourced from the CIA World Factbook valid July 2014

- UK data from www.gov.uk/government/uploads/system/uploads/attachment_data/file/337649/chapter_5.pdf valid end of December 2013. Northern Irish statistics are not included as these operate on a different electricity grid

\subsection{Information required for power systems reliability assessment}

As discussed above, it is as yet unclear precisely what reliability or access metrics will be appropriate in the Kenyan and Ghanaian context. However whatever metrics are used, similar data will be needed on supply, demand, balancing demand and supply, the transmission infrastructure and some additional risk factors.

Supply data required includes a list of generating stations, including planned additions and anticipated requirements. Availability statistics are also required for each generator. For conventional units depending on the calculation to be performed this might be the probability of units being available at any point in time, or mean times to failure and repair. If there are significant risks of fuel supply interruptions, this may have to be taken into account also. For hydro stations there may be additional seasonal restrictions on the total energy generated, arising from a finite water supply. Thus appropriate historic data to assess the variability between years of water may also be needed. For renewables such as wind and solar, historic resource data (either metered output from existing installations, or meteorological data converted to generator output) will be needed to estimate future availability patterns. It is not yet clear what other data will be available in Kenya and Ghana, particularly with respect to renewable projects which are planned but have not yet been built. It will also be necessary to determine whether the same generic availability 
statistics apply to all generating units of a given class. This will usually not be the case with renewables (wind or solar resource is strongly location dependent), but for conventional generation this should be considered on a case by case basis (it may be the case that all units of a given technology may be considered equivalent, or there might be particular knowledge suggesting that bespoke data should be used for each unit.).

Demand data includes as a starting point a historic time series of demand, showing a representative range of current demand patterns. In the Kenyan and Ghanaian context, however, metered historic demand might not be representative of future needs even under an assumption of unchanging basic demand patterns, if the demand met is regularly constrained by available generation. It may therefore be necessary to assess patterns of total demand by means other than estimation based on historic data. Where demand curtailment is a regular feature of a system, information on the relative priorities given to meeting different tranches of demand will also be important, including whether there is a component of demand which must be met.

Where there is particular interest in integrating variable output renewables such as wind and solar generation, it may also be necessary to assess whether the other plants on the system have the flexibility to meet the up- and down-ramps of net demand (i.e. demand minus renewables). This might include assessment of whether additional investment in flexible conventional technologies or hydro would allow greater take-up of renewables.

In order to determine whether finite network capacity restricts the ability of renewables to deliver increased energy access, information on the capacities and other properties of the transmission lines is required. The most detailed results would be obtained from a modelling exercise considering every single transmission network element explicitly, however it may be possible to obtain meaningful results using a reduced model which divides the network into zones, with the only transfer constraints considered being between zones. It is also important to understand whether any network operational security measures (e.g. reducing transfer capacities between regions to improve resilience against sudden fault events) is significant in these assessments.

Any additional country-specific risk factors (e.g. theft, supply chains for fuel, areas of political instability etc.) need to be identified and, to the extent that they meaningfully can be, quantified.

These data requirements are summarised in Table 7.2.

Table 7.2 Data requirements for power systems analysis

\begin{tabular}{|c|c|}
\hline Element of the system & Data \\
\hline Supply & $\begin{array}{l}\text { - List of generating stations including planned additions and anticipated } \\
\text { retirements } \\
\text { - Availability statistics for each generator }\end{array}$ \\
\hline Demand & $\begin{array}{ll}\text { - } & \text { Historic time series of demand } \\
\text { - } & \text { Estimates of supressed demand due to generation constraints } \\
\text { - } & \text { Relative priorities given to meeting difference tranches of demand }\end{array}$ \\
\hline Balancing supply and demand & 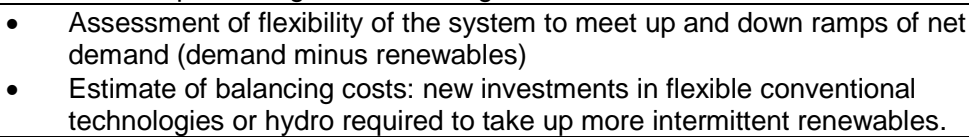 \\
\hline Transmission infrastructure & $\begin{array}{l}\text { - } \quad \text { Capacity and properties of transmission lines } \\
\text { - } \quad \text { Network operational security measures (e.g. reducing transfer capacities } \\
\text { between regions to improve resilience against sudden fault events) }\end{array}$ \\
\hline Additional risk factors & For example: theft, supply chains for fuel, areas of political instability etc \\
\hline
\end{tabular}




\section{Conclusions}

This literature review shows the state of the art on our research questions. This is the starting point of our research on Green Growth Diagnostics for Africa, which will target the gaps identified in the existing literature and apply our analysis to two specific countries: Kenya and Ghana.

The first step of the analysis concerns the identification of promising renewable energy technologies, which are economically and financially feasible, but underinvested. Existing literature uses predominantly the LCOE to compare renewable generation options with fossil fuel alternatives. LCOE are useful for comparison of different generation sources but have a number of shortcomings. Because LCOE depend on a number of highly specific assumptions, they need to be estimated case by case to provide a real assessment of competitiveness. Also, they should be complemented with a measurement of financial viability that takes into account the actual cost of finance, an integral part of renewable energy project costs. Additionally, assessing the economic and financial viability of renewable generation technologies requires some judgement on what amount of policy and financial support is acceptable to maximise the economic returns to society. Inclusiveness of specific generation technologies requires an understanding of who will benefit from improved access to electricity as a result of further investment. All this points at the need for a clear methodology for policymakers to be able to target the most promising renewable energy technologies as regards economic and financial viability and inclusiveness in a particular location.

Once the target renewable generation technologies are identified, we aim at unravelling what is holding back investment in these. Considerable research has looked at the obstacles to renewable energy investment in general, and in developing countries in particular. A wide range of obstacles - technical, economic, financial, institutional, political - are often cited, with suites of reforms recommended on all fronts. We identified two publications ranking constraints by looking at how different barriers and their associated risks have a differential impact on financing costs for specific countries and technologies. Their ranking was based on direct questioning to investors, not following a systematic and replicable approach that combines readily available data with stakeholders insights. This state of the art resembles historical research on boosting growth in developing countries. Again, a wide range of factors were cited, and far-reaching reforms proposed. This drove Hausmann et al. (2004) to develop the Growth Diagnostics approach arguing that there may be many reasons why an economy does not grow as fast as it could. Each reason will generate a distinctive set of 'symptoms' that can become the basis for a different diagnostic of the problem. The Growth Diagnostic framework uses a decision-tree framework to cut through this complexity, identify the binding constraints on growth, and then focus policy interventions in these areas. The growth diagnostics approach developed by Haussmann et al. (2004) has proven to be effective. We believe a similar approach could be developed as 'Green Growth Diagnostics'. Developing a decision tree and applying it to investment in the renewable energy sector, rather than the national growth rate, is part of the next stage of this project.

Our green growth diagnostics approach will not stop with the identification of the binding constraint and related policy mix. To have their predicted effect, policies need to be 
implemented and evidence shows that whether or not policies that make economic and environmental sense are finally implemented is often a case of political feasibility. Our review of political economy analyses of who drives renewable energy policies and who holds them back suggests that actors who believe in green causes cannot bring about the required advances on their own (Newell and Paterson 2011). Those with motives other than climate change need to be brought into the picture. Their main motives can include energy security, industrial development, new employment opportunities or the provision of energy access for the poor. Alliances of actors with different motivations are required to bring about policies that drive the green transformation. Insights from literature on South Africa show that the incumbent regime reliant on capital accumulation through large scale mineral extraction, cheap fossil fuel based energy provision and associated downstream sectors blocked a widespread transition to renewable energy. However, as a result of a crisis in the supply of electricity all potential energy sources were put on the policy table, creating a platform in favour of policies that benefit investment in renewable energy. Political economy analysis specific to our target countries: Kenya and Ghana will be required to ascertain the chances of the most relevant renewable energy policies being implemented instead of alternative fossil fuel based generation such as cheap coal from South Africa or gas in Ghana.

The next step in our analysis concerns the economy-wide repercussions of increased investments in renewable energy and the public policies required to achieve it. These economy-wide repercussions can be understood through the adoption of multi-sectoral general equilibrium models. Existing studies show that policies that change the relative prices of fossil fuels and low-carbon energy sources can lead to the emergence of a double dividend in the form of additional economic growth on top of the environmental benefits associated to renewable energy sources. Besides, if complemented with compensatory transfer payments for the poor, policies that increase the price of fossil fuels can have a pro-poor effect. None of the studies reviewed consider the impact of a removal of non-price barriers to the adoption of economically viable low-carbon technology options that are the focus of the present study and all CGE studies for SubSaharan Africa to date focus almost exclusively on South Africa. These gaps in the literature justify the need for a new CGE analysis for our target countries Kenya and Ghana.

Finally, an assessment of the inclusiveness of targeted renewable energy technologies requires an understanding of the link between both on and off-grid renewable energy capacity and access to electricity in developing countries. The link is straightforward for off-grid generation, but it is complex for variable renewables such as wind and solar integrated to the national grid. Power system reliability analysis is the tool traditionally used to make assessments of the proportion of time for which all electrical demand cannot be supplied by the power system, or of the amount of energy which is demanded by users and not supplied. However, power system reliability analysis is mostly based on the paradigm that everyone gets all the supply they want almost all the time, which does not hold in most Sub-Saharan African systems severely limited by available supply. The application of power systems reliability analysis to the African context requires the redefinition of metrics to assess if additional renewable energy will increase access and reliability. Rather than look at how much renewable energy resources may improve further already high quality supply (as in developed countries), model structures need to be defined with different risk index outputs such as the amount and quality of new additional access provided. Determination and application of these metrics will be one of the main subjects of the engineering part of the Green Growth Diagnostics for Africa project. 


\section{Appendix- Barriers to increased investment in renewable energies and related policies}

\begin{tabular}{|c|c|c|}
\hline & Barriers & Policies \\
\hline \multirow{9}{*}{$\begin{array}{l}\text { Economic and } \\
\text { financial }\end{array}$} & Higher cost than fossil fuels & $\begin{array}{l}\text { Increase the relative price of fossil fuels: } \\
\text { - } \quad \text { Carbon tax } \\
\text { - } \quad \text { Emissions trading }\end{array}$ \\
\hline & High upfront investment required & - $\quad$ Subsidies to upfront fixed capital expenditure \\
\hline & $\begin{array}{l}\text { Returns not large enough relative to } \\
\text { risk }\end{array}$ & $\begin{array}{l}\text { - } \quad \text { Guarantees from developed countries } \\
\text { - } \quad \text { Foreign exchange liquidity facilities }\end{array}$ \\
\hline & Low returns relative to alternatives & $\begin{array}{l}\text { - } \quad \text { Phase out fossil fuel subsidies } \\
\text { - } \quad \text { Premium tariffs for electricity generated from renewable } \\
\text { sources }\end{array}$ \\
\hline & Low prices of electricity & $\begin{array}{l}\text { - } \quad \text { Phase out fossil fuel subsidies } \\
\text { - } \quad \text { Reform of pricing procedures to allow for cost recovery }\end{array}$ \\
\hline & $\begin{array}{l}\text { High cost of finance in developing } \\
\text { countries due to country risk }\end{array}$ & - $\quad$ Concessional or lower cost finance \\
\hline & Non-payment risk & $\begin{array}{l}\text { - Counterparty guarantees by development banks for equity } \\
\text { holders }\end{array}$ \\
\hline & $\begin{array}{l}\text { Capital scarcity for green } \\
\text { infrastructure }\end{array}$ & $\begin{array}{ll} & \text { Public seed equity capital } \\
\text { - } & \text { Non-concessional public loans } \\
\text { - } & \text { Partial loan guarantees }\end{array}$ \\
\hline & Lack of scale & - $\quad$ Pledge funds \\
\hline \multirow{4}{*}{$\begin{array}{l}\text { Regulatory and } \\
\text { political }\end{array}$} & $\begin{array}{l}\text { Longevity and certainty of policy } \\
\text { support }\end{array}$ & $\begin{array}{ll}\text { - } & \text { Policy insurance } \\
\text { - } & \text { Put options by official agencies } \\
\text { - } & \text { Co-investment with a multilateral or bilateral agency } \\
\text { - } & \text { Support for renewable energy policy design }\end{array}$ \\
\hline & $\begin{array}{l}\text { Transaction costs of obtaining } \\
\text { permits and licenses }\end{array}$ & $\begin{array}{ll}\text { - } & \text { Establish a one-stop show for renewable energy permits } \\
\text { - } & \text { Streamline processes for permits }\end{array}$ \\
\hline & Uncertain market access and prices & $\begin{array}{ll}\text { - } & \text { Feed-in-tariffs } \\
\text { - } & \text { PPA-based auctions or tendering processes }\end{array}$ \\
\hline & Political risk & - $\quad$ Political insurance \\
\hline \multirow{4}{*}{ Technical } & $\begin{array}{l}\text { Technology risk for technologies } \\
\text { that are immature or not yet proven } \\
\text { in the country }\end{array}$ & $\begin{array}{l}\text { - } \quad \text { Development of local technology standards } \\
\text { - Con-investment through public-private funds for promising } \\
\text { new technologies }\end{array}$ \\
\hline & $\begin{array}{l}\text { Uncertainty about size and cost of } \\
\text { renewable resource }\end{array}$ & $\begin{array}{l}\text { - Public finance for the preparation of renewable resource } \\
\text { assessments } \\
\text { - Capacity building for the local preparation of resource } \\
\text { assessments }\end{array}$ \\
\hline & $\begin{array}{l}\text { Inadequate transmission } \\
\text { infrastructure }\end{array}$ & $\begin{array}{l}\text { - } \quad \text { Financial support for national grid infrastructure } \\
\text { development }\end{array}$ \\
\hline & Lack of standards for the integration & - $\quad$ Formulation of a grid code for new renewable energy \\
\hline
\end{tabular}




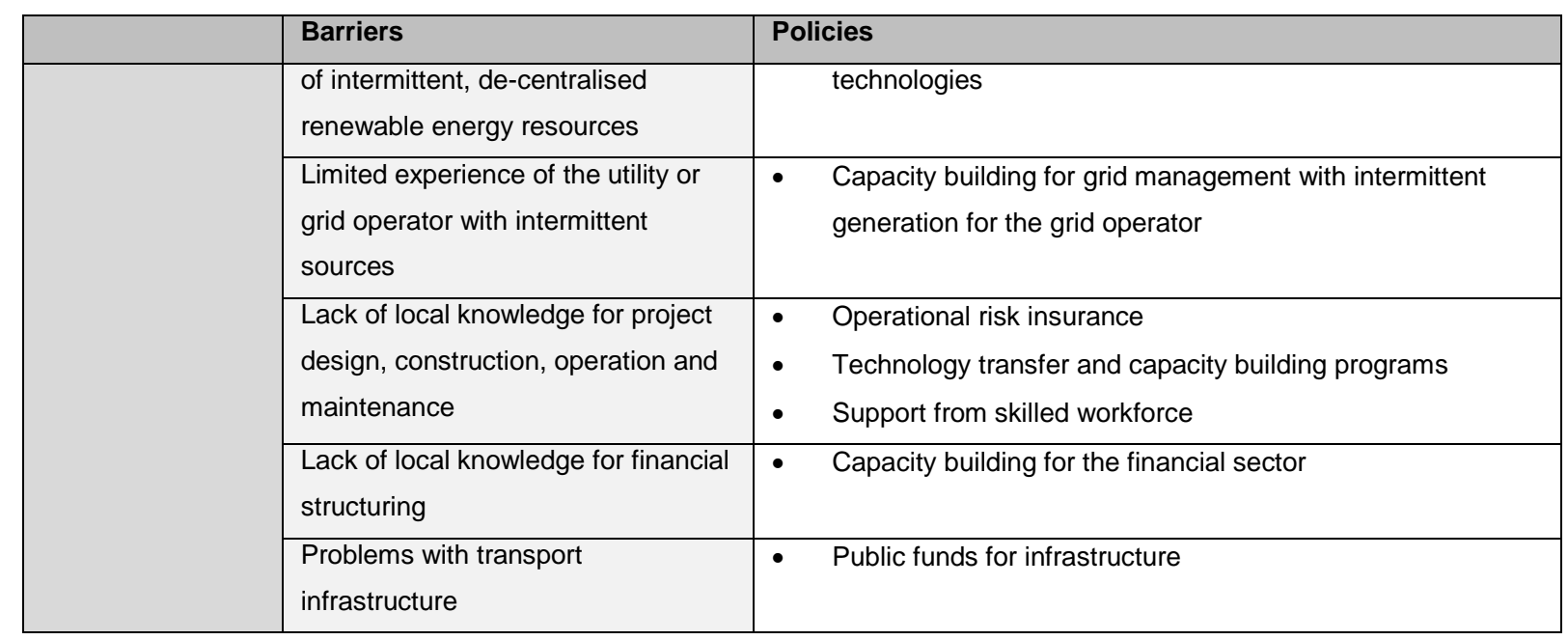




\section{References}

Abdel-Latif, A. and Schmitz, H. (2010) 'Growth Alliances: Insights from Egypt', Business and Politics 12.4: 1-27

Africa Infrastructure Country Diagnostic (2010) Overview: Africa's Infrastructure: A Time for Transformation. World Bank, www.infrastructureafrica.org/ (last accessed March 2015)

Agence Française de Développement (2010) Partnering with Banks to Finance 'Green' Growth, Paris: Agence Française de Développement

Ali, I. and H. H. Son (2007) 'Measuring Inclusive Growth', Asian Development Review 24.1: 11

Alton T, Arndt, C.; Davies, R.; Hartley, F.; Makrelov, K.; Thurlow, J. and Ubogu, D. (2012) The Economic Implications of Introducing Carbon Taxes in South Africa, UNUWIDER Working Paper No. 2012/46, Helsinki: UNU-WIDER

Arze del Granado, J.; Coady, D. and Gillingham, R. (2012) 'The Unequal Benefits of Fuel Subsidies: A Review of Evidence for Developing Countries', World Development 40.11: $2234-48$

Awerbuch, S. and Yang, S. (2007) 'Efficient Electricity Generating Portfolios for Europe: Maximising Energy Security and Climate Change Mitigation', EIB Papers 7/2007, Luxembourg: European Investment Bank, Economics Department

Baker, L. (2012) The Political Economy of Socio-technical Transitions in South Africa, PhD Thesis, School of Development Studies, University of East Anglia, chapter 5

Baker, L.; Newell, P. and Phillips, J. (2014) The Political Economy of Energy Transitions: The Case of South Africa, New Political Economy, 19.6:791-818 DOI: 10.1080/13563467.2013.849674

Barnett, A. (2014) Political Considerations Relevant to Energy and Economic Growth, Brighton: The Policy Practice, DOI: http://dx.doi.org/10.12774/eod_hd.november2014.barnetta

Barnett, A.; Lucas, H. and Standing, H. (2002) Energy, Poverty and Gender: a Review of the Evidence and Case Studies in Rural China, A Report for the World Bank, Brighton: The Institute of Development Studies

Bawakyillenuo, S. (2012) 'Deconstructing the Dichotomies of Solar Photovoltaic (PV) Dissemination Trajectories in Ghana, Kenya and Zimbabwe from the 1960s to 2007', Energy Policy 49: 410-21

Bawakyillenuo, S. (2009) Policy and Institutional Failures: The bane of photovoltaic solar household system (PV/SHS) dissemination in Ghana. Energy and Environment Journal, Vol. 20, No. 6, pp. 927-947 
Beckman, J.; Hertel, T. and W. Tyner (2011) Validating Energy-Oriented CGE Models. Energy Economics 33, 799-806

Bhattacharya, A.; M. Romani, and Stern, N. (2012) 'Infrastructure for Development: Meeting the Challenge', London: Centre for Climate Change Economics and Policy, www.cccep.ac.uk/Publications/Policy/docs/PP-infrastructure-fordevelopment-meeting-the-challenge.pdf

Bhattacharyya, S. C. (1996) 'Applied General Equilibrium Models for Energy Studies: A Survey', Energy Economics 18.3: 145-64

Bibas, R. and Mejean, A. (2012) 'Negative Emissions and Ambitious Climate Policies in a Second Best World: A General Equilibrium Assessment of Technology Options in the Electricity Sector', International Conference on Economic Modeling- EcoMod, Seville: 2012

Billinton, R. and Allan, R. N. (1996) Reliability Evaluation of Power Systems, (2, Ed.). London: Springer

Blackorby, C. and Russell, R. R. (1989) 'Will the Real Elasticity of Substitution Please Stand Up? (A Comparison of the Allen / Uzawa and Morishima Elasticities)', American Economic Review 79.2: 882-8

Bloomberg New Energy Finance (2013) 'Global Trends in New Energy Investment 2013', Frankfurt: Frankfurt School of Finance and Management

Bloomberg New Energy Finance (2011) 'Towards a Green Climate Framework', Bloomberg New Energy Finance

Bloomberg New Energy Finance (2010) 'Crossing the Valley of Death: Solutions to the Next Generation Clean Energy Project Financing Gap', Retrieved April 10: 2011

Boccanfuso, D.; Estache, A. and Savard, L. (2011) 'The Intra-Country Distributional Impact of Policies to Fight Climate Change: A Survey', Journal of Development Studies 47.1: 97-117

Boeters, S. and Koornneef, J. (2011) 'Supply of Renewable Energy Sources and the Cost of EU Climate Policy', Energy Economics 33: 1024-34

Böhringer, C. and Löschel, A. (2006) ‘Promoting Renewable Energy in Europe', The Energy Journal 27.SI2L: 136-50

Böhringer, C. and Löschel, A. (2004) 'A Computable General Equilibrium Model for Climate and Trade Policy Analysis', in C. Böhringer and A. Löschel (eds) Climate Change Policy and Global Trade, Heidelberg and New York: Physica-Verlag (Springer), 111-144

Böhringer, C.; Löschel, A.and Rutherford, T.F. (2009) 'Policy Analysis Based on Computable General Equilibrium (PACE)', in V. Bosetti, R.Gerlagh and S.P. Schleicher (eds) Modelling Sustainable Development: Transitions to a Sustainable Future, Cheltenham: Edward Elgar, 202-220 
Böhringer, C. and Rutherford, T.F. (2013) 'Transition towards a Low Carbon Economy: A Computable General Equilibrium Analysis for Poland', Energy Policy 55: 16-26

Böhringer, C. and Rutherford, T.F. (2008) 'Combining Bottom-Up and Top-Down', Energy Economics 30: 574-96

Brown, J. (2011) 'Leveraging Private Investment: The Role of Public Sector Climate Finance', ODI Background Note, London: Overseas Development Institute

Bulkeley, H. and Newell, P. (2010) Governing Climate Change, London and New York: Routledge

Burniaux, J.-M. and Truong, T.P. (2002) 'GTAP-E: An Energy Environmental Version of the GTAP Model', GTAP Technical Paper No.16, West LaFayette: Centre for Global Trade Analysis

Byrne, R.; Ockwell, D.; Uruma, K.; Ozor, N.; Kirumba, E.; Ely, A.; Becker, S. and Gollwitzer, L. (2014) Sustainable Energy for Whom? Governing Pro-poor Lowcarbon Pathways to Development: Lessons from Solar PV in Kenya, STEPS Working Paper, Brighton: STEPS Centre

Caperton, R. (2010) Leveraging Private Finance for Clean Energy: A Summary of Proposed Tools for Leveraging Private Sector Investment in Developing Countries, Washington, DC: Center for America Progress

Chaudhary, A.; Narain, A.; Krishnan, C. and Sagar, A. (2014) Who Shapes Climate Action in India? Insights from the Wind and Solar Energy Sectors, IDS Evidence Report 46, Brighton: Institute of Development Studies

Chi, Y.; Guo, Z.; Zheng, Y. and Zhang, X. (2014) 'Scenarios Analysis of the Energies' Consumption and Carbon Emissions in China Based on a Dynamic CGE Model', Sustainability 6.2: 487-512

Chubu Electric Power Company \& Economic Consulting Associates Ltd (2012) 'Model for Electricity Technology Assessments (META)', www.esmap.org/node/3051 (last accessed March 2015)

Climate Investment Funds (n.d.) 'Kenya', Scaling-Up Renewable Energy in Low Income Countries

Programwww.climateinvestmentfunds.org/cif/sites/climateinvestmentfunds.org/file s/SREP_Kenya.pdf (last accesssed March 2015)

Collier, P. (2010) The Plundered Planet: Why We Must--and How We Can--Manage Nature for Global Prosperity, Oxford: Oxford University Press

Couture, T. and Gagnon, Y. (2010) 'An Analysis of Feed-In Tariff Remuneration Models: Implications for Renewable Energy Investment', Energy Policy 38.2: 955-65

Cox, S.; Katz, J. and Würtenberger, L. (2014) Assessing Development Impacts Associated with Low Emission Development Strategies: Lessons Learned from Pilot Efforts in Kenya and Montenegro, National Renewable Energy Laboratory technical report, Golden USA: National Renewable Energy Laboratory 
Dai, Y. (2014) 'Who Drives Climate-Relevant Policies in China?' mimeo, School of Public Policy and Management, Tsinghua University, Beijing

Dawkins, C.; Srinivasan, T.N. and Whalley, J. (2001) 'Calibration', in J.J. Heckman and E. Leamer (eds) Handbook of Econometrics Vol. 5, Amsterdam: North-Holland

Deichmann, U.; Meisner, C.; Murray, S. and Wheeler, D. (2011) 'The Economics of Renewable Energy Expansion in Rural Sub-Saharan Africa', Energy Policy 39: $215-27$

Deutsche-Bank (2011) Investing in Climate Change 2011. The Mega-Trend Continues: Exploring Risk And Return, New York: Deutsche Bank Climate Change Advisors

Devarajan, S.; Go, D.S.; Robinson, S. and Thierfelder, K. (2011) 'Tax Policy To Reduce Carbon Emissions in a Distorted Economy: Illustrations from a South African CGE Model', BE Journal of Economic Analysis and Policy 11.1: 1-22

Devarajan, S.; Go, D.S.; Robinson, S. and Thierfelder, K. (2009) Tax Policy to Reduce Carbon Emissions in South Africa, World Bank Policy Research Working Paper No.4933, Washington DC: The World Bank

Dubash, N. K.; Raghunandan, D.; Sant, G. and Sreenivas, A. (2013) 'Indian Climate Change Policy - Exploring a Co-Benefits Based Approach', Economic \& Political Weekly EPW June 1, Vol XLVIII. 22: 47 - 61

Dubash, N.K and Williams, J. (2011) 'The Political Economy of Electricity Liberalization', in J. Byrne; N. Toly and L. Glover (eds), Transforming Power: Energy, Environment and Society in Conflict, New Brunswick: Transaction Publishers

Eberhard, A. (2007), 'The Political Economy of Power Sector Reform in South Africa', in D.Victor and T.Heller (eds), The Political Economy of Power Sector Reform: The Experiences of Five Major Developing Countries, Cambridge: Cambridge University Press, pp 215-253

Eberhard , A.; Rosnes, O.; Shkaratan, M. and Vennemo, H. (2011) Africa's Power Infrastructure: Investment, Integration, Efficiency, Washington: World Bank,.https://openknowledge.worldbank.org/handle/10986/2290, (last accessed March 2015)

Ellis, J. (2010) The Effects of Fossil-Fuel Subsidy Reform: A Review of Modelling and Empirical Studies, Geneva: International Institute for Sustainable Development

den Elzen, M. G. J.; Olivier, J. G. J.; Höhne, N. and Janssens-Maenhout, G. (2013) 'Countries' Contributions to Climate Change: Effect of Accounting for All Greenhouse Gases, Recent Trends, Basic Needs and Technological Progress', Climatic Change 121.2: 397-412

Department for International Development (2009) 'Political Economy Analysis How to Note', DfID Practice Paper, London: Department for International Development, www.gsdrc.org/docs/open/PO58.pdf, (last accessed March 2015) 
ESMAP (2014) 'A New Multi-Tier Approach to Measuring Energy Access', www.esmap.org/sites/esmap.org/files/DocumentLibrary/Multitier\%20BBL_Feb19_Final_no\%20annex.pdf, (last accessed March 2015)

Fay, M. (2012) Inclusive Green Growth: The Pathway to Sustainable Development, Washington DC: World Bank Publications

Fortes, P.; Simões, S.; Seixas, J.; van Regemorter, D. and Ferreira, F. (2013) 'Top-Down and Bottom-Up Modelling to Support Low-Carbon Scenarios: Climate Policy Implications', Climate Policy 13.3: 285-304

Foster, K. R.; Vecchia, P. and Repacholi, M. H. (2000) 'Science and the Precautionary Principle', Science 288.5468: 979-81

Fritz, V.; Kaiser, K. and Levy, B. (2009) Problem-driven governance and political economy analysis: Good practice framework, Washington DC: World Bank

Geels, F. (2014) 'Regime Resistance Against Low-Carbon Transitions: Introducing Politics and Power into the Multi-Level Perspectives', Theory, Culture \& Society June 27: 1-20

Glemarec, Y.; Rickerson, W. and Waissbein, O. (2012) Transforming On-Grid Renewable Energy Markets. A Review of UNDP-GEF Support for Feed-in Tariffs and Related Price and Market-Access Instruments, New York: United Nations Development Programme

Goedhuys, M. and Sleuwaegen, L. (2010) 'High-Growth Entrepreneurial Firms in Africa: a Quantile Regression Approach', Small Business Economics 34.1: 31-51

Goulder, L. H. and Schein, A. (2013) Carbon Taxes Vs. Cap and Trade: A Critical Review, NBER Working Paper No. 19338, Cambridge, MA: National Bureau of Economic Research

Gray, R. H. (1990) The Greening of Accountancy: the Profession after Pearce, London: Certified Accountants Publications

Griffith-Jones, S.; Ocampo, J. A. and Spratt, S.. (2012) 'Financing Renewable Energy in Developing Countries: Mechanisms and Responsibilities', European Report on Development

Hansen, J. E. (2009) 'Carbon Tax \& 100\% Dividend vs. Tax \& Trade', Testimony submitted to the Committee on Ways and Means, US House of Representative 25

Harrison, T. and Kostka, G. (2012) Manoeuvres for a Low Carbon State - The Local Politics of Climate Change in China and India, Development Leadership Research Paper 22, Retrieved from Developmental Leadership Program, www.dlprog.org

Hartwick, J. M. (1977) 'Intergenerational Equity and the Investing of Rents from Exhaustible Resources', The American Economic Review: 972-74

Haussmann, R.; Rodrik, D. and Velasco, A. (2004) Growth Diagnostics, John F. Kennedy School of Government, Harvard University 
Haselip, J. (2011) 'FIT for Use Everywhere? Assessing Experiences with Renewable Energy Feed-In Tariffs', in J. Haselip; I. Nygaard; U. Hansen and E. Ackom, Diffusion of Renewable Energy Technologies: Case Studies of Enabling Frameworks in Developing Countries, UNEP Risø Centre on Energy, Climate and Sustainable Development. Department of Management Engineering. Technical University of Denmark (DTU)

Hourcade, J.-C.; Jaccard, M.; Bataille, C. and Ghersi, F. (2006) 'Hybrid Modeling: New Answers to Old Challenges', The Energy Journal 27.SI2: 1-11

lanchovichina, E. and Lundstrom, S. (2009) What is Inclusive Green Growth? Background Note Requested by Donors Supporting the Diagnostic Facility for Shared Growth, Washington DC: World Bank

International Finance Corporation (n.d.) 'Syndicated Loans and Management. B Loan Structure and Benefits', www.ifc.org/wps/wcm/connect/Topics_Ext_Content/IFC_External_Corporate_Site/ IFC+Syndications/

Overview_Benefits_Structure/Syndications/B+Loan+Structure+And+Benefits/ (Last accessed March 2015)

International Electrotechnical Commission (2012) 'Grid Integration of Large-Capacity Renewable Energy Sources and the Use of Large-Capacity Electrical Energy Storage', IEC White Paper, Geneva: International Electrotechnical Commission, www.iec.ch/whitepaper/pdf/iecWP-gridintegrationlargecapacity-LR-en.pdf (last accessed March 2015)

International Energy Agency (2014) Energy Technology Perspectives 2014, Paris: International Energy Agency

International Energy Agency (2013) World Energy Outlook Paris, Paris: International Energy Agency

International Energy Agency (2010) Projected Costs of Generating Electricity, 2010 Edition, Paris: IEA

International Finance Corporation (2013) Climate Finance: Engaging the Private Sector, A report prepared at the request of G20 Finance Ministers, Washington: International Finance Corporation

Intergovernmental Panel on Climate Change (2014) 'Climate Change 2014: Mitigation of Climate Change', Contribution of Working Group III to the Fifth Assessment Report of the Intergovernmental Panel on Climate, Cambridge, United Kingdom and New York, USA: Cambridge University Press

Intergovernmental Panel on Climate Change (2012) Renewable Energy Sources and Climate Change Mitigation. IPCC Special Report of the Intergovernmental Panel on Climate Change, Cambridge: Cambridge University Press

IRENA (2012) Financial Mechanisms and Investment Frameworks for Renewables in Developing Countries, Abu Dhabi: International Renewable Energy Agency 
IRENA (2013) 'East African Power Pool', www.irena.org/DocumentDownloads/events/2013/July/Afriac CEC session 2_EAPP_Gebrehiwot_220613.pdf, (accessed 30 April 2014)

Jackson, T. (2011) Prosperity Without Growth: Economics for a Finite Planet, Abingdon: Routledge

Kearney, M. (2008) Modelling the Impact of CO2 Taxes in Combination with the Long Term Mitigation Scenarios on Emissions in South Africa using a Dynamic Computable General Equilibrium Model, Cape Town: Energy Research Centre

Kemfert, C. (1998) 'Estimated Substitution Elasticities of a Nested CES Production Function Approach for Germany', Energy Economics 20.3: 249-64

Klasen, S. (2010) 'Measuring and Monitoring Inclusive Growth: Multiple Definitions, Open Questions, and Some Constructive Proposals', ADB Working Paper Series 12, Manila: Asian Development Bank

Klein, A.; Held, A.; Ragwitz, M.; Resch, G. and Faber, T. (2007) 'Evaluation of Different Feed-In Tariff Design Options: Best Practice Paper for the International Feed-in Cooperation.' Karlsruhe, Germany and Laxenburg, Austria: Fraunhofer Institut für Systemtechnik und Innovationsforschung and Vienna University of Technology Energy Economics Group

Koesler, S. and Schymura, M. (2012) 'Substitution Elasticities for CGE Models: An Empirical Analysis on the Basis of Non-Linear Least Squares Estimations', International Conference on Economic Modeling- EcoMod 2012, Seville

Koetse, M.J.; de Groot, H.L.F and Florax, R.J.G.M. (2008) 'Capital-Energy Substitution and Shifts in Factor Demand: A Meta-Analysis', Energy Economics 30.5: 2236-51

Kost, K.; Mayer, J.; Thomsen, J.; Hartmann, N.; Senkpiel, C.; Philips, S.; Nold, S.; Lude, S.; Saad, N. and Schlegl, T. (2013) Levelized Cost of Electricity. Renewable Energy Technologies, Fraunhofer Institute for Solar Energy Technologies

Laitner, J.A and Hanson, D. A. (2006) 'Modeling Detailed Energy-Efficiency Technologies and Technology Policies within a CGE Framework', The Energy Journal 27.SI2: $151-70$

Lanz, B. and Rausch, S. (2011) 'General Equilibrium, Electricity Generation Technologies and the Cost of Carbon Abatement: A Structural Sensitivity Analysis', Energy Economics 33: 1035-47

Latin, H. A. (2012) Climate Change Policy Failures, Singapore: World Scientific

Leach, M. and Scoones, I. (2015), 'Mobilising for Green Transformations', in I. Scoones, P. Newell and M. Leach (eds) 'The Politics of Green Transformations', Oxford: Routledge/Earthscan

Levin, T. and Thomas, V. M. (2012) 'Least-Cost Network Evaluation of Centralized and Decentralized Contributions to Global Electrification', Energy Policy 41: 286-302 
Leftwich, A. (2009) Bringing Agency Back in: Politics and Human Agency in Building Institutions and States, Synthesis and Overview Report of Phase One of the Leaders, Elites and Coalitions Research Programme, Research Paper 06, York: Department of Politics, University of York

Lesser, J. A. and Su, X. (2008) 'Design of an Economically Efficient Feed-In Tariff Structure For Renewable Energy Development', Energy Policy 36.3: 981-90

Lilliestam, J.; Battaglini, A.; Finlay, C.; Fuerstenwerth, D.; Patt, A. Schellekens, G. and Schmidt, P. (2012) 'An Alternative to a Global Climate Deal May Be Unfolding Before Our Eyes', Climate and Development 4.1: 1-4

Lockwood, M. (2014) 'The Political Dynamics of Green Transformations: Feedback Effects and Institutional Context', in I. Scoones, P. Newell, M. Leach (eds) The Politics of Green Transformations, Oxford: Routledge/Earthscan

Luetkenhorst, W. and Pegels, A. (2014) Stable policies: Turbulent Markets, Germany's Green Industrial Policies: The Costs and Benefits of Promoting Solar PV and Wind Energy, IISD Research Report, Winnipeg: International Institute for Sustainable Development

Lu, C.Y; Tong, Q. and Liu, X.M. (2010) 'The Impacts of Carbon Tax and Complementary Policies on Chinese Economy', Energy Policy 38: 7278-85

Markandya, A. (2012) Externalities from Electricity Generation and Renewable Energy. Methodology and Application in Europe and Spain, Cuadernos Economicos del ICE 83

Masini, A. and Menichetti, E. (2013) 'Investment Decisions in the Renewable Energy Sector: an Analysis of Non-Financial Drivers', Technological Forecasting and Social Change 80.3: 510-24

Maxfield, S. (1991) 'Bankers' Alliances and Economic Policy Patterns: Evidence from Mexico and Brazil', Comparative Political Studies 23: 419-58

McFarland, J.R.; Reilly, J.M. and Herzog, H.J. (2004) 'Representing Energy Technologies in Top-Down Economic Models Using Bottom-Up Information', Energy Economics, 26: $685-707$

Morris, M. and Martin, L. (201410, Who Drives Climate-Relevant Policies in South Africa?, Report for IDS PEACH Project, PRISM, Capetown: Economics Department, University of Cape Town

Nelson, D. and Pierpont, B. (2013) The Challenge of Institutional Investment in Renewable Energy, San Francisco: Climate Policy Initative

NERC (2010) Special Report: Potential Reliability Impacts of Emerging Flexible Resources, NERC Special Report, Princeton: North American Electric Reliability Corporation, www.nerc.com/files/IVGTF_Task_1_5_Final.pdf (last accessed March 2015)

Neumayer, E. (2003) Weak Versus Strong Sustainability: Exploring the Limits of Two Opposing Paradigms, Cheltenham: Edward Elgar Publishing 
Newell, P. and Paterson, M. (2011) 'Climate Capitalism', in E. Altvater and A. Brunnengräber (eds), After Cancun: Climate Governance or Climate Conflicts, Berlin: VS Verlag

Newell, P.; Philipps, J. and Pueyo, A. (2014) The Political Economy of Low Carbon Energy in Kenya, IDS Working Paper No 445, Brighton: Institute of Development Studies

Nwaobi, G.C. (2004) 'Emission Policies and the Nigerian Economy: Simulations from a Dynamic Applied General Equilibrium Model', Energy Economics 26.5: 921-36

OECD (2010) Cities and Climate Change, Paris: OECD Publishing DOI:10.1787/9789264091375-en

OECD (2014) Enabling Investment in Sustainable Energy Infrastructure. OECD and Post2015 Reflections, Paris: Organisation for Economic Cooperation and Development Element 4

Okagawa, A.; Masui, T.; Akashi, O.; Hijioka, Y.; Matsumoto, K. and Kainuma, M. (2012) 'Assessment of GHG Emission Reduction Pathways in a Society without Carbon Capture and Nuclear Technologies', Energy Economics 34: 5391-98

Parhelion (2010) Can Capital Markets Bridge the Climate Change Financing Gap? London: Parhelion Underwriting Ltd

Parshall, L.; Pillai, D.; Mohan, S.; Sanoh, A. and Modi, V. (2009) National Electricity Planning in Settings with Low Pre-Existing Grid Coverage: Development of a Spatial Model and Case Study of Kenya, Energy Policy 37: 2395-410

Pauw, K. (2007) Economy-Wide Modeling: An Input into the Long Term Mitigation Scenarios Process, LTMS Input Report No.4., Cape Town: Energy Research Centre

Pegels, A. (2014) 'Politics of South African Renewable Energy Support', in A. Pegels (ed), Green Industrial Policies in Emerging Countries, London: Routledge

Peiffer, C. (2012) Reform coalitions - Patterns and hypotheses from a Survey of the Literature, DLP Concept Paper 03, Developmental Leadership Program: www.dlprog.org, (last accessed March 2015)

Pueyo, A.; Gonzalez, F.; Dent, C. and DeMartino, S. (2013) The Evidence of Benefits for Poor People of Increased Renewable Electricity Capacity: Literature Review, IDS Evidence Report 31, Brighton: Institute of Development Studies

Republic of Kenya Ministry of Energy and Petroleum (2013) The National Energy Policy. www.rea.co.ke/index.php?option $=$ com_docman\&task=cat_view\&gid $=51 \&$ Itemid $=5$ 05 (last accessed March 2015)

Republic of Rwanda Ministry of Finance and Economic Planning (n.d.) Economic Development and Poverty Reduction Strategy 2013-2018, www.minecofin.gov.rw/fileadmin/General/EDPRS_2/EDPRS_2_FINAL1.pdf (last accessed March 2015) 
Rauniyar, G. and Kanbur, R. (2010) 'Inclusive Development: Two Papers on Conceptualization, Application, and the ADB Perspective', January draft Independent Evaluation Department, Manila: Asian Development Bank

Richstein, J. C.; Chappin, E. J. and de Vries, L. J. (2014) 'Cross-Border Electricity Market Effects Due to Price Caps in an Emission Trading System: An Agent-Based Approach', Energy Policy 71:139-58

Robinson, S., Willenbockel, D. and Strzepek, K. (2012) 'A Dynamic General Equilibrium Analysis of Adaptation to Climate Change in Ethiopia', Review of Development Economics 16.3: 489-502

Rockström, J.; Steffen, W. et al. (2009) 'A Safe Operating Space for Humanity.' Nature 461.7263: 472-5

Ropenus, S. and Skytte, K. (2005) 'Regulatory Review and Barriers for the Electricity Supply System for Distributed Generation in EU-15', Future Power Systems, 2005 International Conference on IEEE, Amsterdam, 18 November 2005

Rosnes, O. and Vennemo, H. (2008) Powering Up: Costing Power Infrastructure Spending Needs in Sub-Saharan Africa, Background Paper No 5, Washington DC: World Bank

Sassi O.; Crassous, R.; Hourcade, J.-C.; Gitz, V.; Waisman, H. and Guivarch, C. (2010) 'IMACLIM-R: A Modelling Framework to Simulate Sustainable Development Pathways'. International Journal of Global Environmental Issues 10.1-2: 5-24

Schmitz, H. (2014a), 'Green Transformation: Is there are a Fast Track?', in I. Scoones, P. Newell and M. Leach (eds), The Politics of Green Transformations, Oxford: Routledge/Earthscan

Schmitz, H. (2015) 'How Does China's Rise Affect the Green Transformation?', Journal of Technology and Globalisation, in press

Spratt, S. (2009) Assessing the Alternatives: Financing Climate Change Mitigation and Adaptation in Developing Countries, London: Stamp Out Poverty

Spratt, S. and Collins, L. R. (2012) 'Development Finance Institutions and Infrastructure: A Systematic Review of Evidence for Development Additionality', PIDG Report Commissioned by the Private Infrastructure Development Group, Sutton: PIDG

Spratt, S.; Griffith-Jones, S. and Ocampo, J. (2013) Mobilising Investment for Inclusive Green Growth in Low-Income Countries, Bonn: Deutsche Gesellschaft für Internationale Zusammenarbeit

Spratt, S.; Dong, W., Krishna, C., Sagar, A. and Ye, Q. (2014) What Drives Wind and Solar Energy Investment in India and China?, IDS Evidence Report 87, Brighton,: Institute of Development Studies

Stadelmann, M.; Castro, P. and Michaelowa, A. (2011) Mobilising Private Finance for Low-Carbon Development, Tackling Barriers to Investments in Developing Countries and Accounting of Private Climate Flows, Final Paper, London: Climate Strategies 
Stern, D.I. (2009) Interfuel Substitution: A Meta-Analysis, MPRA Paper No.15792, http://mpra.ub.uni-muenchen.de/15792/3/MPRA_paper_15792.pdf (last accessed March 2015)

Stern, N. (2006) Stern Review: The Economics of Climate Change, London: HM Treasury

Sue Wing, I. (2008) 'The Synthesis of Bottom-up and Top-down Approaches to Climate Policy Modeling: Electric Power Technology Detail in a Social Accounting Framework', Energy Economics 30: 547-73

Sue Wing, I. (2009) 'Computable General Equilibrium Models for the Analysis of Energy and Climate Policies', in J. Evans and L.C. Hunt (eds), International Handbook on the Economics of Energy, Cheltenham: Edward Elgar

Sullivan, R. (2011) Investment-Grade Climate Change Policy: Financing the Transition to the Low-Carbon Economy, Report, IIGCC, INCR, IGCC, UNEP FI

Tan, N. (2012) Financing Renewable Energy Projects in the US, Case Studies and Opportunities Spring 2012. New York: Kay Scholer LLP

Tenenbaum, B.; Greacen, C.; Siyambalapitiya,T. and Knuckles, J. (2014) From the Bottom Up: How Small Power Producers and Mini-Grids Can Deliver Electrification and Renewable Energy in Africa. Directions in Development, Washington DC: World Bank, doi: 10.1596/978-1-4648-0093-1

Thompson, H. (2006) 'The Applied Theory of Energy Substitution in Production', Energy Economics 28.4: 410-25

Thompson, P. and Taylor, T. (1995) 'The Capital-Energy Substitutability Debate: A New Look', Review of Economics and Statistics 77.3: 565-9

United Nations Development Programme (2012) Fossil Fuel Fiscal Policies and Greenhouse Gas Emissions in Viet Nam, Ha Noi: United Nations Development Programme

United Nations Development Programme (2011) Global Management Meeting Session Report on Greening Human Development Report, New York: United Nations Development Programme

United Nations Environment Programme (2012) Financing Renewable Energy in Developing Countries: Drivers and Barriers for Private Finance in Sub-Saharan Africa, UNEP Finance Initiative, Geneva: UNEP Finance Initiative

United Nations Environment Programme. (n.d.) 'Feed-in tariffs in Kenya', www.unep.org/greeneconomy/SuccessStories/FeedintariffsinKenya/tabid/29864/D efault.aspx (accessed 30 April 2014)

United Nations Framework Convention on Climate Change (2006) Innovative Options for Financing The Development and Transfer Of Technologies, UN Technical Paper, New York: United Nations 
Unsworth, S. and Williams, G. (2011) 'Using Political Economy Analysis to Improve Development Effectiveness', A DEVCO Concept Paper, http://capacity4dev.ec.europa.eu/political-economy/blog/using-political-economyanalysis-improve-eu-development-effectivenessdraft, (last accessed March 2015)

van der Werf, E. (2008) 'Production Functions for Climate Policy Modeling: An Empirical Analysis', Energy Economics 30: 2964-79

Victor, D. and Heller, T. (eds) (2007) The Political Economy of Power Sector Reform: The Experiences of Five Major Developing Countries, Cambridge: Cambridge University Press

VividEconomics (2009) 'Catalysing Low-carbon Growth in Developing Economies: Public Finance Mechanisms to Scale up Private Sector Investment in Climate Solutions: Case Study Analysis', Nairobi: UNEP and Partners,

Volta River Authority. (2012) 'Ghana's Power Outlook', www.vraghana.com/resources/others/power_outlook_may_2013.pdf (accessed 30 April 2014)

Waissbein, O.; Glemarec, Y.; Bayraktar, H. and Schmidt, T. S. (2013) Derisking Renewable Energy Investment. A Framework to Support Policymakers in Selecting Public Instruments to Promote Renewable Energy Investment in Developing Countries, New York: United Nations Development Programme

WBGU (2011) World in Transition. A Social Contract for Sustainability, Berlin: German Advisory Council on Global Change (WBGU)

Whittaker, S. (2012) Applicability of FIT and Auctions to Different Power Markets, Presentation by the IFC

Willenbockel, D. (2015) 'Reflections on the Prospects for Pro-Poor Low-Carbon Growth', in L. Haddad, H. Kato and N. Meisel (eds) Growth is Dead, Long Live Growth: the Quality of Economic Growth and Why It Matters, Tokyo: Japan International Cooperation Agency, 159-85

Willenbockel, D. (2013) Biofuels, Land-Use Change and Food Prices: A Model-Based Scenario Analysis for Kenya and Uganda, Report commissioned by Potsdam Institute for Climate Impact Research (PIK), Potsdam: Potsdam Institute for Climate Impact Research

Willenbockel, D. and Hoa, H.C. (2011) 'Fossil Fuel Prices and Taxes: Effects on Economic Development and Income Distribution in Viet Nam', Background Report for UNDP (2012)

Williams, G.; Duncan, D.; Landell-Mills, P. and Unsworth, S. (2008) 'Politics and Growth', Development Policy Review 29.s1: 299-321, http://onlinelibrary.wiley.com/doi/10.1111/j.1467-7679.2009.00433.x/pdf. (last accessed March 2015)

World Bank (2012) Inclusive Green Growth - The Pathway to Sustainable Development, Washington DC: The World Bank 
World Bank (2011) Doing Business 2011: Making a Difference for Entrepreneurs, Washington: The World Bank

World Bank (2011b) Mobilizing Climate Finance, Paper prepared at the request of G20 Finance Ministers, Washington DC: The World Bank

World Bank (2010) The Economics of Adaptation to Climate Change, Ghana, Washington DC: The World Bank

World Bank Data (2014) 'Electric Power Transmission and Distribution Losses (\% of output)', http://data.worldbank.org/indicator/EG.ELC.LOSS.ZS (last accessed March 2015)

World Energy Council (2013) World Energy Perspective - Cost of Energy Technologies, London: World Energy Council, www.worldenergy.org/wpcontent/uploads/2013/09/WEC_J1143_CostofTECHNOLOGIES_021013_WEB_Fi nal.pdf (last accessed March 2015)

WWF (2011) 'Transition to a Low Carbon Economy: The Role of Banks', Credit Suisse and WWF 